\title{
VIII.
}

Aus der Kgl. Universitäts-Obrenklinik des Geh. Medieinalraths Prof. Dr. Sehwartze in Halle a. S.

\section{Jahresbericht über die Thätigkeit der Kgl. Universitäts-0hren- klinik zu Halle a.S. vom 1. April 1898 bis 31. März 1899.}

\author{
Von
}

Priv. - Doc. Dr. K. Grunert und Dr. W. Zeroni, Assistenten der Klinik.

Mit 2 Abbildungen.

Im Etatsjahre 1898/99 wurden in der $\mathrm{Kgl}$. UniversitätsOhrenklinik zu Halle a. S. 2516 Patienten behandelt, wobei die aus vorigem Berichtsjahre verbliebenen nicht eingeschlossen sind.

In der stationären Klinik wurden aus dem Vorjahre übernommen 20 Patienten, 12 männliche und 8 weibliche. Neu aufgenommen wurden 218 Kranke, 131 männliche und 87 weibliche, so dass im Ganzen 238 verpflegt wurden, 143 männliche und 95 weibliche. Von diesen 238 Kranken wurden 199 entlassen, 122 männliche und 77 weibliche, es starben 16, 9 männliche und 7 weibliche, so dass am 31. März 1899 noch ein Bestand blieb von 23 Kranken, 12 männlichen und 11 weiblichen.

Auf die Gesammtzahl von 238 stationär behandelten Kranken kommen 7716 Verpflegungstage, mithin durchschnittlich auf einen Kranken 32 Tage. Der tägliche Krankenbestand betrug: durchschnittlich 21; der höchste Krankenbestand umfasste am 13. Mai 189824 Kranke, der niedrigste am 1. Oetober 1898 15 Kranke.

Von Jahr zu Jahr wird der Uebelstand einer der Frequenz der Aufnahme suchenden Kranken nicht entsprechenden Bettenzahl fuhlbarer. Selbst mit Zuhülfenahme unserer klinischen Dependenzen konnte nicht allen Anforderungen genügt werden, so dass wir öfters selbst Kranke zurtickweisen mussten, deren Zustand bedrohlich für das Leben erschien. Dank dem liebenswürdigen Entgegenkommen des Directors der medicinischen Klinik, Herrn Geheimrath W eber, konnten solche Ohrenkranke, 
nachdem wir sie operirt, mehrfach in der medizinischen Klinik Aufnahme finden, wo sie dann von uns aus behandelt wurden. Wenn wir der Ursache dieses immer grösser werdenden Uebelstandes nachgehen, so ist dieselbe vor Allem in der von Jahr zu Jahr wachsenden Anzahl der die Hilfe der Klinik in Anspruch nehmenden Patienten zu suchen, welche folgende tabellarisohe Uebersicht treffend iilustrirt:

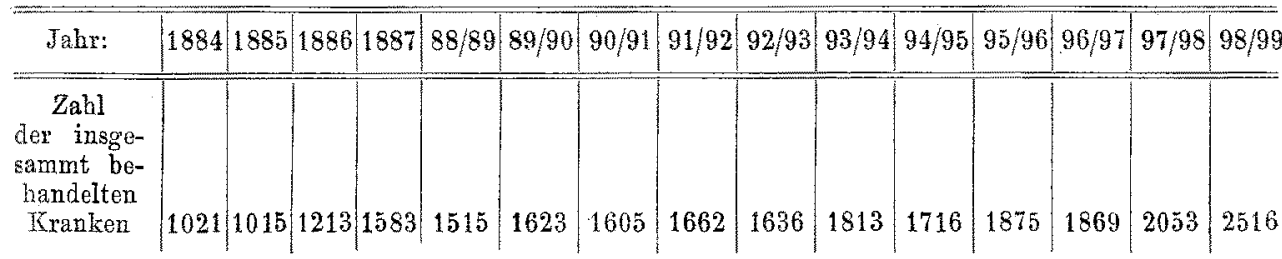

Ausser der enormen Steigerung der Frequenz um weit mehr als das Doppelte in einem Zeitraum von nur 15 Jahren, zeigt uns diese Vebersicht eine fast gleichmässige Znnahme der jährlichen Frequenz. Die wenigen Ausnahmen, z. B. der Untersehied resp. der scheinbare Zurïckgang 1885 gegen 1884 und 1888/89 gegen 1887 erklären sich daraus, dass der Jahresbericht 1884, sowie 1887 (s. d. Arch.) 5/4 Jahre umfasst. Als Assistenten fungirten im Berichtsjahre die Herren Privatdocent Dr. Grunert und Dr. Zeroni, als etatsmässiger Hilfsassistent Dr. Walther. Ausserdem wurden noch regelmässig Volontärärzte beschäftigt.

Die Verhältnisse des Alters, der Heimath der Patienten, der Erkrankungsformen und der Operationen ergeben sich aus folgenden Tabellen:

\section{Alterstabelle.}

\begin{tabular}{c|c|c|c}
\hline \hline Alter & Mannlieh & Weiblich & Summa \\
\hline $0-2$ Jahre & 177 & 174 & 351 \\
$2-10=$ & 336 & 324 & 660 \\
$11-20=$ & 372 & 356 & 728 \\
$21-30=$ & 142 & 131 & 273 \\
$31-40=$ & 104 & 89 & 193 \\
$41-50=$ & 150 & 51 & 201 \\
$51-60=$ & 40 & 24 & 64 \\
$51-70=$ & 22 & 10 & 32 \\
$71-80=$ & 7 & 2 & 9 \\
$81-90=$ & - & 1 & 1 \\
Dnbekannt & 3 & 1 & 4 \\
\hline & 1353 & 1163 & 2516
\end{tabular}


Jahresbericht d. Kgl. Universităts-Ohrenklinik zu Halle a. S. 1898/99. 99

\section{Heimathstabelle.}

Halle a. S. 1370

Provinz Sachsen . . . . . . : 946

Hannover : . . . . . 14

Hessen-Nassau . . . . . 1

Westphalen . . . . . . . 1

Brandenburg . . . . . . 18

Scblesien . . . . . . . 4

Königreich Sachsen . . . . . . . . 14

Grossherzogthum Sachsen-Weimar . 24

Herzogthum Anhalt . . . . . . . 54

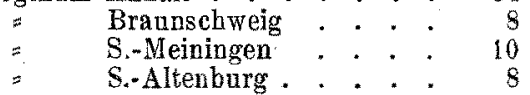

Fürstenthum Schwarzburg-Sondersh. 8

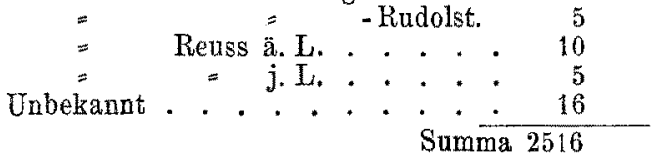

\section{Krankheitstabelle.}

\begin{tabular}{|c|c|c|c|c|c|c|c|c|}
\hline Nomen morbi & 莺 & : & 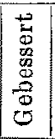 & 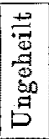 & 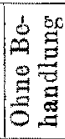 & $\mid \begin{array}{l}80 \\
30 \\
30 \\
03 \\
03 \\
03\end{array}$ & 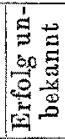 & 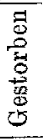 \\
\hline Ohrmusehel. & & & & & & & & \\
\hline Missbildung . . . . . . . . . . & 2 & - & - & - & 2 & - & - & - \\
\hline Verletzungen $\ldots \ldots \ldots \ldots$ & 3 & 1 & - & - & - & 一 & 2 & - \\
\hline Perichondritis ... & 1 & 1 & - & - & - & - & - & - \\
\hline Neubildungen (Carcinom) $\ldots \ldots \ldots$ & 2 & 2 & - & - & - & - & - & - \\
\hline Othaematom (traumatisch) $\ldots \ldots \ldots$ & 2 & 2 & - & - & - & - & - & - \\
\hline Erysipel $\ldots \ldots \ldots \ldots \ldots \ldots$ & 3 & 3 & - & - & - & - & - & - \\
\hline Aeusserer Gebörgang. & & & & & & & & \\
\hline Verletzungen $\ldots \ldots$ : . . . . & 2 & 2 & - & - & ـ & - & - & - \\
\hline 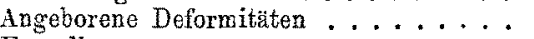 & 3 & - & - & 1 & 2 & 一 & - & - \\
\hline Fremdkörper $\ldots \ldots \ldots \ldots \ldots$ & 134 & 101 & - & - & - & - & 33 & - \\
\hline Vermeintlicher Fremdkörper ....... & 2 & - & - & - & - & - & - & - \\
\hline $\begin{array}{l}\text { Cerumen obturans (einseitig } 140 \text {, dop- } \\
\text { pels. } 70) \ldots \ldots \ldots \ldots \ldots\end{array}$ & 280 & - & - & - & - & - & - & - \\
\hline 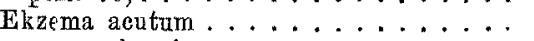 & 60 & $\overline{29}$ & - & 一 & - & - & $\overline{31}$ & - \\
\hline$=$ chronicum $\ldots \ldots \ldots \ldots$ & 59 & 30 & - & - & - & - & 29 & - \\
\hline Otitis externa circumseripta (Furunkel) & & & & & & & & \\
\hline (acut 82, ebronisch 8$) \ldots \ldots \ldots$ & 90 & 61 & - & - & - & - & 29 & 一 \\
\hline Otitis externa diffusa acnta . . . . . . & 21 & 10 & - & - & - & - & 11 & 一 \\
\hline$=\quad=\quad=$ ehronica $\ldots \ldots$ & 34 & 20 & - & - & - & - & 14 & - \\
\hline Tron & & & & & & & & \\
\hline Ruptur (durch Obrfeige 12) . . . & 13 & 9 & - & - & - & - & 4 & 一 \\
\hline Mittelobr. & & & & & & & & \\
\hline $\begin{array}{l}\text { Acuter seröser Katarrh (einseitig 101, dop- } \\
\text { pels, } 74 . \ldots \ldots \ldots \ldots \ldots \\
\text { Acuter schleimiger Katarrh } \ldots \ldots \ldots \ldots\end{array}$ & 249 & 131 & - & - & - & - & 118 & 一 \\
\hline Subacuter Katarrh (einseitig 61 , doppels. 50) & 161 & 108 & -1 & - & - & - & 153 & - \\
\hline Transport & 1122 & & & & & & & \\
\hline
\end{tabular}




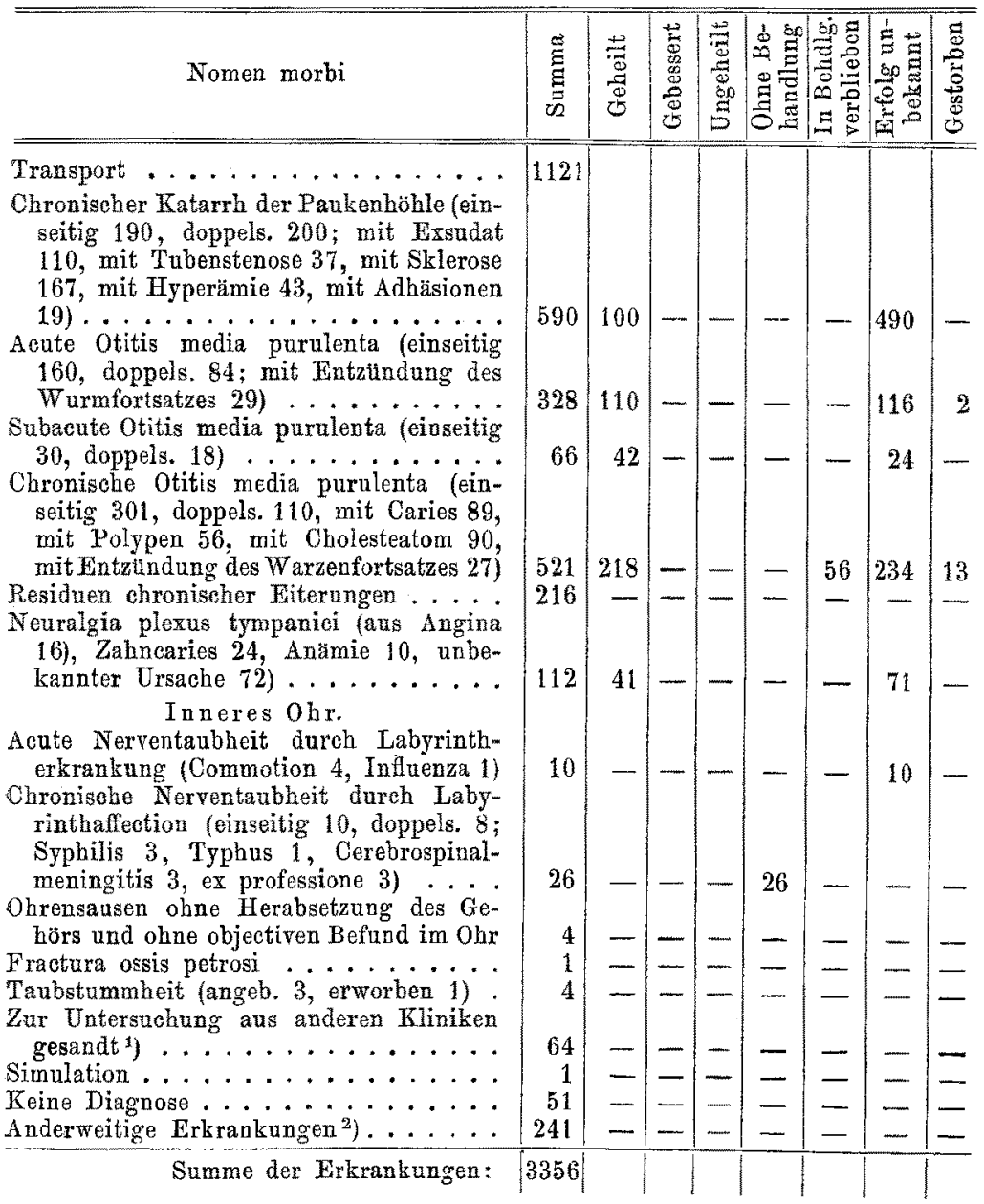

IV. Operationstabelle.

\begin{tabular}{|c|c|c|c|c|c|c|c|c|}
\hline Nomen operationis & 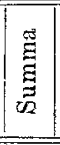 & 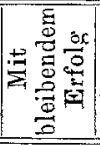 & 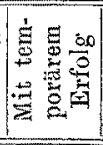 & $\frac{8}{0}$ & 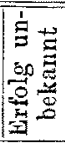 & 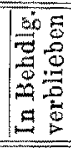 & \begin{tabular}{|c|} 
\\
0 \\
0 \\
0 \\
0 \\
0 \\
0 \\
0 \\
0 \\
0
\end{tabular} & Bemerkungen \\
\hline $\begin{array}{l}\text { Operationen an der Ohr- } \\
\text { musehel } \\
\text { Inscision des Gehörgangs } \\
\text { Entfernung von Fremdloor- } \\
\text { pern (durch Injection } 96, \\
\text { instrumentell 3, näch Vor- } \\
\text { klapp. d ohrmuschel 2) }\end{array}$ & $\begin{array}{r}3 \\
18\end{array}$ & $\begin{array}{r}3 \\
18\end{array}$ & - & $=$ & - & $=$ & $=$ & $\begin{array}{l}2 \text { Carcinom, } \\
1 \text { Perichondr. } \\
-\end{array}$ \\
\hline Transport & 122 & & & & & & & \\
\hline
\end{tabular}

1) Mit negativem Obrbefund. 2) Betrifft grösstentheils Nasenerkranknngen. 
Jahresbericht d. Kgl. Universitäts. Ohrenklinik zu Ealle a. S. 1898/99. 101

\begin{tabular}{|c|c|c|c|c|c|c|c|c|}
\hline Nomen operationis & 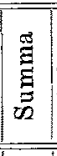 & 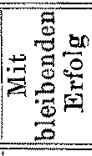 & 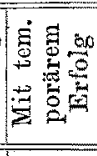 & $\stackrel{\oplus}{\stackrel{3}{0}}$ & 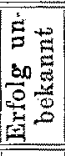 & 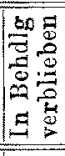 & $\begin{array}{l}5 \\
0 \\
0 \\
0 \\
0 \\
0 \\
0 \\
0 \\
0\end{array}$ & Bemerkungen \\
\hline Transport & 122 & & & & & & & \\
\hline Polypenextraction $\ldots \ldots$ & 38 & - & - & - & - & - & - & - \\
\hline 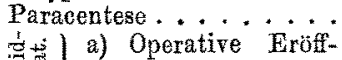 & 102 & - & - & - & - & - & - & - \\
\hline nung des Antrum & 36 & 23 & - & 2 & 7 & 1 & 3 & 一 \\
\hline (5) b) Totalaufmeisslung & 99 & 56 & - & 6 & 27 & 2 & 8 & - \\
\hline Hammerezcis. v. Gehörgange & 1 & - & - & - & 1 & - & - & - \\
\hline Hammer - Ambossextraetion & 10 & 4 & - & $\rightarrow$ & 3 & 一 & - & $\begin{array}{l}\text { Spater aufge- } \\
\text { meisselt } 3\end{array}$ \\
\hline Adenoide Vegetationen ca. & 150 & - & - & - & - & - & - & Stirnhöhle 4. \\
\hline Naseppolypen $\ldots \ldots$. & 29 & - & - & - & - & - & - & Highmors- \\
\hline $\begin{array}{l}\text { Operative Eroffinung der } \\
\text { Nebenbohlen der Nase. }\end{array}$ & 80 & - & $\overline{-}$ & 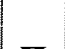 & - & 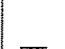 & - & $\begin{array}{l}\text { boble } 4 . \\
\text { Siebbeinl. } 2 .\end{array}$ \\
\hline $\begin{array}{l}\text { Exstirpation von Geschw ti]- } \\
\text { sten in der Umgebung des } \\
\text { Ohres und Erôffnung von }\end{array}$ & 10 & 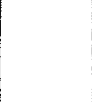 & - & - & & $=$ & $\because$ & \\
\hline Senkungsabscessen $\ldots$ & 2 & 2 & - & 一 & - & - & - & - \\
\hline Tonsillotomie........ & 81 & 81 & - & - & - & - & - & - \\
\hline Summa & 680 & & & & & & & \\
\hline
\end{tabular}

Folgende Arbeiten sind im Berichtsjahre aus der Klinik hervorgegangen:

1) Casuistischer Beitrag zur Lehre von den intracraniellen Complicationen der Otitis (Jordan); d. Arch. Bd. 44, S. $169 \mathrm{ff}$.

2) Zur Entstehung der Fistula auris und Aurieulae congenita (Grunert); d. Arch. Bd. 45, S. 10 ff.

3) Zur Kritik der thierexperimentellen Ergebnisse Kirch ners bei seinen Vergiftungsversuchen mit Salieylsäure und Chinin. Ein Beitrag zur experimentellen Pathologie des Gehörorganes (Grunert); d. Arch. Bd. 42, S. $161 \mathrm{ff}$.

4) Beitrag zur Kenntniss der Heilungsvorgänge nach der operativen Freilegung der Mittelobrräume (Zeroni); d. Arch. Bd. 45, S. $171 \mathrm{ff}$.

5) Kritischer Beitrag zur Steigbügelextraction zum Zwecke der Hörverbesserung; Diss. inaug. (Evers).

Unseren in den früheren Jahresberichten niedgr:selenten Hits theilungen über die Hammer-Ambossexcision vo 6 Gehörgange aus, sowie uber die Mastoidoperation haben wit-nuts Wesent-

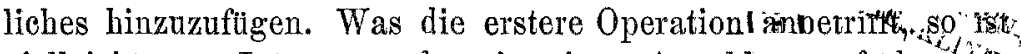
vielleicht von Interesse, dass in einer Anzahl von fribler ids "nicht geheilt" registrirten Fällen die Ohreiterung" nachträglicl 
noch zur Ausheilung gekommen ist, ohne dass die Mastoidoperation secundär ausgeführt worden ist. Dieses Eintreten der Spätheilung der Eiterung nach Vornahme der Hammer-Ambossexeision rom Gehörgange aus kann nicht Wunder nehmen, wenn man bedenkt, um wie viel günstiger sich nach diesem kleinen Eingriffe der Eiterabfluss aus Kuppelraum und Antrum gestaltet. Anderseits veranlasst uns diese Erfahrung, die Indication zur Gesammtaufmeisslung zu Gunsten der Hammer-Ambossexcision vom Gehörgange aus noch mehr einzuschränken wie bisher.

Unter den zu referirenden Todesfällen des Berichtsjahres ist die relativ grosse Zahl von Sinusthrombosen mit ihren Folgezuständen auffällig, umsomehr, als ausgedehnte operative Eingriffe vorgenommen worden sind, um den localen Krankheitsherd im Sinus gegen die Circulation abzuschliessen und die pyaemische Allgemeininfection zu beschränken. Wie aus den betreffenden Krankengeschichten aber zur Genüge hervorgeht, kamen die Kranken in der Regel erst mit ausgesprochenen pyaemischen Allgemeinsymptomen und insbesondere mit bereits vorhandenen Anzeichen von Lungenmetastasen in unsere Behandlung, so dass von vornherein die Chancen auf Erhaltung des Lebens gering erschienen. Wir vertreten trotzdem das Princip, jeden scheinbar hoffnungslosen Fall von Ohrpyaemie zu operiren, so lange nicht eine Complication mit eitriger Meningitis sicher nachweisbar ist. Dass die Durchführung dieses Principes manchem sonst hoffnungslosen Kranken das Leben erhalten hat, wird aus einigen den letalen Fällen vorzuschickenden Krankengeschichten hervorgehen, unter denen sich u. A. ein Fall befindet mit deutlichen Anzeichen schon bestehender Lungengangrän, welcher aber nichts destoweniger mit dem Ausgange in volle Genesung endigte. Die betreffenden nach vielen Richtungen hin interessanten Fälle sind die folgenden:

Hans H., Schneidermeisterssohn aus Weissenfels, 8 Jahre alt, aufgenommen am 8. April 1898.

Ohreiterung links seit Kindheit; Ursache Scharlach. Seit 8 Tagen wegen schwerer Erscheinungen bettlägerig geworden. Hohes Fieber, wiederholt Erbrechen, mehrere Schüttelfröste mit folgendem Schweissausbruch, so auch in der letzten $\mathrm{Nacht}$ ein solcher von 10 Minuten Dauer.

Stat. praes.: Sehr schwächlicher, anämischer Knabe. Pupillen: Langsame Reaction auf Lichteinfall, die linke vielleicht etwas enger als die rechte (?). Augenhintergrund normal. Taumelnder Gang. Urin eiweiss- und zackerfrei. Obstipation. Umgebung des Ohres: Links Infiltration unterhalb der Spitze. Druckempfindlichkeit. weit nach dem Occiput zu gehend.

Gehörgangs - und Trommelfellbefund: Links: Gehörgang nicht verengt; Defect in der hinteren Trommelfellhälfte. Durch denselben Epidermismassen und Eiter in der Paukenhoble sichtbar. Rechts: Einziehung und Trubung. 
Jahresbericht d. Kgl. Universitäts-Ohrenklinik zu Halle a. S. 1895/99. 103

Functionsprïfung: Leise Flüstersprache links direct, rechts drei Meter. C. 1 vom Scheitel unbestimmt, Fis 4 links herabgesetzt.

8. April. Temp. $37,0^{\circ}, 38,0^{\circ}, 39,8^{\circ}, 38,2^{\circ}$.

9. April. Operation, nachdem die Lumbalpunction klaren leukocytenfreien unter hohem Druck stehenden Liquor ergeben hatte: Frellegung der Mittelohrräume nach Stacke von innen nach aussen; dieselben sind mit einem grossen zerfallenen Cholesteatom erfüllt. Ossiculareste nicht mehr vorhanden. Eine Fistel, aus welcher Jauche hervorquillt, führt von der Cholesteatomhöhle in die hintere Schädelgrube. Durch breite Eroffnung derselben mit der Knochenzange wird ein walluussgrosser extrasinöser, jauchiger Abscess entleert; die Dura erwies sich in Handtellergrosse erkrankt, sie war mit eitrig-fibrinösem Belag versehen, die laterale Sinuswand war schwarz verfärbt, nekrotisch. Nun erst wurde die Vena jug. int. unte rbunden. Sie zeigte sich collabirt, inr Lumen war leer. Darauf Freilegung des Sinus transv. nach hinten in Fingerläge bis fast zum Torcular Herophili, Spaltung desselben, Enternung des darin befindlichen schwarzen nekrotischen Thrombus mit dem scharfen Löffel, bis schliesslich von dem Torcular ber schwarzes Blut in dickem Strahl hervorstüzte. Nach unten warde der Sinus sigm. bis fast zum Bulb. vena jug. mit dem scharfen Löffel von seinen Thrombenmassen befreit. Verkleinerung der grossen Wunde dnrch einige Näbte in den Wundwinkeln nach Spaltung der hinteren băutigen Gehörgangswand und Tamponade der Ohroperationshöhle.

9. April. Temp. $37.5^{\circ}, 37,9^{\circ}$. Operation. $38,2^{\circ}, 39,9^{\circ}, 38,7^{\circ}$, (Puls 108), $37,8^{\circ}, 37,3^{\circ}, 37,0^{\circ}$.

10. April. Allgemeinbefinden gut. Temp. 36, $7^{\circ}, 37,9^{\circ}, 38,2^{\circ}$, (Puls 104), $39,1^{\circ}, 39,5^{\circ}, 39,7^{\circ}, 38,9^{\circ}, 37,5^{\circ}$.

11. April. Temp. $37,5^{\circ}, 37,6^{\circ}, 38,1^{\circ}, 39,2^{\circ}, 39,7^{\circ}$, (Puls 120), 39,30, $39,0^{\circ}, 38,3^{\circ}, 38,6^{\circ}, 38,5^{\circ}$. Zunehmende Respirationsfrequenz bis 72.

12. April. Temp. $38,0^{\circ}, 37,8^{\circ}, 38,1^{\circ}, 38,7^{\circ}, 38,2$, (Puls 100), 37,6 $37,4^{\circ}, 37,3^{\circ}$. Resp. $64_{\text {. }}$

13. April. Links vorn oben Dämpfung des Percussionsschalles über dem Thorax nachweisbar. Ord. Kühle Bäder. Infus. rad. Ipecac. Temp. $37,6^{\circ}$, (Puls 118), 38, $6^{\circ}, 38,2^{\circ}, 38,4^{\circ}, 38^{\circ}, 38,1^{\circ}, 37,7^{\circ}, 37,4^{\circ}, 37^{\circ} 1^{\circ}$. Resp. 64 .

14. April. Temp. 36, $7^{\circ}, 38,0^{\circ}, 38,5^{\circ}, 33,5^{\circ}$, (Puls 132), (Resp. 76), $38,1^{\circ}$, (Puls 136), (Resp. 42 in Schlaf), 38, $2^{\circ}, 38,5^{\circ}, 37,8$.

15. April. Verbandwechsel. Wunde von gutem Aussehen; aus dem centralen Sinusende kommt noch wenig trübe, braune Flüssigkeit. Appetit leidlich. Temp. 37,30, (Puls 100), 37,6 $6^{\circ}, 38,1^{\circ}, 38,0^{\circ}, 38,2^{\circ}$, (Puls 110), (Resp. 48), 38, $0^{0}, 37,6^{\circ}, 37,4^{\circ}, 37,1^{\circ}, 37,0^{\circ}$. Abends Durchfall. Süsslicher Geruch der Athemluft, Nasenflügelathmen.

16. April. Durchfall ohne Leibschmerzen. Infiltration in der oberen Jugularisgegend.

Temp. $37,0^{\circ}, 37,8^{\circ}, 37,8^{\circ}, 38,5^{\circ}$, (Puls 112), 37,3 $, 37,7^{\circ}, 37,3^{\circ}, 37,0^{\circ}$. Resp. in Schlaf 44.

17. Aprìl. Bei Druck auf die infiltrirte Partie entleert sich stinkender Eiter aus der Halswunde; dieselbe wird in leichter Narkose stumpf erweitert. Feuchter Verband mit Burow'scher Lösung. Foetider Hasten.

Temp. $37,1^{\circ}, 37,6^{\circ}, 37,8^{\circ}, 38,0^{\circ}, 38,0^{\circ}, 37,5^{\circ}, 37,1^{0}, 37,0^{\circ}, 36,8^{\circ}$.

18. April. Wunde gut. Oefter Hästeln ohne Auswure. Im linken Oberlappen der Lunge Rasselgeränsche.

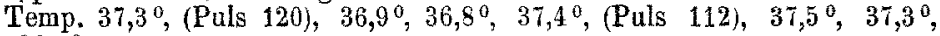
$37,0^{\circ}, 36,6^{\circ}$.

19. April. Temp. zwischen 36,7 und 37,8 . Puls 100 .

20. April. Temp. zwischen 36,3 und $37,5^{\circ}$. Puls 120 .

21. April. Allgemeinbefinden gut, Respirationsfrequenz geringer. Noch fotider Husten ohne Auswurf. Aus einer nach unten gehenden Tasche der Halswunde kommt noch Fiter. Temp. zwischen $36,8^{\circ}$ and $37,7^{\circ}$.

22. April. Temp. zwischen $36,9^{\circ}$ und $37,8^{\circ}$.

23. April. Temp. zwischen $36,8^{\circ}$ und $38,1^{\circ}$ (Pals 92). 
24. April. Lungendämpfung geringer. Halswunde noch eiternd, Sinuswunde reinigt sich gut. Temp. zwischen $37,0^{\circ}$ and $37,8^{\circ}$.

25. April. Heute kein Eiter melr aus der tiefen Halstasche zu entleeren. Allgemeinbefinden und Appetit ansgezeicbnet. $\mathrm{Ab}$ und zu wirft Pat. bräunliches fötides Sputum aus. Temp. zwischen $37,0^{\circ}$ and $38,9^{\circ}$, Puls 128. finden gut

26. April. Temp. zwischen $37,2^{\circ}$ and $38,6^{\circ}$ (Puls 122). Allgemeinbe-

27. April. Temp. zwischen $37,2^{\circ}$ und $38,1^{\circ}$.

Vom 28. April an war Pat. vollkommen fieberfrei.

28. April. Halswunde fest geschlossen. Husten geringer, Nasenflügelathmung verschwunden.

29. April. Auswurf von reichlichem braunen, zähen Sputum.

1. Mai. Auswurf geringer.

In weiteren Verlaufe bildeten sich die Lungenerscheinungen allmählich zurück, der Auswurf verschwand. Das Allgemeinbefinden war stets ein sebr gutes. Das blasse Aussehen des Knaben besserte sich sichtlich. Local war Hals- und Sinuswunde im Juni verheilt, nachdem sich vorher noch ein oberflächliches Knochenstuck von der Corticalis des Occiput durch Nekrose abgestossen hatte. Die Ohroperationshöble epidermisirte prompt bis auf eine kleine Stelle, die dem horizontalen Bogengang entsprach. An dieser Stelle bildete sich von Zeit zu Zeit eine Kruste, und bei Berübrung dieser fistelverdăchtigen Partie zeigte der Kranke stets horizontalen Nystagmus und starkes Schwindelgefuhl. Im August 1898 war das Ohr trocken.

Epikrise: Es konnte bei der Aufnahme des Kranken keinem Zweifel unterliegen, dass ein intracranieller Folgezustand der Otitis vorlag. Die ganzen Erseheinungen, welche er darbot, - Sehüttelfröste, hohes Fieber, Erbrechen - deuteten auf eine Sinuserkrankung, extrasinösen Abscess oder Sinusthrombose oder eine Complication beider pathologischer Zustände hin. Daneben mussten wir mit Rücksicht auf die vermeintliche (?) Pupillendifferenz auch an die Möglichkeit des Vorhandenseins einer diffusen Leptomeningitis denken. Dureh die Lumbalpunction konnten wir diese, jeden operativen Eingriff aussichtslos machende, Complication ausschliessen und entschlossen uns nun zu der Ohrund Sinusoperation. Die Prognose derselben erschien uns desshalb günstig, weil wir das Vorhandensein von Metastasen, besonders in der Lunge, nicht nachweisen konnten, wenn wir uns auch der Möglichkeit bewusst waren, dass die Aussaat zn denselben bereits erfolgt sein konnte. Die Operation stellte ein ausgedehntes Ohrcholesteatom, einen grossen jauchigen extrasinösen Abscess mit Nekrose der äusseren Sinus sigm.-Wand fest. War mit Rücksicht auf letzteren Befund das Vorhandensein eines Thrombus im Sinus schon in bohem Maasse wahrscheinlich, so wurde es zur Gewissheit, als wir die freigelegte Vena jugul. int. blutleer und collabirt fanden. Wir incidirten den weit freigelegten Sinus, entfernten die zerfallenen Thrombenmassen, soweit sie uns zugänglich waren, und sehalteten durch Tamponade des peripheren Sinusendes den für den Kranken gefährlichen Bezirk 
des Gefässrohres aus der Circulation aus, d. h. wir verhinderten, dass er von der Blutwelle im peripheren Sinusende bespült werden und so zur Bildung einer weiteren retrograden Thrombose in diesem Sinusabschnitt Veranlassung geben konnte. Dass die Thrombose eventuell retrograd in den beiden Sinus petrosi weiterschritt, das zu verhindern, lag ausserhalb des Bereiches der Mögliehkeit. Zweifelbaft gestaltete sich die Prognose vom zweiten Tage nach der Operation, als die zunehmende Respirationsfrequenz (72) im Verein mit dem höheren Fieber die Entwicklung von Lungenmetastasen zur Gewissheit machten. Diese Lungenmetastasen standen in den folgenden Wochen im Vordergrund des klinisehen Bildes und liessen uns beständig für das Leben des Kranken furchten, so erfreulioh anch der locale Wundverlauf war. Wenn der Kranke genas, obwohl sich deutlich die Erscheinungen von Lungengangrän ausbildeten, so ist dies wohl nur dem Umstande zu verdanken, dass der kranke Lungenherd vielleicht nur ein vereinzelter und beschränkter geblieben ist und dass bei dem guten Appetit der allgemeine Ernährungszustand des Kranken sich von Tag zu Tag mehr hob.

Reinhold Steinkopf, 47 Jahre alt; Schlosser aus Halle a. S. Aufgenommen am 6. Februar 1898 wegen acuter rechtsseitiger Mittelohreiterung mit Mastoiditis.

Pat., schon früher wegen Schwerhörigkeit vorübergehend behandelt, erkrankte im December 1897 an acuter rechtsseitiger Mittelohreiterung. Er wurde ambulatorisch regelmässig behandelt. Galvanokaustische Paracentese. Am 1. F'ebruar 1898 sistirte die Ohreiterung, am 3. bekam er heftigste Schmerzen im rechten Ohr und in der rechten Kopfhälfte, Schwindel und Appetitlosigkeit. Er will auch einige Schüttelfröste gehabt haben. Seit einigen Nächten Schlaflosigkeit.

Status praesens: Leidlich genährter Mann von blasser Gesichtsfarbe und krankem Aussehen. Geht wegen des Kopfschmerzes langsam und vorsichtig, doch ohne Schwindelgefühl und objective Gleichgewichtsstörungen. Pupillen gleich weit, reagiren prompt. Augenhintergrund normal. Urin ohne Zucker und Eiweiss.

Ungebung des Ohres: Der rechte Warzenfortsatz ist bei leisester Berührung schmerzhaft, ebenso seine Umgebung.

Gehörgangs-und Trommelfellbefund: Starke Secretion aus dem ekzematösen in seinem knöchernen Theile durch Schwellung der hinteren Wand stenosirten Gehörgange.

Börprüfung: C. vom Scheitel unbestimmt, meist beids. gleich.

Temp. $39,4^{\circ}$, (Puls 80), $39,3^{\circ}, 39,0^{\circ},(82)$.

7. Februar. Früh Erbrechen nach dem Kaffee, Mittag spontan. Erheblicher Wechsel der Pulsfrequenz, früh 8 Ubr 90, 10 Uhr 78. Beim Versuche aufzustehen Schwindel bis zum Umfallen. Starker Durst, Zunge ganz trocken. Excessive Ëmpfindlichkeit der ganzen Haut hinter, über, unter und vor dem rechten $\mathrm{Ohr}$. Infiltration der Weichtheile über dem Warzenfortsatz. 0,01 Morph. subc. hat ihm Nachts für 6 Stunden Schlaf gebracht. Temp. $39,7^{\circ}, 40,6^{\circ}, 39,4^{\circ}, 39,9^{\circ}$.

Mittags: Lumbalpunction ergiebt klare unter nicht wesentlich erhöhtem Druck stehende Flüssigkeit. Mikrosk. wenige, der geringen Blutbeimengung entsprechende Leukocyten. 
Operation: Schnitt durch die speckig infiltrirten Weichtheile. Corticalis direct hinter der Spina etwas gräulich verfärbt und abnorm blutreich. Bei den ersten Meisselschlägen quilit janchiger Eiter mit Gasblasen untermischt hervor. Antrum eröffnet, nichts darin. In den Zellen der Spitze des Warzenfortsatzes theilweise jauchiger Eiter, theilweise Blutcoagula, theilweise normal aussehende Sohleimhautanskleidung. Der jau chige Eiter $\mathrm{kommt}$ aus einer zur Fossa sigmoidea führenden Fistel. Die Wand des bis zum Knie freigelegten Sinus sigm. ist an einzelnen Stellen schwarzlich verfarbt and theilweise mit fibrinosem Exsudat bedeckt. Lockere Tamponade der grossen Wundhöble mit Jodoformgaze.

8. Februar. Temp. $37,8^{\circ}, 37,7^{\circ}, 37,3^{\circ}, 37,0^{\circ}$. Kopfschmerzen und Schmerzen in der Hinterohrgegend verschwunden. Zunge beginnt feucht $\mathrm{zu}$ werden. Appetit stellt sich ein.

9. Februar. Temp. $36,6^{\circ}, 36,4^{\circ}, 37,2^{\circ}$.

10. Februar. Temp. $38,4^{\circ}, 38,5^{\circ}, 37,7^{\circ}, 37,6^{\circ}$. In der Nacht sehr unruhig gewesen und $40^{\circ}$ Temp. gehabt mit lange anhaltendem Schweissausbruch ohne vorhergegangenen Frost. Delirien.

11. Februar. Temp. $38,0^{\circ}$, (Puls 72 ), $37^{\circ}, 38,7^{\circ},(74), 38,5$.

Unterbindung der Vena jug. int. Dieselbe war schwer zu isoliren, weil sie nach dem peripheren Ende hin vollkommen leer und collabirt war und aach dem centralen Ende hin sich nur bei starken exspiratorischen Hustenstösen fülte. Der Sinus transp. wird breit gespalten, es quillt hierbei etwas bräuliche Jauche hervor. Der in dem Sinus befindliche brauniche, fast zerfallene Thrombus wird entfernt, der Sinus nach oben und unten mit Jodoformgaze tamponirt. Vor der Operation pulsirte der Sinus deutlich.

12. Februar. Nachts etwas Schlaf, starke Schluckschmerzen. Sonst subjectives Wohlbefinden. Temp. 37,90 (Puls 68), 39,80, 38,8 , (Puls 72).

13. Febroar. Schluckschmerzen dauern fort. Athemfrequenz erhöht (32).

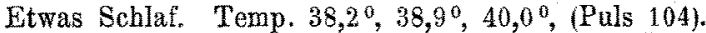

14. Februar. Allgemeinbefinden besser. Feste Speisen können wegen der Schluckschmerzen noch nicht genommen werden. Temp. $37,4^{\circ}$, (Puls 66), (Resp. 28), 38,50, (Puls 78).

15. Februar. Temp. 37,00, (Puls 70, Resp. 24), 37,70, 38, $2^{\circ},(66)$.

16. Februar. Temp. $39,6^{\circ}$, (Puls 100), $38,9^{\circ}$, (80) $38,6^{\circ}$. Leichter Icterus bei subjectivem Wohlbefinden. Verbandwechsel: Wunde gut aussehend, Sinus nach unten ganz leer, keine Blutung. Abends leichte Delirien, doch auf Fragen klare Antworten. Chinin ausgebrochen.

17. Februar. Fieberfrei. Puls zwischen $6 \pm$ und 88 . Pat. ist müde und abgefallen. Leichter Tremor. Icterus noch ausgesprochener. Keine Schmerzen, geringer Appetit. Abends Schüttelfrost. Temp. während des Frostes $37,7^{\circ}$, nach zwei Stunden $38,5^{\circ}$. Puls gut. In der Nacht plötzlich Zuckungen, die bis zum Erscheinen des Arates vorüber sind. Stuhl und Urin in's Bett.

18. Februar. Höchste Tagestemperatur Morgens 8 Uhr mit $37,7^{0}$, (Puls 84). Verschiedene Krampfanfälle tagsüber beobachtet. Dieselben beginnen im linken Arme unter Zwangsstellung der weit aufgerissenen Augen nach links. Sỉe pflanzen sich über die ganze linke Körperhälfte fort und gehen dann erst auf die andere Seite über, wo die Zuckungen indess etwas gelinder erscheinen. Nahrungsaufnahme minimal. Zunge trocken, fuliginös, Lippen rissig. Conjunctivitis. Nachts noch Zuckungen. Sensorium meist frei. Unbestimmte Schmerzen in der Genickgegend. Rechte Pupille grösser als die linke.

19. Februar. Verbandwechsel. Viel Eiter in der Iugulariswunde, der nach der Fntfernung desselben nachquillt. Spülwasser vom Sinus aus dringt aus der Halswunde heraus. Allgemeinbefinden viel besser. Pat. trinkt ca. 4 Ltr. Milch, Bouillon mit Ei, Cognac mit Ei, Wein. Tagsüber noch mehrere Krampfantälle. Keine Schmerzen, leichte Delirien. Nachts keine Krämpfe mehr. Zeitweilige Amnesie fär gering zurückliegende Vorgănge. 
Pupillen gleich weit, eng, reagiren prompt. Seit vergangener Nacht lässt Pat. den Stubl nicht mehr unter sich gehen. Temp. $36,6-37,0^{\circ}$. Puis 80 .

20. Februar. Wesentlich besseres Aussehen, Appetit und Allgemeinbefinden gut. Verbandwechsel. Das Durchspülen ron oben gelingt nur mit Mühe. Abends Schlaf, von heiteren Delirien unterbrochen. Temp. $36,4^{0}$ bis $36,9^{\circ}$, (Puls 60).

21. Februar. $O b$ noch Icterus vorhanden, ist $z$ weifelhaft. Verbandwechsel. Durchspülen gelingt nicht. Aus dem centralen Sinusende dringt wenig bräunliche Flüssigkeit. In der Iugulariswunde wenig Eiter mehr. Allgemeinbefinden gut. Etwas weniger. Appetit. Guter Schlaf. Temp. 36,6, $36,5^{\circ}$, (Puls $62-70$ ).

22. Februar. Beim Verbandwechsel dringt das Spülwasser wieder von oben nach unten durch. Nachmittags etwas Kopfschmerzen. Herpes labialis et auriculae sinistrae. Schmerzen in der linken Brustseite. Temp. $36,4^{\circ}$ bis $37,5^{\circ}$, (Puls 60-66).

23. Februar. Schmerzen auf der Brust stärker. Durchspülung gelingt wieder. Augenhintergrund normal. Temp. 36,3-37,60, (Puls 62-72).

24. Februar. Brustschmerzen noch unverändert, koin Husten. Objectiv nichts nachweisbar. Pat. entwickelt guten Appetit. Durchspülung gelingt. Temp. $36,2-38,1^{\circ}$.

25. Februar. Unverändertes Befinden. Die Durchspülung des Sinus Jugularis. Bezirkes gelingt heute trotz verschiedener Versuche nicht. Danach Ansteigen der Temperatur bis $39,1^{\circ}$ bei subjectivem Wohlbefinden.

26. Februar. Fieberfrei. Verbandwechsel sehr schmerzhaft. Aus dem peripheren Sinusende noch Eiter. Durchspülung unmöglich. Allgemeinbefinden gut bis auf die Brustschmerzen.

27. Februar. Temp. $36,3-37,8^{\circ}$. Puls $68-75$. Sonst unverändert.

28. Februar. Starke Eiterentleerung aus dem centralen Sinusende. In der lugulariswunde viel Eiter in dem unteren Wundwinkel. Nachmittags steht Patient etwas auf. Abends Kopfschmerzen. Temp. 36,6-37,20, (Puls $72-80)$.

1. März. Fieberfrei.

2. März. Kein Secret aus dem Sinus. Die Jugularisgegend ist nicht mehr infiltrirt. In der Iagulariswunde noch etwas Eiter. Temp. $36,6-37,8^{\circ}$. 3: März. Das centrale Sinusende ist zugranulirt. Temp. $36,6-37,10$, (Puls 76-80).

4. März. Kopfschmerzen. Etwas Eiter aus dem oberen Wundwinkel; die Sonde stösst hier auf rauhen Krochen. Temp. 36,7-37,50. Kopfschmerzen nur beim Liegen, sie vergehon beim Aufsitzen. Temp. $36,7-37,50$.

5. -8. März. Vollkommen fieberfrei. Am 7. März lassen sich die Jugularisunterbindungsfäden durch leichtes Ziehen an denselben entfernen.

9. und 10. Mărz. Stärkere Kopfschmerzen beim Liegen. Oedem über dem Proc. zygomaticus, Auf Druck an dieser Stelle entleert sich reichlich hellgelbe Flussigkeit in den vorderen oberen Wundwinkel. Mit der Sonde kann man ziemlich weit zwischen Haut und Knochen eindringen. Nach der Eiterentleerung jedesmal Nachlass der Schmerzen und aligemeine Erleichterung. Temp. am 9. März 36,5-38,10, am 10. März 36,3-36,8. Der weitere Temperaturverlauf ist vollkommen normal.

14. Marz. Die nächtlichen Kopfschmerzen sind heftiger geworden. Spaltung eines Abscesses im Muscul. temporalis. Da aus einer Stelle der freigelegten Squama Granalationen herauskamen, wurde hier der Knochen bis zur Dura fortgeneisselt, ohne dass man auf Eiter stiess. Temp. 36,6 bis 36,7, (Puls 92).

16. März. Keine Kopfschmerzen mehr.

Im weiteren Verlaufe treten wieder stärkere Kopfschmerzen auf.

6. April. Trotz dex verdächtigen Kopfschmerzen zu ambulatorischer Behandlung entlassen. Puls immer gleichmässig. Keine cerebralen Symptome weiter. Allmählich tritt $z u$ den Kopfschmerzen eine täglich deutlicher werdende Parese des linken Facialis hinzu, die nur die Mnndäste betrifft.

12. April. Fast Paralyse der Mundäste des linken Facialis. Sonst keine Motilitătsstörungen. 
13. April. Facialislähmung besser. Im weiteren Verlauf Wechsel der Facialisanomalie. Das Ange konnte stets vollständig geschlossen werden.

5. Mai. Facialisparese völlig verschwunden. Pat. klagt spontan über grosse Vergesslichkeit.

11. Mai. Ophthalmoskop. Untersuchung (Priv. Doc. Dr. Braunschweig). „Beids. Neuritis optica und zwar rechts complet, sodass nicht ein einziger Punkt des Opticusumfanges klar erkennbar ist. Die Papille geht uberall ohne Andeutung von Grenzen in den Fundus über. Im umgekehrten Bilde finden sich oberhalb der Papille zwei, und nach innen und etwas nach unten eine kleine Blutung, die, weil noch nicht entfärbt, wohl als relativ friseh anzusprechen sind. Links ist die gesammte nasale Grenze verwischt, unten ist unmittelbar am Opticus auch die Netzhaut betheiligt, da hierliegende Ge. fässtheile durch das Netzhaut-Oedem völig verschleiert sind; also sehon Uebergang zur Neuro-Retinis".

27. Mai. Papillengrenze deutlicher. Rechts noch Eiterung aus dem Gehörgang

24. Juni. Die Neuritis optica zuräckgegangen (Dr. Braunschweig). Kopfschmerzen fast ganz verschwunden. Eiterung aus dem noch engen Gehörgang gering. In der Tiefe der Warzenfortsatzwunde noch einige kleinere Sequester.

7. Juli. Keine Beschwerden mehr. Noch geringe Eiterung aus dem rechten Gehörgange. Die retroauriculäre Wunde ist vernarbt, es befinden sich jedoch noch einjge verdächtige Stellen in der Narbe.

Später ist der Kranke wiederholt controllirt und auch die Eiterung vollkommen zux Ausheilung gelangt.

Epikritische Bemerkungen: Auch in diesem Falle hat die Lumbalpunction ihre diagnostische Bedeutung bewährt und unseren Verdacht einer schon bestehenden diffusen Leptomeningitis umgestossen. Dass wir nach Eröffnung der Hohlräume des Warzenfortsatzes und nach Entleerung des jauchigen extrasinösen Abscesses zunächst Halt machten und nicht gleich anch den Sinus in den Bereich unserer Operation zogen, ist selbstverständlich, da der Befund der 1. Operation für alle klinischen Erscheinungen eine ausreichende Erklärung gab. Und in der That erweckte der klinische Verlauf gleich nach der Operation, das Aufhören des Schmerzes in Kopf und Hinterohrgegend, der Abfall der hohen Temperatur bis zur Norm, in uns den Glauben, dass eine Sinusthrombose nicht weiter vorhanden sei. Der Umstand, dass wir bei der Freilegung der Fossa sigm. die Sinuswand an einzelnen Stellen schwärzlich verfärbt gefunden hatten, konnte diese unsere Anffassung nicht ersehüttern, da derartige circumseripte Nekrosen an der Aussenfläehe der Sinuswand so oberflächlich sitzen können, dass dabei die Innenfläche des Sinus vollkommen intact ist. Indess lehrte uns das Wiederansteigen der 'Temperatur bis 400 am zweiten Tage nach der ersten Operation, dass Gefahr im Verzuge und ein weiteres Verzögern der Sinusoperation nicht zu rechtfertigen war. Wir legten zunächst die Vena jug. int. frei, um sie vor der Eröffnung der Sinus sigm. zu unterbinden und hierbei machte uns der Umstand, 
dass ihr peripheres Ende blutleer und collabirt war, das Vorhandensein eines Thrombus im Gefüssrohr weiter aufwärts zur Gewissheit. Der weitere Verlauf nach der Entleerung der Thrombenmassen aus dem Sinus bietet noch vieles Interessante und theilweise anch Unaufgeklärtes. Aus den variabeln Symptomen, welche der Kranke nach der Sinusoperation noch darbot, lassen sich einige herausnehmen und zwanglos zur Construction des klinischen Bildes der Sepsis verwenden, nämlich das Fieber, die Delirien und der Ioterus. Ob auch die zeitweilige Amnesie, die eigenthümlichen vom linken Arm ausgehenden und dann rasch allgemein werdenden Convulsionen, welche in uns im Verein mit dem Fieber und der Pupillendifferenz den Verdacht einer entzündlichen Hirnhautaffection erweckten, dem Rahmen dieses Bildes eingereiht werden können oder nur zu beziehen sind auf eine durch die lange, sohwere Krankheit bedingte Ernährungsstörung des Gehirns, muss dahin gestellt bleiben. Auf welchem Wege trotz der Sinusoperation die weitere Verschleppung infectiösen Materiales erfolgt ist - Brustschmerzen mit erhöhter Respirationsfrequenz, allerdings ohne physikalisch nachweisbare Herde, Abscess im rechten $M$. temporalis, jedenfalls metastatischer Natur, Herpes labialis et auriculae sinistrae - entzieht sich natürlich dom Nachweise. Der Wiedereintritt heftiger Kopfschmerzen nach Entleerung des Temporalmuskelabscesses, die spontane Angabe uber Vergesslichkeit, die ansgesprochene Neuroretinitis, die Parese der Mundäste des linken Facialis sind ein Erseheinungscomplex, an welchem das Auffälligste ist, dass er sich in kurzer Zeit wieder vollkommen zurückgebildet hat und zu dessen Deutung uns daher jede Unterlage fehlt, da der Kranke wieder vollkommen gesund und arbeitsfähig geworden nud geblieben ist.

Hervorzuheben wären noeh zwei Punkte bei diesem Falle, erstens die, wie in anderen Fällen unserer Klinik, auch hier wieder beobachteten mehrtägigen Schluckbeschwerden nach der Jugularisunterbindung ohne objectiven Befund im Halse, und zweitens die vorübergehende Temperatursteigerung auf 39,1 bei dem Versuche der Durchspülung vom Sinus nach der eröffneten Jugularis zu.

Otto Göbel, 6 Jahre alt, Halle a. S. In der medicinischen Klinik wegen schwerer Scarlatina untergebracht, erkrankte er daselbst an doppelseitiger acuter Mittelobreiterung links mit Entzündungserscheinungen am Warzenfortsatz. Am 14. Juli und in der Nacht vom 14. zum 15. traten plotzlich mehrere Schüttelfröste anf mit einer Steigerung der vorher normal gewesenen Temperatur auf $40,2^{\circ}$. Da per exclusionem das Ohrleiden als 
Ursache dieser pyämischen Erscheinungen angesehen wurde, wurde er zwecks Operation in die Ohrenklinik überführt.

Es wurde zunächst das linke Ohr operirt, welches objectiv die grösseren Veränderungen (ausser der Eiterung Druckschmerzhaftigkeit des Warzenfortsatzes) darbot.

Operation am 15. Juli, links: Weichtheile normal; Corticalis grau verfärbt. Bei den ersten Meisselschlägen quillt bräunliche Jauche hervor. In den Zellen des Warzenfortsatzes Eiter, ohne dass makroskopische Veränderungen der Schleimbaut erkennbar waren. In der.freigelegten Fossa sigmoidea Jauche; der Sinus sigm. theilweise mit fibrinoser weisser Auflagerung, theilweise mit einem Gran lationspolster bedeckt. Der mit der Knochenzange in Marl*stückgrösse freigelegte Sinus rupturirt plötzlich spontan. Dilatation der Rupturstelle mit dem Paracentese-Dilatations messer. Dabei ergoss sich ein Schwall braunlichen, dunnen Biutes, so dass eine Inspection der Intima des Sinus nicht möglich war. Nach oben und unten Tamponade des Sinus mit Jodoformgaze. Verkleinerung der Wunde durch einige Năcbte.

Bei der typischen Aufmeisslung des anderen Warzenfortsatzes nach Schwartze fand sich nur in einzeinen peripheren Zellen etwas Eiter und sulzig verdickte Schleimhaut. Der freigelegte Sinus zeigte makroskopisch keine Verănderungen.

Im weiteren Verlaufe bestand das Fieber mit pyaemischem Charakter fort, wenn die böheren Temperatursteigungen auch nur selten eintraten: Temp. am 16. Juli: $38,5^{\circ}, 37,4^{\circ}, 37,4^{\circ}$.

Temp. am 17. Juli: $37,9^{\circ}, 36,9^{\circ}, 37,0^{\circ}, 40^{\circ}$.

Temp. am 18. Juli: $37,4^{\circ}, 39,0^{\circ}, 37,7^{\circ}, 37^{\circ}, 36,7^{\circ}, 36,1^{\circ}$.

Temp. am 19. Juli: $37,5^{\circ}, 37^{\circ}, 37,4^{\circ}, 37,4^{\circ}, 39,4^{\circ}, 38,8^{\circ}, 38,3^{\circ}$.

Temp. am 20. Juli: $36,6^{\circ}, 36,5^{\circ}, 36,9^{\circ}, 38,5^{\circ}, 39,3^{\circ}, 37,7^{\circ}, 37,0^{\circ}$.

Temp. am 21. Juli : $36,9^{\circ}, 37,0^{\circ}, 36,6^{\circ}, 35,9^{\circ}, 36,0^{\circ}, 36,40,36,5^{\circ}$.

Temp. am 22. Juli : $36,5^{\circ}, 36,8^{\circ}, 37,6^{\circ}, 38,5^{\circ}, 39,9^{\circ}, 38,9^{\circ}$.

Temp. am 23. Juli: $35,4^{\circ}, 35,9^{\circ}, 36,3^{\circ}, 36,2^{\circ}, 36,0^{\circ}, 36,3^{\circ}, 35,9$.

Temp. am 24. Juli: $36,8^{\circ}, 36,8^{\circ}, 36,4^{\circ}, 36,0^{\circ}, 36,4^{\circ}, 36,20^{\circ}, 36,9^{\circ}, 38,7^{\circ}$.

Temp. am 25. Juli: $38,3^{\circ}, 37,9^{\circ}, 36,4^{0}, 38,2^{\circ}, 38,8^{\circ}, 38,0^{\circ}, 38,7^{\circ}$.

Temp. am 26. Juli: $38,3^{\circ}, 38,2^{\circ}, 38,5^{\circ}, 39,0^{\circ}$.

Ausserdem zeigte Pat. an 5 Tagen Erbrechen, beim Verbandwechsel entleerte sich ans dem centralen Sinusende Eiter; am 26. Juli morgens wurde ein Abscess am unteren Ende der rechten Tibia bemerkt, und so entschlossen wir uns noch zur secundären. Unterbindung der Vena jugularis.

26. Juli. Doppelte Unterbindung der linken Vena jug. int. Oberhalb der Unterbindungsstelle wurde die Vene aufgeschnitten. In derselben befand sich ein theilweise organisirter Thrombus. Derselbe wird peripheriewärts mit dem kleinen scharfen Löffel entfernt, bis man auf erweichte Thrombusmassen stiess. Jodoformgazestreifen in das periphere Venenende geschoben. Spaltung eines kleinen Senkungsabscesses, der vom unteren Winkel der retroauriculären Wunde ausging.

27. Juli. Temp. $36,4^{\circ}, 36,9^{\circ}, 37,5^{\circ}, 37,3^{\circ}$.

28. Juli. Temp. $37,7^{\circ}, 37,5^{\circ}, 37,7^{\circ}, 37,5^{\circ}, 39,2^{\circ}, 38,4^{\circ}$.

29. Juli. Temp. 37,8 o, (Puls 120, Resp. 28), 38,80,39,3, 39,0 , (Puls 132). Verbandwechsel: Aus dem Sinus quillt bei Druck anf das periphere lugularisende Eiter hervor. Auf den Lungen nichts Abnormes nachweisbar.

30. Juli. Temp. 36,90, (Puls 128, Resp. 28), 37,60, 39, $5^{\circ}$, (Puls 146), $38,6^{\circ}$, (Puls 128, Resp. 32). Befinden subjectiv besser. Appetit gut. Unter Schleich'scher Infiltrationsanaesthesie wird der Abscess am Unterschenkel geöffnet. Respirationsfrequenz bis 32. Patient will im Bett immer sitzen, da er nach seiner Angabe im Liegen an Luftmangel leidet.

31. Juli. Temp. 36, $8^{\circ}$, (Resp. 24), 37, $9^{\circ}, 38,3^{\circ}$, (Resp. 32), 39, $3^{\circ}$. Beim Verbandwechsel entleert sich gelber Eiter aus dem centralen Sinusende. D urchspülung von der Sinusöffnung nach der Halswunde zu gelingt nicht.

1. August. Temp. zwischen $36,8^{\circ}$ and $37,9^{\circ}$.

2. August. Temp. zwischen $36,8^{\circ}$ und $37,8^{\circ}$. 
3. August. Temp. zwischen $37,0^{\circ}$ und $37,2^{\circ}$.

4.-7. August. Fieberfrei.

8. August. Temp. $37,5-38,2^{\circ}$.

9. August. Temp. $37,8-38,10$.

10. August. Temp. $37,1-38,8^{\circ}$. Aus der Sinuswunde entleert sich guter gelber Eiter in geringer Menge. Zeitweise Durchfälle und Husten. Im weiteren Verlaufe vollkommen fieberfrei.

12. August. Die Ingularisligaturfäden werden entfernt. Gestern häufiger Schmerzen in der linken Brustseite. Noch starke rahmige Eiterung ans dem centralen Sinusende. Narkose.

18. August. Spaltung einer neuen Abscesstasche am Unterschenkel in

10. April 1900. Der Kranke hat sich in der Zwischenzeit stets wohl befunden, eine geringe Eiterung indess aus der Paukenböhle besteht fort.

Epikritisehe Bemerkungen: Von Interesse ist in diesem Falle die Spontanruptur des Sinus sigm. nach Eröffnung der mit Jauche erfüllten Fossa sigm. Sie beweist, dass die Sinuswand an der betreffenden Stelle ihre normale Resistenz eingebüsst hatte und erweicht war. Dass zu dieser Zeit schon eine - vielleicht wandständige - Thrombose im Sinus bestand, kann keinem Zweifel unterliegen, wenn dieselbe auch in Folge des starken Blutergusses aus dem rupturirten Sinus nicht unserem Auge zugänglich gemacht werden konnte. Indess war auch die dünne Besehaffenheit des sich ergiessenden Blutschwalles, seine bräunliche Farbe, in hohem Maasse verdächtig für eine krankhafte Veränderung des Sinusinhaltes. Die Berechtigung zur secundären Unterbindung der Vena jug. am 12. Tage nach der ersten Operation kann bei dem Fortbestand des Fiebers mit pyaemischem Charakter, bei dem Eiterausfluss aus dem centralen Sinusende, bei dem wiederholten Erbrechen, bei dem Eintritt einer Metastase am Untersehenkel nicht in Zweifel gezogen werden. Dass wir mit der nachträglichen Unterbindung so lange zauderten, kann bei dem Temperaturverlauf, der so vielfach normale Temperaturen aufwies und dadurch in uns die trügerisehe Hoffnung erweckte, dass eine weitere Verschleppung infectiösen Materiales nicht mehr stattfinden würde und dass der krankhafte Vorgang zum Stillstand gekommen, erklärt werden. Indess zeigte der Befund in der. Jugularvene (fast organisirter Thrombus), dass auf diesem Wege die Versehleppung unmöglich stattfinden könnte und daher auch die Unterbindung voraussichtlich den weiteren Krankheitsverlauf nicht beeinflussen würde. Der Weg: indess, auf welehem die weitere Anssaat infectiösen Materiales stattgefunden, konnte, da der Kranke genas, bei dem Mangel einer Autopsie nicht eruirt werden. Dass nach der Unterbindung noch eine Resorption pyrogener. Stoffe stattgefunden, zeigt der 
weitere Temperaturverlauf. Denn auf die Abscedirung am Unterschenkel allein kann das noch fortbestehende Fieber nicht bezogen werden, da auch noch nach der Spaltung des Abscesses Temperaturen bis 39,50 beobachtet wurden. Auf einen Punkt möchten wir noch die Aufmerksamkeit der Fachgenossen lenken. Wie wir dies schon in anderen Fällen von Pyaemie in Folge Sinusthrombose in ähnlicher Weise gesehen, so entwickelten sich auch hier im Verlaufe der Krankheit Erscheinungen, welche anf die Lunge hindeuteten und den Verdacht einer beginnenden Lungenmetastase wachriefen: Erhöhung der Respirationsfrequenz, Luftmangel, Brustschmerzen. Die physikalisehe Untersuchung der Lungen ergab stets einen negativen Befund. Diese Erseheinungen gingen stets nach einem bis wenigen Tagen wieder vorüber, ohne dass es zu manifesten Symptomen einer Lungenmetastase kam. Ob wir es hierbei mit Metastasen zu thun hatten, die klein genug waren, dass sie sich dem physikalischen Nachweise entzogen und mit denen der Körper fertig wurde, oder ob diese beunruhigenden klinischen Erscheinungen als Folge eines geringen bei der Unterbindung der Jugularis zu Stande kommenden Vagusinsultes aufzufassen waren, hat sich bisher Mangels von Sectionen in diesem Stadium der Krankheit unserem Nachweise entzogen.

Fräulein Käthe R, 141/2 Jahr alt, aus Dippmannsdorf bei Belzig.

Pat. war am 30. September 1897 wegen Caries des rechten Schläfenbeins operirt worden (Freilegung der Mittelohrräume). Während der Nach. behandlung machte die hintere und hintere obere Antrumwand grosse Schwierigkeiten. Die Tamponade, ja das Berühren und Abtupfen dieser Partie war für die Kranke sehr schmerzhaft, immer wieder schossen trotz regelmässiger Aetzung Granulationen an dieser Stelle empor, beim Sondiren mit der Sonde konnte man deutlich rauhen cariösen Knochen feststellen. Schon längst zu ambulatorischer Behandlung entlassen, erfolgte die Wiederaufnahme der Patientin am 15. März 1898. Sie hatte draussen unter hohem Fieber eine für Mumps angesprochene Anschwellang vor dem rechten Ohre und zugleich eine Lymphadenitis am Halse bekommen. Seitdem viele Ohrschmerzen. Die Eiterung aus dem Ohre vermehrt. In der Zeit vom 15.-31. März war die Temperatur in der Regel normal gewesen, an einigen Tagen Abends leicht febril (höchstens $38,3^{\circ}$ ). Beständig hatte sie tuber Schmerzen in den Augen, in der Stirne, im rechten Obr und hinter dem rechten $\mathrm{Ohr}$ geklagt; häufig auch Schmerzen in der rechten und selten in der linken Sehläfe. Objectiv war in der Umgebung des rechten Ohres nie eine Anschwellung oder Oedem nachweisbar gewesen, aber die Narbe und die ganze retroauriculäre Gegend bis nach dem Occiput waren stets sehr druckempfindlich gewesen; Eisbeutel hatte den Zustand verschlechtert, Jodanstrich und Narkotica waren ohne Erfolg gewesen. Priessnitz hatte nur vorübergehende Linderung verschafft.

1. April. Deutliches Oedem in Thalergrösse an circumscripter Stelle nach dem Occiput $\mathrm{zu}$, an der Grenze des Warzenfortsatzes beginnend. Abends Temp. $39,1^{\circ}$. Zunge stark belegt, colossale Kopfschmerzen. Augenhintergrund normal.

2. April. Temp. fräh $38,5^{\circ}$. Zweite Operation (Sinusoperation). T Schnitt durch die alte Narbe und die oedematöse Partie. Der Knochen 
vom hinteren Rande der alten Operationshöhle nach dem Occiput zu in Thalergrösse blossgelegt. In der Mitte des blossgelegten Corticalisbezirkes war eine linsengrosse schwarze Gewebsmasse sichtbar. Beim Eingehen mit dem Meissel von dieser Stelle aus stellte es sich heraus, dass die schwarze Gewebsmasse in den den, Knochen schräg durchsetzenden, Emissariumcanal fuhrte. Die Vene des Emissarium war thrombosirt, die Venenwand von Eiter durchbrochen. Der Sinus sigm. und seine Umgebung wurden in $6: 3 \mathrm{~cm}$ Ausdehnung freigelegt. Die Sinuswand war mit schmutzig verfárbten Granulationen bedeckt, zwischenihr und dem Knochen befand sich Eiter. Der Sinus selbst pulsirte nicht, wölbte sich bei Compression der Iugularis uicht vor, und es war in ihm ein deutlicher Strang fühlbar. Bei Incision des Sinus zanächst so spärliche Blutung, dass daraus das Vorhandensein eines Thrombus in demselben zur Sicherheit wurde. Bei Verlängerung des Sinusschnittes nach oben stürzte, während es aus dem centralen Sinusende nicht blutete, eine solche Menge venösen Blutes hervor, dass schleunige Tamponade nothwendig erschien. Der Weg, auf welchem die Sinuserkrankung inducirt worden war, warde bei der Operation deutlich aufgedeckt: die hintere Antrumwand war nekrotisch und von hier aus waren bis zum Sinus eine Anzahl von Zellen, die mit Eiter und Granulationen erfüllt waren, verfolgbar. Temp, nach der Operation $37,5^{0}, 37,8^{\circ}, 39,1^{\circ}$.

3. April. Temp. $39,0^{\circ}, 39,3^{\circ}, 39,3^{\circ}$, (Puls 120, Resp. 56), $39,0^{\circ}, 38,7^{\circ}$, $38,4 \%$ Klage über starke Kopfschmerzen.

4. April. Temp. $38,6^{\circ}, 40,0^{\circ}, 41^{\circ}, 40,6^{\circ}, 40,1^{\circ}, 40,3^{\circ}, 39,6^{\circ}$, (Puls 124). Kopfschmerzen haben zugenommen. Unrubiges Hinundherwerfen, Stöhnea, zeitweises Aufschreien. Angenhintergrund normal. Nimmt Mileh und Cognae mit Ei zu sich.

5. April. Temp. $38,9^{\circ}$, (Puls 100), 38,50, 38, $3^{\circ}, 33,8^{\circ}, 39,4^{\circ}, 39,6^{\circ}$. Kopfschmerzen geringer. Zeitweise ist Pat, ganz vergnügt und rubig. $A b$ und zu treten die Kopfschmerzen wieder heftiger auf. Appetit leidlich. 6. April. Temp. $38,7^{\circ}$, (Puls 96), 39,2 ${ }^{\circ}, 39,5^{\circ}, 39,2^{\circ}, 39^{\circ} 5^{\circ}$. Schmerzen im rechten Schultergelenk ohne sicht- oder fühlbare Anschwellung. Die Bewegnng im Gelenk ist nicht behindert, aber schmerzhaft. Jodtincturpinsing. Appetit etwas besser. Nachts Schlaf ohne - wie bisher - Narkoticum.

7. April. Temp. $37,6^{\circ}, 37,8^{\circ}, 38,5^{\circ}, 38,5^{\circ}, 38,9^{\circ}, 39^{\circ}, 39,8^{\circ}$.

8. April. Temp. $37,6^{\circ}$, (Puls 84), $36,8^{\circ}, 37,5^{\circ}, 37,5^{\circ}, 37,6^{\circ}, 37,2^{\circ}$. Abends Genickschmerzen; Respiration beschleunigt (32-56), Brustschmerzen.

9. April. Temp. im weiteren Verlaufe vollkommen normal.

10. April. Nachts noch Schmerzen im Kopf, gewöhnlich plötzlich einsetzend. Tagsuber gutes Allgemeinbefinden. Appetit besser. Zweiter Verbandwechsel; die Wunde gut aussehend.

16. April. Es treten immer noch Kopfschmerzen zeitweise auf. Appetit nicht besonders. Schlaf erst spät eintretend and mit Unterbrechungen.

August 1898. Allgemeinbefinden gut, abgesehen von zeitweise auftretenden Kopfschmerzen (Astigmatismus). Sinuswunde unverdächtig. Aus dem Ohr noch geringe Eiterung.

Epikritisch e Bemerkungen: Das Ungewöhnliche dieses Falles ist, dass sich unter unseren Augen die klinischen Erscheinungen der Sinusthrombose entwickelten und zwar während der Nachbehandlung eines vor Monaten wegen Caries operirten Ohres. Allerdings wurde schon während der Nachbehandlung bemerkt, dass die nach dem Sinus sigm. zu liegende hintere Antrumwand noch cariös war (s. Anamnese). Es waren somit Verhältnisse gegeben, unter denen es, obwohl die Mittelohrräume freigelegt waren, trotzdem noch zur Entwieklung einer intracraniellen Complication kommen konnte und retrospectiv lässt sich 
wohl sagen, dass durch eine Nachoperation der Eintritt derselben hätte verhüitet werden können. Zeigte doch der Befund bei der Sinusoperation - die Erkrankung des Knochens bis an den Sinus heran - auf das Unzweidentigste, dass auf diesem Wege die spät einsetzende Sinusthrombose indueirt worden war. Den Beginn der Sinuserkrankung müssen wir wohl schon vor dem 17. März annehmen. Vielleicht ist die Anschwellung vor dem rechten Ohre, welche draussen für Mumps gehalten wurde, schon auf Conto der Sinusaffection zu setzen, ebenso die Schmerzen in und hinter dem rechten Obre und die leicht febrilen Temperatursteigerungen des Abends in der zweiten Hälfte des März. Dass während des ganzen Verlaufes der Sinuserkrankung keine Schïttelfröste auftraten, ist ja nicht das gewöhnliche Verhalten, aber doch auch nicht exorbitant. Das Oedem nach dem Hinterhaupte zu, sowie das plötzliohe Ansteigen der Temperatur am 1. April auf $39,1^{0}$ wies direct auf die Fossa sigm. resp, den Sinus hin. Von der Lumbalpunetion glaubten wir vor Vornahme der Sinusoperation Abstand nehmen zu können, da das ganze klinische Bild den Verdacht des Bestehens einer Leptomeningitis in uns nicht hervorrief. $O b$ die Unterlassung der Unterbindung der Vena jug. die Ursache war, dass wir noch sechs Tage lang nach der Operation theilweise recht bohes Fieber batten - bis $41^{\circ}$ - und dass vielleicht auf dem Wege der Vena jug. vor dem Abschluss dieses Weges durch Thrombenorganisation die Bildung der wenn auch geringfügigen metastatischen Affection des rechten Schultergelenks zu Stande kommen konnte, mag dahingestellt bleiben. Betonen möchten wir noch das besorgnisserregende Krankheitsbild nach der Sinusoperation, welches an beginnende Leptomeningitis erinnerte - hohes Fieber, excessive Kopfschmerzen, Stöhnen, Unrube - sowie den Umstand, dass auch hier vortibergehend Erscheinungen bestanden, welche an die Entwicklung einer Lungenmetastase denken liessen.

Margarethe Hessler, $\&$ Jahre alt. Geschirrtührerstochter aus Halle a. S. Aufgenommen am 13. October 1898, entlassen am 24. December 1898. Rechts acute Scharlacheiterung seit 3 Wochen; Anschwellang hinter dem Ohr seit einigen Tagen.

Status praesens: Sehr heruntergekommenes, noch schuppendes Kind.

Umgebung des Ohres: Dem Durchbrechen naher Abscess hinter dem rechten Ohre, der die Ohrmuschel rechtwinklig abdrängt.

Aus dem rechten nicht stenosirten Gehörgange reichliche Eiterung. Grosse nierenförmige Perforation. Links Trübung des Trommelfells.

13. October. Temp. $36,6^{\circ}, 37,0^{\circ}, 37,5^{\circ}, 37,6^{\circ}, 37,6^{\circ}, 38,0^{\circ}, 38,5^{\circ}$.

14. October. Temp. $37,9^{\circ}, 38,8^{\circ}, 37,3^{\circ}, 40^{\circ}$, (Puls 90-100), 37, $8^{\circ}$, $37,3^{\circ}, 36,9^{\circ}, 37,8^{\circ}$. 
Operation: Spaltung des janchigen taubeneigrossen retroauriculären Abscesses. Periost in Markstückgrösse vom Knochen abgehoben. Die Corticalis selbst theils abnorm weiss, theils graugrünlich verfärbt. Bei den ersten Meisselschlägen quillt foetider Eiter hervor. Jauchiges Empyem des Antrum und der Spitze des Proc. mast.; Excision der Abscessmembran. Hintere Schädelgrube nicht eröffnet. Am Abend Klage über starke Kopfschmerzen $\left(40,0^{\circ}\right)$. Augenhintergmnd normal. Nachts wenig Schlaf, öfteres Aufschreien. 15. October. Temp. $37,4^{\circ}, 38,2^{\circ}, 38,7^{\circ}, 38,9^{\circ}$, (Puls 112, Resp. 24), $39,0^{\circ}, 38,2^{\circ}, 38,2^{\circ}, 37,8^{\circ}, 37,3^{\circ}$. gelenkes.

Sehr schmerzhafte Infiltration an der Aussenseite des linken Ellbogen-

16. October. Temp. $39,0^{\circ},(140)$ Resp. $32,39,5^{\circ}, 39,3^{\circ}, 39,4^{\circ}, 37,9^{\circ}$, $37,8^{\circ}, 37,5^{\circ}, 38,0^{\circ}$.

Nach oben und unten rom Ellbogengelenk ist der linke Arm stark geschwollen. Der gleiche Process beginnt rechts.

Chinin 1,0 pro die. Leichtes Hutsteln, Respirationsfrequenz erhöht.

17. October. Temp. $37^{\circ}$ (Puls 120, Resp. 28), 37,5 $5^{\circ}, 38,6^{\circ}, 38,7^{\circ}, 39,3^{\circ}$, (144) $39,5^{\circ}, 37,8^{\circ}, 37,3^{\circ}, 37,0^{\circ}$. Rechter Arm stark geschwollen, linker im Anschwellen begriffen. Appetit sehr gut.

18. October. Temp. 37, $3^{\circ}$, (Puls 140, Resp. 32), 38, $0^{\circ}, 38,5^{\circ}, 38,8^{\circ}$, $38,5^{\circ}$, (Resp. 40, Puls 144) 37, $0^{\circ}, 37,0^{\circ}, 36,9^{\circ}, 37,3^{\circ}$,

19. October. Temp. $37,3^{\circ}, 37,9^{\circ}, 38,3^{\circ}, 38,3^{\circ}, 38,0^{\circ}, 38,0^{\circ}, 37,9^{\circ}, 37,3^{\circ}$.

20. October. Höchste Temp. $37,8^{\circ}$, niedrigste 36,8 .

Pralle Anschwellung der rechten Mandibulargegend; Priessnitz.

21. October. Temp. $36,7-37,8^{\circ}$. Incision eines auf der Kuppe des linken Ellbogengelenkes befindlichen taubeneigrossen Abscesses.

22. October. Temp, 37-38,50.

23. October. Temp. 37,4-38,20. Beide Arme besser, Schwellung fast ganz zurückgegangen.

24. October. Temp. 37,2-37,7\%. Halsanschwellung weicher.

25. October. Temp. $37,0-38,0^{\circ}$.

26. October. Temp. 36,8-37,9 ${ }^{\circ}$. Spaltung der abscedirten Halsanschwellung; Drainage der Abscessböble.

1. November. Normale 'Temperaturen. Am rechten Arm innen ist tiefliegende Fluctuation zu fühlen. Arm im allgemeinen abgeschwollen.

4. November. Der rechte Arm ist fast ganz abgeschwollen. Fluctuation nicht mehr deutlich. Der Abscess am Halse ist in den äusseren Gehörgang durchgebrochen. Spaltung des Abscesses in Narkose. Leichte Temperatursteigerungen in den nächsten Tagen.

8. December. Der rechte Arm ganz abgeschwollen. Kann gut bewegt werden. Das Allgemeinbefinden hebt sich.

24. December. Antrum noch weit offen. Am Boden des Antrum und an dem medialsten Theil der hinteren Gehörgangswand ist blossliegender Knochen sichtbar. Tägliche Durchspülung. Die Patientin wird aus der Klinik entlassen.

13. Februar 1899. Retroauriculäre Wunde geschlossen. Wenig Secretion ans der noch offenen Perforation.

Epikrise: Wir haben in diesem Falle abweiohend ron unserer sonstigen Gepflogenheit den Sinus nicht aufgesucht, obwohl sich das Bestehen einer Pyämie in den ersten Tagen nacb der Operation auf das unzweifelhafteste äusserte. Obgleich uns der günstige Ausgang sehon allein zur Rechtfertigung dienen kann, wollen wir doch die Begründung unserer Zurückhaltung: nicht umgehen. Vor der Operation wurde an eine Sinuscomplication nicht gedacht. Die geringe damals beobachtete Temperaturerhöhung von 38,80 wurde anf die Resorption pyrogener Stoffe 
aus dem dem Durehbruch nahen subperiostalen Abscess bezogen. Nach der Operation wurde es allerdings aus den metastatisehen Entzündungen der Ellenbogengelenke und aus dem fortdauernden höheren Fieber klar, dass eine Pyämie bestand. Es kam nun natürlich in Erwägung, durch eine weitere Operation den Sinus freizulegen und eventuell zu eröffnen. Wir sahen aber zunächst davon $a b$, da das Allgemeinbefinden des durch die vorangegangene Scharlacherkrankung und durch die Operation sehr heruntergekommenen Kindes es wünschenswerth erseheinen liess, dasselbe, wenn irgend möglich, nicht sofort wieder einer nochmaligen Narkose und Operation auszusetzen. Zudem hatten wir den Hauptkrankheitsherd, die Eiteransammlung im Warzenfortsatz entfernt, ausgedehntere Knochenerkrankung war nicht gefunden worden und bei dem kurzem Bestande der Ohreiterung auch nicht wahrscheinlich. In diesem Falle schienen uns daher die Chancen für die Ausheilung der Thrombose grösser, wenn wir den Sinus vorläufig wenigstens unberührt liessen und durch Kräftigung des Allgemeinzustandes die Folgen der von dort ausgehenden Infection bekämpften. Und schon die nächsten Tage bewiesen uns, dass unser Thun in diesem Falle das richtige gewesen war. Die Temperatur behielt nur drei Tage pyämischen Charakter, um dann abzufallen und nach der Entleerung der metastatisehen Abseesse in normaler Höhe zu bleiben. Wir kamen somit nicht in die Lage, die Sinusoperation, von der wir nur vorläufig absehen zu muissen glaubten, nachträglich noch vorzunehmen und hatten die Freude, das Kind bald der vollständigen Genesung von seiner schweren Infection entgegengehen zu sehen.

Herrmann Olberg, 19 Jahre alt. Ziegelarbeiter aus Wellaune. Aufgenommen am 8. September 1898.

Seit 14 Tagen an acuter Mittelohreiterung des rechten Obres erkrankt. In den ersten 8 Tagen seiner Erkrankung mehrmals täglich Erbrechen mit Schwindel und Uebelbefinden. So heftige Schmerzen, dass er Nachts nicht schlafen konnte. In den letzten 8 Tagen öfters Schüttelfröste, oft 3 mal täglich. Der Appetit war in der letzten Zeit sehr schlecht, Stuhlgang immer in Ordnung.

Status praesens: Krăftiger junger Mann von schwerkrankem Aussehen. Geht mühsam und unsicher, Beim Aufrichten in dem Bette wird ihm auf einige Secunden schwarz vor den Augen. Bewegungen des Kopfes gut ausführbar und schmerzfrei. Zunge stark belegt, etwas Foetor ex ore. Klage über Kopfschmerzen, über Schmerzen im Genick und rechten Ohr. Linke Pupille erscheint grösser als die rechte. Reaction der Pupillen auf Licht gut. Beiderseits ausgesprochene Stauungspapille, rechts stärker als links. Sensorium völlig frei.

Umgebung des rechten Ohres: Kein Oedem, circumscripte Klopfempfindlichkeit etwa der Gegend des Sinusknies entsprechend. 
Gehörgang und Trommelfellbefund: Rechts sackartige Vorwölbung des hinteren oberen Trommelfellquadranten. Auf Paracentese reichliche Eiterentleerung.

Temp. bei der Aufnahme $38,2^{\circ}$, steigt auf $40,1^{\circ}$, Puls $80-90$, nicht ganz regelmässig. 9 Uhr Abends Schüttelfrost von etwa 10 Minuten Dauer, desgleichen um 10 Uhr. Ordin. Eisblase. Abends 0,01 Morph. subcutan.

9. September. $37,3^{\circ}$, (Puls 96), 39,0 ${ }^{\circ}$.

Operation: Lumbalpunction ergiebt unter starkem Druck stehende wasserklare Flüssigkeit. Mikroskopisch nichts Besonderes.

Weichtheile des Warzenfortsatzes normal, Corticalis abnorm blutreich. Nach den ersten Meisselschlägen quillt unter Pulsation in Menge von etwa 2-3 Essloffeln jauchiger Eiter hervor. Es ergab sich, dass der Sinus sigm. in der grossen Warzenböble freilag; seine Wand grauroth und mit Granulationen und fibrinösem Exsudat bedeckt. Die Freilegung des Sinus resp. der umliegenden Dura bis ins Gesunde macht bei dem abnorm dicken Knochen und der starken Blutung grosse Schwierigkeiten. Bei dem letzten Meisselschlag Sinusblutung, welche auf Tamponade mit Jodoformgaze (nicht in den Sinus hinein) steht. Verband.

Temp. nach der Operation: $39,6^{\circ}, 38,3^{\circ}, 38,2^{\circ}, 37,6^{\circ}, 37,2^{\circ}$, $37,5^{\circ}, 37,3^{\circ}$. Patient fühlt grosse Erleichterung, schläft Nachts leidich.

10. September. Temp. 37,10, (Puls 76), 37,6 $, 37,7^{\circ}, 38,0^{\circ}$, (Puls 68), $38^{\circ}$, (Puls 64), 37,40,37,60, 37,6. Morgens Befinden gut; gegen Abend setzen wieder beftige Kopfschmerzen ein, so dass Patient einige Male laut aufschreit. Sensorium völlig frei, Appetit gut.

11. September. Temp. $37,2^{\circ}$, (Puls 64), 37, $8^{\circ}, 37,8^{\circ}, 37,3^{\circ}, 38,1^{\circ},(72)$, $38,2^{\circ}$, (Puls 60), 37,60, 37,0. Fortwährend Kopfschmerzen in der Stirn, die rom Hinterkopf ausgehen. Genick frei und ohne Sebmerzen beweglich. Nachts Schlaf erst auf 0,01 Morph.

12. September. Temp. $37,0^{\circ}, 37,8^{\circ}, 38,6^{\circ}, 38,7^{\circ}$, (Puls 68), $38,8^{\circ}, 39,0^{\circ}$, $38,8^{\circ}, 38,2^{\circ}, 37,8^{\circ}$. Kopfschmerzen wie gestern. Unangeuehmes unbestimmtes Gefühl in der Wunde. Verbandwechsel: Aus dem Antrum kommt etwas Eiter. Aus der bei der ersten Operation verletzten Stelle im Sinus quillt pulsirend Jauche hervor, und zwar bei Druck auf die Vena jugularis jedesmal stärker, bei längerem Drücken wird das Secret schliesslich mehr eitrig. Im äussern Gehörgang viel Eiter, starke Pulsation in der Paracentesenöfinung des Trommelfells.

13. September. $37,5^{\circ}$, (Puls 62), 37,5 $, 37,6^{\circ}, 37,9^{\circ}$, (Puls 80), 38,30, $38,3^{\circ}, 38,0^{\circ}$. Unterbindung der $\mathrm{V}$. jug. int. dextra oberhalb der Mündung der Vena facialis comm. Die um den Sinus herumliegende schwarze, brandige Dura wird mit der Knochenzange in weiter Ausdebnung freigelegt. Die Venedes Emissar.mastoid. ist thrombosirt, schwarz. Der Sinus sigmoideus wird gespalten. Der darin befindliche eitrig zerfallene Thrombus wird mit dem kleinen scharfen Löfel nach Möglichkeit (peripherwärts und centralwärs) entfernt. In das periphere Sinusende, ans welchem schliesslich beim Auslöffeln des Thrombus ein Blutschwall hervorsturzte, wurde ein Jodoformgazetampon eingefuhrt. Jugul. int, oberhalb dex Unterbindungs stelle aufgeschlitzt, enthielt kein flüssiges Blut, sonderanur etwas Gerinnsel. Indie Venew urde eindünnes Drainrohr eingeführt. Nach dex Operation auffällig heiterer Gemüthszustand. Nachmittags guter Appetit. Nachts guter Schlaf ohne Narkoticum.

14. September. Höchste Temperatur $37,9^{\circ}$, vom 15 . September an vollkommen fieberfrei.

18. September. Verbandwechsel. Jugulariswande frei von Eiter. Das in der Vene liegende Drainrohr leer. Aus dem centralen Sinusende reichlich hellgelber Eiter. Spülung, Tamponade.

27. September. Kein Eiter mehr aus dem centralen Sinusende. Die den Auge zugängliche mediale Sinuswand sieht noch schmierig und nekrotisch aus.

5. October. Aus dem Sinus kein Eiter mehr. Jugularisfäden abgelöst.

Die Heilung des operirten Ohres ging nicht vorwärts trotz täglicher Durchspülungen. In der Tiefe des Antrums war stets rauher Knochen zu 
fühlen. Deshalb wird am 24. Januar 1899 die Totalaufmeisshung vorgenommen. Es fand sich, dass der Hammer cariòs war, der Amboss fehlte vollständig. Im Antrum und weit nach hinten unten fand sich ein Recess mit schmutzig verfärbten Granulationen.

6. März 1899. Patient wird geheilt entlassen.

Epik ris e: Wir beschränkten uns hier bei der ersten Operation auf die Freilegung des entzündeten Sinus. Dass ein obturirender grösserer Thrombus damals noch nicht darin war, bewies die Blutung aus der Läsionsstelle. Der Abfall der Temperatur und das Aufhören der Schüttelfröste in den nächsten; Tagen schienen auch gegen eine weitere Complication zu sprechen. Indess wurde es am dritten Tage nach der Operation durch Entleerung von Jauche aus der Sinusöffnung und durch wieder auftretendes höheres Fieber klar, dass doch noch eine Thrombose vorlag. Das nach der Sinusöffnung erfolgende prompte Abfallen der Temperafur und die rasche Reconvalescenz bewies, dass es gelungen war, den Thrombus vollständig aus dem Blutkreislauf auszuschalten, während wir uns noch lange Zeit duxch Eiterentleerung aus dem centralen Sinusende von der Dauer des intravenösen Processes taberzeugen konnten. Der Befund bei der späterhin nothwendigen Totalaufmeisslung lässt es, wenn man die grossen bei der ersten Operation gefundenen Zerstörungen auch in Berucksichtigung zielt, wahrseheinlich erscheinen, dass unsere ursprüngliche Annahme, dass eine acute Otitis der Erkrankung zu Grunde lag, eine irrige war, sondern dass vielmehr eine alte chronisehe Eiterung mit Caries die Ursache war.

Heinrich Jost, 9 Jahre alt, Bergmann's Kind aus Burgörner. Aufgenommen am 30. November 1898, entlassen am 2. Januar 1899. Nach brieflicher Mitheilung des Arztes soll Pat. seit einigen Wochen stinkende Ohreneiterung links gehabt haben. Durch eine Obrfeige seitens des Lehrers aollen plötzlich heftige Schmerzen im Kopf, im Ohr, im Proc. mastoideus, ferner Schwindel und Schwellung hinter dem Ohre aufgetreten sein. Wegen erwarteter Eiterretention im Proc. mast. hat der Herr College die Mastoidoperation begonnen, ist in den peripheren Zellen des Warzenfortsatzes anch auf einge Eitertropfen gestossen, hat aber dann die Operation abbrechen müssen, weil bei einem Meisselschlage sich plötzlich ein sehr starker Blutstrom aus der Tiefe ergoss, sodass sofortige Tamponade angezeigt erschien. In den ersten Tagen nach der Operation reactionsloser Wundverlauf, dann aber Pulsbeschleunigung, mehrmaliges Erbrechen und Fieber, weshalb der Kranke unserer Klinik zugeführt wurde.

Status praesens: Bel der Aufnahme am 30. Norember fruh 9 Uhr batte der Pat. $37,8^{\circ}$ Temp., kräftigen, regelmässigen Puls, 120 . Objectiv kein Schwindel nachweisbar. Zunge mässig belegt, gute Reaction der gleich weiten Pupillen auf Lichteinfall. Im Augenhintergrunde des rechten Kages vielleicht die nasale Hälfte der Pupille a. o. nicht ganz deutlich, Sensorium frei, Keine Klage über Kopfschmerz.

Umgebung des Ohres: Schnitiwunde hinter dem Ohre. Im rechten Trommelfell keine Perforation, kein Perforationsgerausch und kein Rasseln bei Katheter. Im Gehörgange Borpulver. Die Temp. stieg 
Jahresbericht d. Kgl, Universitäts-Ohrenklinik zu Halle a. S. 1898/99, 119

am Aufnahmetage bis $39,6^{\circ}$ Mittags und $40^{\circ}$ Abends, Pals dabei 100 bis 120 , klein.

1. December. Morgentemp. $38,9^{\circ}$. Operation: Die schon bestehende Operationswunde erweitert, die Corticalis des ganzen Warzenfortsatzes freigelegt. Etwa $1 \mathrm{~cm}$ hinter dem Planum mast. ein etwa pfennig* stuckgrosser Defect in der Corticalis, aus welchem eineblasse, pulsirende, in der Mitte eitrig zerfallene Grantiationsmasse hervorragt. Nah Eweiterung des Corticalis-Defectes ergab sich, dass diese Granulationsmasse der Wand des Sinas sigm. anfsass. Nun erst doppelte Unterbindung derVena ingul. int., die Venezwischen den Ligaturen durehschnitten, kein Throm bus an dieser Stelle. Der beschriebenen eitrig zerfallenen Granulationsstelle entsprechend zeigtesich derSinuseroffnet, er wurde mit dem Knopfmesserweit a ufgeschlitzt; es befanden sich theilweise zerfallene Thrombenmassen darin, welche mit dem scharfen Löffel entfernt wurden, so dass ron oben und unten ein starker Blatstrom hervorstitirzte. Tamponade nach oben und unten mit Jodoformgaze.

2. December. Fieber abgefallen; in der vergangenen Nacht Schmerzen in der Gegend des Torcular Herophili. Appetit leidlich.

3. December. Tagsüber fieberfrei, Nachts $39^{\circ}$. Schlechter Schlaf.

4. December. Höheres Fieber, Puls 120-130, Athmung beschleunigt. Abends Verbandwechsel. Nach Entfernung des oberen Sinustampons mässige Blutung, 0,5 Chinin.

5. December. Temp. zwischen 35 und $390^{\circ}$. Verbandwechsel. Sinus blutet nicht. Abends Durchfälle. Tannalbin 2 mal à 1,0 .

6. December. Appetit schlechter, einmal Erbrechen bei der Nahrungsaufnahme, zeitweise Exaltation, leichte Delirien. Acht Stüble von gelber Farbe und dünner Consistenz. In der Nacht soll er viel gehustet haben.

7. December. Allgemeinbefinden besser, ebenso der Appetit. Beim Verbandwechsel kommt ans der unteren Sinusöffnung etwas gelbbraune Flitissigkeit.

8. December. Fieber geringer; beim Verbandwechsel dringt durch Druck auf die lugularis zuerst viel bräunliches Secret, dann eine feste schwärzlichbraune Masse hervor. Spülung mit Sublimat.

9. December. Fieberfrei. Hustet Nachts stark ohne Auswarf. Athemfrequenz wechselnd. Aus dem unteren Sinusende entleert sich wieder dunkelbraune Flüssigkeit. Geringe Anschwellung der Inframandibulargegend.

10. December. Wieder Fieber bis $39,4^{\circ}$. Täglich von nenem Entleerung von viel bräunlich-eitriger Flüssigkeit aus dem unteren Sinusende auf Druck. Abwechselnd Durchfall und Verstopfung mit Meteorismus.

11. December. Fieber abfallend, Sinus leer. Inframandibularanschwellung geringer.

14. December. Fleberfrei seit 11. December. Sinus ganz frei.

17. December. Fieberfrei geblieben. Sinus leer. Aus der Ingulariswunde Abstossung von nekrotischen Fetzen.

2. Januar. Wunde fast verhellt. Entlassen. Vollkommene Heilung später festgestellt.

Epikritische Bemerkungen: Bei dem ausserhalb der Klinik vorgenommenen Versuche der Mastoidoperation ist der normal gelegene Sinus in Folge der Anlegung der Operationsöffnung nach hinten vom Planum mastoideum verletzt worden. Die Wunde in der Sinuswand haben wir bei der klinisch ausgeführten Operation gefunden. Die Sinusverletzung war gefolgt von der Bildung eines Thrombus im Sinus an der Laesionsstelle. Der zunächst gutartige Thrombus ist inficirt worden durch die 
Eiterung in dem umgebenden Knochen und hat zu der Pyämie geführt. Ein ursächlicher Zusammenhang zwisehen der erhaltenen Ohrfeige und der Ohrerkrankung kann wohl mit Sicherheit in Abrede gestellt werden. Dass nach der Sinusoperation noch tagelang höheres Fieber bestand, dessen pyämiseher Charakter durch die Durchfälle erwiesen ist, findet seine Erklärung in dem Umstande, dass in dem centralen Sinusstüek bei der Auslöfflung des Thrombus noeh Thrombenreste zurüekgeblieben sein müssen, wie es ja auch der weitere Wundverlauf bewies, welehe vielleicht auf dem Wege der Vena vertebralis in die Blutbahn gelangt sind. Dies Zurückbleiben von Thrombenresten ist nicht auffallend, selbst wenn man mit dem scharfen Löffel so lange die Thrombenmassen nach unten und oben auslöffelt, bis eine starke Sinusblutung eintritt.

Dieser Fall von traumatischer Thrombophlebitis purulenta beweist, dass Sinusverletzungen nicht so gefahrlos sind, wie es behauptet worden ist.

Die Todesfälle des Berichtsjahres sind die folgenden:

1. Wilh. Leichert, 34 Jahre alt, Handarbeiter aus Brehna bei Bitterfeld. Aufgenommen am 10. März 1898, gestorben am 4. April 1898. Patient war im Jahre 1897 mit Erfolg wegen Cholesteatom des linken Ohres operirt. Damals schon war die Diagnose Cholesteatom des rechten Ohres gestellt worden, Patient konnte aber wegen Ablaufs der Krankenkassenverpflichtung auf dem rechten Ohre nicht mebr operirt werden.

Status praesens: Keinerlei Cerebralerscheinungen. Urin ohne Zucker und Eiweiss. Umgebung des Ohres ohne Befund.

Gehörgang und Trommelfelibefund: Rechts: Trommelfeil zurückgesunken, Hanmer etwas vorspringend. Hinten oben grosser Krater, ans welchem Eiter mit bröcklichen Massen vermischt herauskommt. Links: Spiegelglatte ausgeheilte Radicaloperationshöhle.

Hörprüfung: Flüstersprache rechts 40 , links $30 \mathrm{~cm}$. Cr rom ganzen Schädel nach rechts. Fis 4 rechts bei leisem Fingerkuppenanschlag, links bei stärkstem Fingerkuppenanschlag.

12. Mārz. Operative Freilegung der Mittelohrräume. Befund: Cholesteatom und Granulationen im Antrum. Osteosklerose der Corticalis. Sinus in Linsengrősse freigelegt, erscheint intact. Im weiteren Verlauf vollkommen normaler fieberfreier Wundverlauf, sodass Pat, am 21. Mărz zu ambulatorischer Weiterbehandlung entlassen wird.

28. Mărz. Plötzlich Abends Temperaturstejgerung auf 40,60. Wiederaufnahme. Temp. weiterhin $38,2^{\circ}, 39,0^{\circ}$. Keine Beschwerden.

29. Mărz. Fieber hält an. Eitrige Pharyngitis. Sonst nichts nachweisbar. Wunde gut aussehend.

30. März. Zwei sehr dünne Stühle.

31. März. Scbmerzen im rechten Ellbogen und rechten Kniegelenk. Hohes Fieber; dasselbe geht auf Natr. salicyl. etwas herunter.

1. April. Temp. $39,5^{\circ}, 40,7^{\circ}, 40,0^{\circ}$. Nach 1,0 Phenacetin $39,2^{\circ}$. Abends 9 Vhr $36,9^{\circ}$. Schwellung und Röthung des rechtên Ellbogengelenks etwas oberbalb der Condylen hinten am Bicepsansatz.

2. April. Schwellung des Ellenbogengelenks hat zugenommen, auch im linken Knie sind Schmerzen aufgetreten. Natr. salicyl. 1,0. Fieber geht etwas herunter, Abends nach 1,0 Phenacetin auf $37,2^{0}$, Sensorium nicht ganz frei. Schlechter Appetit. 
3. April. Hört kein gesprochenes Wort mehr (Salicylwirkung). Ausgesprochene icterische Färbung der Conjunctiva und Gesichtshaut.

4. April. Exitus letalis.

Auszug aus dem Sectionsprotokoll: Diagnosis p. m.: Icterus. Alte pleuritische Verwachsungen. Blutige Imbibition des Endocards. Haemorrhagien der Pleura. Hyperämie und Oedem beider Lungen. Schlaffe Pneumonie des rechten Unterlappens. Milatumor, trinhe Schwellung der Nieren. Anaemie der Leber. Thrombose des rechten Sinus sigmoid. Arrosion der Sinuswand. Hyperämie der Pia, sulzige Infiltration der Oberarmweich theile.

Hinter dem rechten Ohre eine $12 \mathrm{~cm}$ lange senkrechte Wunde mit reactionslosen Rändern. Die Wandungen der gesammten Wundhohlräume trocken and reactionslos. Die Gegend beider Ellenbogengelenke verdickt. Zwerchfellstand rechts 3, links 4 . Rippe. Linke Lunge gut zurückgesunken, die rechte in ganzer Ausdehnung mit der Brustwand durch leicht lösliche Verwachsungen verbunden. Pleuraböhle frei. Herz: Endocard des rechten Vorhofs stark blutig imbibirt. Linke Lunge zeigt einige fibröse Auflagerungen. Pleura glatt und glänzend. Veber die Pleura zerstreut zahlreiche punktförmige Blutungen. Oberlappen von grauer Farbe, hyperämisch, sehr saftreich, überall lufthaltig. Aus dem Bronchus dringt auf Durchschnitt reichliche schaumige Flüssigkeit. Bronchialmucosa blass. Rechte Lunge: Oberfläche mit reichlichen fibrösen Auflagerungen bedeckt, im Ganzen von blaurothę Farbe. Unterlappen noch stärker hyperämisch wie links. Luftgebalt stark herabgesetzt. Consistenz etwas stärker.

Milz gross. Länge 16, Breite 10, Dicke $4 \mathrm{~cm}$. Organ äusserst schlaff, Farbe rotviolett. Kapsel glatt und glänzend. Parenchym auf dem Durchschnitt von braunvioletter Earbe, zerfliesst. Follikel vergrössert. Linke Niere von starkem Fettpolster umgeben; Kapsel löst sich nur unter Substanzverlust. Organ ăusserst weich. Farbe der Oberfläche braungelb. Rinde verbreitert, trübe, von braungelber Farbe, von den Pyramiden undeutlich geschieden. Glomeruli als rothe Punkte sichtbar. Consistenz äusserst weich. Rechte Niere wie links.

Leber von normaler Grösse, Oberfläche glatt. Farbe graubraun. Auf dem Durchschnitt ist das Parenchym blass von gelbrother Farbe. Zeichnung undeutlich. Consistenz sehr schlecht.

Schädeldach dick. Im Sinus longit. Blutgerinnsel. Im Sinus sigm. dext. ebenfalls Blutgerinnsel, sowie an einer Stelle festhaftende gelbbraune Thrombusmassen. An dieser Stelle ist die Sinuswand arrodirt und von der oben beschriebenen Hoble im Proc. mast. nur durch eine dünne Membran getrennt, die bei Berührung mit der Sonde einreisst. Pia ziemlich stark injicirt. Ventrikel zeigen nichts Besonderes. Graue Substanz blass. Weisse Substanz von geriugem Blutgehalt. Consistenz gut. Weichtheile des Ellenbogengelenks stark sulaig infiltrirt.

Epikritische Bemerkungen: Als am 16. Tage nach der Operation und zwar nach ganz normalem fieberfreiem Wundverlauf das hohe Fieber einsetzte, dachten wir nicht im Entferntesten an das Vorhandensein einer Sinusthrombose, weil wir nach dem Operationsbefund die Möglichkeit der Entwicklung einer solchen Erkrankung glaubten ausschliessen zu können; hatten wir doch bei der Mastoidoperation den Sinus in Linsengrösse freigelegt und makroskopiseh unverändert gefunden. Dass eine secundäre Infection des freigelegten Sinus während der Wundbehandlung erfolgen könne, war ja a priori nicht auszuschliessen, indess ein nach unseren Erfahrungen noch nicht beobachtetes Ereigniss. Dass wir, als dann Gelenkaffectionen auf- 
traten, an Gelenkrheumatismus dachten, kann nicht Wunder nehmen. Und doch mïssen wir uns hinterher sagen, dass der Kranke an den Folgen einer Sinusthrombose zu Grunde gegangen ist, welche ein etwas aussergewöhnliches klinisohes Bild hervorgerufen hat. Dasselbe kann nicht als reine Pyämie angesprochen werden, sondern muss als septico-pyämische Mischform bezeichnet werden. Mit dieser Auffassung stimmt ja auch das Sectionsergebniss uberein, insbesondere die reichliche blutige Imbibition des Endocards des rechten Ventrikels. Auf welche Weise ist die Thrombose des Sinus sigmoideus zu Stande gekommen? Wir können wohl kaum annehmen, dass der Thrombus schon zur Zeit der Operation vorhanden gewesen ist und während der Zeitdauer von 16 Tagen im Stadium vollkommener Latenz verharrt hat. Weisen wir aber diese Annahme a limine ab, so bleibt uns für die Entstehung der Thrombose mangels einer anderen Erklärung, zu welcher der Sectionsbefnnd berechtigte, allerdings nur die Deutung übrig, dass wir es mit einer artificiellen Thrombose $\mathrm{zu}$ thun haben, artificiell insofern, als die Thrombose erst die mittelbare Folge unserer Mastoidoperation ist, entstanden durch secundäre Infeetion des bei der Operation unbeabsichtigt freigelegten Sinus sigm. Für diese Auffassung spricht in evidenter Weise der Umstand, dass die Veränderungen der Sinuswand, sowie anch die wandständige Thrombose sich gerade an derjenigen Stelle des Sinus vorfanden, welche bei der Mastoidoperation freigelegt worden war. Eine derartige Entstehung von Sinusthrombose ist uns noch nicht begegnet und auch unseres Wissens in der einseblägigen Literatur noch nicht mitgetheilt worden.

2. Minna Schmidt, 18 Jahre alt. Kiesgrubenarbeiterin ans Theisa bei Liebenwerda. Aufgenommen am 6. Juni 1898, Gestorben am 2o. Juni 1898.

Anamnese: Seit Kindheit besteht beiderseits Obreiterung nach Scharlacherkrankung. Die stets hochgradige Schwerhôrigkeit hat seit einigen Jahren noch zugenommen. Seit 4 Wochen leidet Pat. an öfters auftretenden Kopfschmerzen in der Stirn und den beiden Schläfen. Diese Kopfschmerzen traten anfallsweise auf und waren meist mit Schwindel verbunden.

Status praesens: Kräftiges Mädchen von gutem Ernährungszustand. Objectiv ist auch bei geschlossenen Angen kein Schwindel zu bemerken. Invere Organe ohne Befund. Urin frei von Eiweiss und Zucker. Temperatur and Puls normal.

Umgebung des Ohres: Ohne Besonderes.

Gehörgang und Trommelfellbefund: Beiderseits geringe Eiterung. Rechts: Vollständiger Defect des Trommelfelles. Der Hammergriff ist in die granulirende Schleimhaut eingebettet. Die laterale Wand des Atticus feblt fast vollständig. Der Kuppelraum ist, soweit sichtbar, mit Epidermis ausgekleidet, deren oberste Schichten stark gelockert sind. Hammerkopf nicht zu sehen. Vom Kuppelraum aus lässt sich das Antrum sondiren. Die 
Paukenhöhle unten mit Granulationen angefült, die z. Th, vom Promontorium entspringen.

Links: Ein langgestielter Polyp, von hinten oben kommend, rerdeckt fast das ganze Trommelfell.

Hörprufung: Beiderseits wird nur laut ins Ohr Geschrieenes verstanden. $C_{1}$ vom Scheitel wird rechts gehört. $C_{1}$ wird beiderseits nur vom Knochen, nicht per Luft gebört. Fiś beiderseits bei starkem Metallanschlag.

9. Juni. Links Abschnürung des Polypen mit der kalten Schlinge; die Patientin klagt öfters über Schmerzen im rechten Ohr, besonders Nachts.

12. Juni. Rechts drängen sich aus dem Antrum Granulationen über den Harnmergriff. Links ist jetzt die Paukenhöhle gut zu übersehen. Trommelfell bis auf die Membrana flaccida fehlend. Hammer stark retrabirt. Paukenhöhlenwand $z$. Th, epidermisirt. An der Spitze des rechten Warzenfortsatzes ist beute etwas Druckempfindlichkeit zu constatiren.

Temperaturen und Puls stets normal.

14. Juni. Totalaufmeisselung rechts. Nach Wegnahme der hinteren knöchernen Gehörgangswand wird eine mit dem Antrum in Verbindung stehende ziemlich weit lateralwärts reichende Höhle freigelegt, die zum Theil mit Granulationen, zum Theil, besonders nach hinten zu, mit geschichtet en Cholesteatommassen erfüllt ist. Vom Hammer ist nur der Griff vorhanden. Der Amboss fehlt vollständig. In Aditus und Paukenhöhle viel blaurothe Granulationen. Der horizontale Bogengang ist zum Theil zerstôrt, der Knochen in der Umgebung fühlt sich rauh an. Die Sonde kann nicht in den Bogengang eindringen, auch tritt kein Eiter an dieser Stelle hervor. Die Cholesteatomhöhle sendet einen Ausläufer nach hinten oben, der in einem feinen Gang endigt. Auch hier kein Eiter. Dura nirgends freiliegend. Glattung der Höhle. Spaltung. Die retroauriculäre Wunde wird nur in den Winkeln genäht.

Nach der Operation zuaächst reactionsloser fieberfreier Verlauf.

19. Juni. Morgens 38,50. Pat. klagt über Kopfschmerzen. Verbandwechsel. Wunde von gutem Ansehen. Der Knochen in der Tiefe ohne Graunlationsbildung. Starker Foetor, aber wenig freier Eiter. Im Lanfe des Tages auhaltend Kopfschmerzen. Gehör auf dem operirten Ohre entschieden besser als sonst. $\mathrm{C}_{1}$ vom Scheitel nach rechts. Nachmittags tritt Facialisparese rechts auf, zugleich Schmerzen im operirten Ohre. Höchste Ternperatur $39,0^{\circ}$. Rechte Pupille weiter als die linke. Abends stärkere Schmerzen. Manchmal lautes Schreien. Morphium subcutan. Darauf Schlaf bis 5 Uhr Morgens. Erwachen mit heftigem mehrmaligen Erbrechen, aber Nachlass der Kopfschmerzen.

20. Juni. Temp. $36,9-39,2^{\circ}$. Erbrechen. Durchfall. Schleimiger dunkelbrauner, weicher Stuhl mit einzelnen Blutstreifen. Starke Druckempfindlichkeit der obersten Halswirbel aber keine Nackenstarre. Nimmt wenig kalte Milcb zu sich.

21. Juni. Morgens Erbrechen. Die Kopfschmerzen werden in die linke Stirnseite verlegt. Druckempfindlichkeit der Halswirbel wie gestern. Sensorium völlig frei. Lumbalpunction um 12 Uhr ergiebt unter mässigem Druck stehende makroskopisch fast klare Flüssigkeit. Mikroskopiseh zahlreiche Leukocyten und einzelne Kokken. Puls vor der Lumbalpunction 112 p. M. klein. Nach der Lumbalpunction unregelmässig. Abends voller Pals 106 p. M. Augenhintergrand normal. Temp. 38, $7^{\circ}-38,6^{\circ}$. Starke Schweisse. Morphium mehrmals subcutan.

22. Juni. Kopfschmerzen wie gestern. Zeitweise Apathie. Intentionszucken des rechten Armes und Beines. Manchmal auch links. Temp. 39,06 bis $38,5^{\circ}$.

23. Juni. Gehör heute schlechter. Weber nach Jiaks. Intentionszucken rechts stärker als gestern. Temp. $37,2^{\circ}-38,0^{\circ}$.

24. Juni. Gegen Morgen treten leichte Delirien auf. Pat. antwortet noch richtig und giebt an, keine Schmerzen mehr zu haben. Nimnat Mìlch und Kaffee zu sich, doch ist die Schluckbewegung nicht ganz angestört. Intentionszucken wie gestern. Urin und Stubl ins Bett. Temp. 39, $9^{\circ}-39.0^{\circ}$. 
25. Juni, Von 2 Uhr Nachts an tiefes Coma. Gegen Morgen Nasenfitigelathmung. Unregelmässige tiefe Inspirationen. Exitus letalis $12 \mathrm{Uhr}$ Mittags.

Auszug aus dem Sectionsprotocoll.

Diagnos is post mortem. Meningitis purulenta der Basis. Nekrose an der rechten hinteren Felsenbeinfläche. Eiterige Thrombose der obersten Enden beider Sinus petrosi. Hyperämie der Hirnhăute. Oedem des Gehirns. Hyperämie der Lungen. Dilatation des rechten Herzens. Splenitis. Aussenfläche der Dura stark injlicirt, glatt und glänzend. Innenfläche der Dura an einigen wenigen Stellen mit rostfarbenen, leicht abstreifbaren zarten Membranen belegt. Die weichen Häute der Convexität ziemlich stark injicirt. Nach der Herausnabme des Gehirns in der hinteren Schädelgrube trübe Flüssigkeit. Dura über dem Clivas and den Spitzen der Schläfenbeine eitrig belegt. Im obersten Theile beider Sinus petrosi findet sich dicker, gelber Eiter. der sich Dach beiden Seiten auf die Gangl. Gasseri. besonders links fortsetzt. Dura an mehreren Stellen über der hinteren Fläche des rechten Schläfenbeines missfarbig gefürbt. Ein aus dem inneren Gehörgang zusammen mit einem Nerv austretendes Gefäss ist missfarben gefärbt und eitrig thrombosirt. Entsprechend der Stelle des Aquaeductus vestibuli is der Knochen rauh und sein Grund leicht eitrig infiltrirt. Die Oberflache des linken Felsenbeines zeigt keine Veränderungen. Die weichen Häute der Basis über der Medulla, vorderem und unterem Thelle des Kleinhirns, Pons, Chiasma, sowie entlang den beiden Fossae Sylvii sind eitrig inflitrit. Basale Gefässe innerhalb der Eiterung mit dunklen, zum Theil erweichten Thromben gefullt. In beiden Seitenventrikeln trübe seröse Flüssigkeit in vermehrter Menge, in den Hinterhörnern dicker Eiter. Gehirn ausserordentlich weich. Ranöpartien von leicht röthlichem Schimmer. Blutpunkte in mässiger Anzahl. Sectionder Schläfenbeine: Rechts: Nach Eröffnung der Paukenhöhle durch Wegnahme der vorderen Gehörgangswand erweist sich der äussere Bogengang vollständig zerstört. Die Sonde diringt nun nach unten und an den beiden freiliegenden Enden gegen das Labyrinth zu ein. Paukenhöble mit Granulationen gefullt. Steigbügel feblt vollständig. Foramen ovale von Granulationen verschlossen. An der hinteren Wand des Felsenbeines, neben dem Aquaeductus vestibuli eine etwa fingernagelgrosse Stelie, an der die Corticalis arrodirt ist. Im Centrum derselben ein kaum mehr als stecknadelkopfgrosser Defect, der in den hinteren Bogengang fübrt. In den eröftueten Bogengängen Eiter. Inbalt des Vorhofs Flüssigireit von zweifelhafter Beschaffenheit. In der Schnecke kein freier Eiter. Windungen derselben mit weisslichem Gewebe angefüllt.

Link 8: Das stark erweiterte Antrum ist von einem compacten Cholesteatom vollständig angefüllt, das nach hinten, gegen den Sinus $\mathrm{zu}$, einen starken, beerenförmigen Ausläufer sendet. Knochen des Proc. mast. hyperämisch. Einjge Zellen desselben eitrig infiltrirt.

Epikrise: Die Section bestätigte die klinisch gestellte Diagnose einer vom operirten Ohre ausgehenden Basilarmeningitis. Ueber den Weg, der die Infection vermittelt hatte, konnte indess nach dem klinischen Bilde noch Zweifel herrsehen; ja man musste sogar, als mit dem Beginn der meningitischen Symptome eine Bessernng des Hörvermögens auf dem operirten Ohre eintrat und der Stimmgabelton rom Scheitel deutlich nach rechts localisirt wurde, eine vom Labyrinth ausgehende Meningitis fiu das am wenigsten Wahrscheinliche halten. Die Section des Schläfenbeines ergah auch, dass die Eiterung sich im wesentlichen in den Bogengängen abspielte. Die schallpercipirenden Organe wurden offenbar erst später ergriffen, so dass wir dort 
auch noch keinen freien Eiter fanden, sondern den krankhaften Process hier noch im Anfangsstadium antrafen. Immerhin erklärt uns dies noch nicht das auffällige Symptom des Besserhörens nach der Operation, das mit dem Beginn der Meningitis zusammenfiel. Man könnte daran denken, dass eine plötzliche Eiterentleerung durch die gefundene Fistel des hinteren Bogenganges eine Entlastung des Labyrinthes und dadurch eine Erhöhung der Function zur Folge gehabt hätte. Dagegen spricht aber, dass die Patientin schon mehrere Jahre schlecht gehört hatte and nicht etwa in der letzten Zeit erst eine Verschlimmerung des Gehörs erlitten hat. Es ist also nicht anzunehmen, dass Eiteransammlung im Labyrinth die ursprüngliche Ursache der Sehwerhörigkeit gewesen ist und konnte daher eine Entleerung des Labyrinthes von Eiter keinen hörverbessernden Erfolg haben. Die eigentliche Eiterung fand sich auf die Bogengänge beschränkt und wenn sie hier anch längere Zeit bereits bestanden haben könnte, so müsste gegen die übrigen Labyrinththeile ein Abschluss sich gebildet haben, der gegen Druckschwankungen jedenfalls einen wirksamen Schutz hätte abgeben müssen. Man könnte daher die auffällige Thatsache der Besserung des Gehörs bei dem Beginn der Meningitis vielleicht so erklären, dass die Erhöhung der Function der Ausdruck eines Reizungszustandes war, der in der beginnenden Entzïndung der Schnecke seine Ursache gehabt hätte, oder in einer Perineuritis des Acusticusstammes. Den gleichen Zusammenhang könnte die am 5. Tage post operationem aufgetretene und von da an zunehmende Facialparese haben. Eine Operationsverletzung des Nerven ist nicht anzunehmen, sonst hätte dieses Symptom schon früher auftreten müssen. Die Affection des Facialis ist also entweder durch Weiterschreiten der Entzündung auf den unterhalb des äusseren Bogenganges gelegenen Theil des Facialeanales, was bei der ausgedehnten Knochenzerstörung dieser Gegend sehr gut möglich war, oder durch Entzündung des in der Nähe der Schnecke gelegenen Nervenstammes hervorgerufen worden. Die Eiterung in den Bogengängen ist entstanden durch Infection des durch den Krankheitsprocess arrodirten und eröffneten horizontalen Bogenganges. Es ist nun die Frage zu beantworten, zu welcher Zeit die Bogengangseiterung eingesetzt hat. Hat sie bereits vor der Operation bestanden, oder ist erst durch die Operation oder nach derselben das eröffnete Labyrinth inficirt worden? Dass eine vorherige Infection sehr viel Möglichkeit gehabt hat, liegt duf 
der Hand. Lag doch in nächster Nähe des eröffneten Bogenganges ein Cholesteatom, und die Umgebung des Bogenganges und selbst die knöcherne Wand desselben waren in grosser Ausdehnung cariös und zerstört. Die Anamnese ergiebt, dass die Patientin seit den letzten vier Wochen von häufigen Sohwindelanfällen und Kopfschmerzen geplagt wurde, was mit einer beginnenden Bogengangeiterung wohl in Einklang zu bringen ist. Doch dürfen wir nicht ausser Acht lassen, dass die gleichen Symptome auch nach einfacher Eröffnung des knöchernen Bogenganges durch Compression des häutigen entstehen und nach gelungener Entfernung des kranken Gewebes meist zurückgehen, ohne dass es zu einer Bogengangseiterung kommt. Dass durch die Operation direct die Infection in das Labyrinth gebracht worden sei, ist nicht wahrscheinlich (die Sondirung der Bogengänge gelang gar nicht); aber es ist nicht auszuschliessen, dass nach der Operation durch die damit verbundene Mobilisirung der bereits im Mittelobr vorhandenen Krankheitserreger der Process von der Oberfläche in die Tiefe des Labyrinthes fortgeschritten ist. Jedenfalls ist nach dem ganzen Verlaufe nicht von der Hand zu weisen, dass, selbst wenn eine Bogengangseiterung schon seit Wochen bestanden hat, die Operation den letalen Ausgang mindestens besehleunigt hat.

Die nächste verhängnissvolle Folge der Bogengangseiterung: war der Durchbruch des hinteren Bogenganges in die hintere Schädelgrube, von wo aus der Process sich rasch weiter fortsetzte. Zur Bildung eines extraduralen Abscesses ist es nicht gekommen, sondern der Entzündungsprocess setzte sich diffus auf die zunächst liegenden Gewebe fort, auf die Vena anditiva interna, auf die beiden Sinus petrosi, so dass bald eine ausgedehnte Thrombose der letzteren sich entwickelte, bis in die Sinus cavernosi. Und von hier aus ist auch jedenfalls die Infection der Meningen erfolgt. Für Fortleitung durch die Dura per contiguitatem gab die Section keinen Anhaltspunkt und die lymphatischen Wege der harten Hirnhaut sind erfahrungsgemäss fürr derartige Fortleitungen wenig geeignet.

Es erubrigt noch eine Kritik unseres Handelns. Eine bestehende Eiterung im Labyrinth konnten wir nicht diagnostieiren. Die Symptome von Schwindel, Kopfschmerzen konnten, wie oben sehon erwähnt, auch auf Compression des intacten häutigen Bogenganges zurückgefuhrt werden. Die lange schon bestehende hochgradige Schwerhörigkeit sprach eher gegen einen noch in 
Entwicklung begriffenen Process. Die Operation wurde unternommen, um die Ursache der Schwindelanfälle festzustellen und in der sicheren Erwartung, dass die knöohernen Theile des Mittelohres von der Eiterung mitergriffen seien. Wir fanden bei der Operation den äusseren Bogengang zerstört. Eine Sondirung desselben gelang nicht. Wir begnügten uns also mit der Wegräumung des kranken Gewebes soweit als möglich, um das Uebrige der Nachbehandlung zu überlassen. Wäre uns aber eine Sondirung gegliekt, so hätten wir uns wohl kaum entschlossen, sofort das Labyrinth breit zu eröffnen. Es wäre zu gewagt, wollte man bei jedem nachweisbaren. Defect eines Bogenganges mit dem Meissel bis zum Vorhof eindringen. Wir mussten Rücksicht auf das, wenn auch nur geringe, aber doch vorhandene Hörvermögen der Patientin nehmen. Hätten wir Eiter ans dem Bogengange fliessen seben, dann hätten wir jedenfalls nicht gezandert, der Fistel nachzugeben und hätten vielleicht das Leben der Patientin noch retten können. So aber mussten wir ein abwartendes Verhalten beobachten. Aber auch bei dem Verbandwechsel am 5. Tage nach der Operation und an den folgenden Tagen war nie Eiter an den Bogengangsöffnungen zu sehen. Der Eiter stand offenbar nie unter stärkerem Druck. Als die meningitischen Symptome auftraten, hätte man allerdings noch versuchen können, den Weg aufzusuchen, den die Eiterung genommen, um eine eventnell circumscripte Meningitis am Weiterschreiten zu hindern. Ein Erfolg wäre aber in unserem Falle sioher ausgeblieben. Der Thrombose der basalen Sinus, die wir als Ursache der Meningitis annebmen, wäre operativ nicht beizukommen gewesen, und die Eröffnung der eiterhaltigen Bogengänge hätte den zum Tode führenden Process nicht aufgehalten.

3. Herman n Reichardt, 17 Jahre alt. Polirlehrling aus Sangerhausen. Aufgenommen den 2. Juli 1898, gestorben den 30. Juli 1898.

Anamnese: Seit Kindheit besteht Eiterung aus dem linken Ohre. Ursache unbekannt. Seit einigen Tagen Stechen im linken Obre, wabrend der Austluss unverändert fortbestand. Vorgestern trat Anschwellung hinter dem linken Ohre und am linken Auge auf. Die ganze Zeit bestand Appetitlosigkeit. Schlaf schlecht. Kein Schwindel, kein Erbrechen, kein Frost. Strabismus convergens seit Kindheit. Pat. ist immer kränklich und schwächlich gewesen. Eltern und Geschwister angeblich gesund.

Status praesens: Schlecht entwickeiter, schwächlicher Knabe. Oedem des linken Auges. Herpes am linken Mundwinkel. Lungen und Herz ohne Befund. Zunge belegt. Foetor ex ore. Temp. $37,5^{\circ} \mathrm{C}$. Puls regelmässig. 80 p. M.

Umgebung des Ohres: Linke Ohrmuschel abstehend. Fluctuirende Schwellung über dem linken Warzenfortsatz. Hautdecke über der Anschwellung geröthet. 
Gehörgang und Trommelfellbefund: Der linke Gehörgang ist aurch Senkung der hinteren oberen Wand in seinem knöchernen Theile verlegt. Aus dem spaltförmigen Lumen entleert sich stinkender Eiter.

Rechts: Grosse trockene Perforation, die die hintere Hälfte des Trommelfeils einnimmt.

Hörprüfung: Flüstersprache rechts $2,5 \mathrm{~m}$, links nicht gehört. $\mathrm{C}_{1}$ vom Scheitel nach links. Fis 4 links bei starkem Nagelanschlag, rechts normal gehört.

6. Juli. Operation: Totalaufmeisselung rechts. Spaltung des Abscesses. Die Corticalis des Warzenfortsatzes ist in grosser Ausdehnung defect, ebenso die hintere knöcherne Gehörgangswand. Freilegung des Antrum durch Wegnahme des Restes der hinteren Gehörgangswand. Der Knochen erweist sich dabei sehr morsch. Einzelne Warzenzellen mit Eiter, andere mit Granulationen gefullt. Sinus in geringer Ausdebnung freigelegt. Im Antrnm, das stark, besonders nach binten erweitert ist, Eiter und geschichtete Epidermismassen. In Aditus und Paukenhöhle blaurothe Granulationen. Hammer fehlt. Amboss am langen Schenkel cariös. Nach hinten im Antrum liegt die Dura frei, die mit Granulationen besetzt ist. Wegnahme des verfärbten Knochens soweit als möglich. Spaltung. Tamponade. Die retroauriculäre Wunde bleibt weit offen.

Abends Temp. $38,2^{\circ}$.

7. Juli. Subjectives Befinden sebr gut, Guter Appetit. Keine Kopfschmerzen. Temp. 36,8-37,8\%.

8. Juli. In der vergangenen Nacht etwas Kopfschmerzen. Geringe Druckempfindlichkeit an den Austrittsstellen der linken Trigeminusäste.

Temp. $36,8^{\circ}-37,7^{\circ}$.

9. Juli. Patient erwacht Morgens $6 \mathrm{Dhr}$ mit starken Kopfschmerzen in der Stirn. Temp, $38,4^{\circ}$ bald Ansteigen auf $40,0^{\circ}$ Puls 104 p. N. Eisblase. Schlechter Appetit. Etwas Unruhe. Sensorium völlig frei. Pupillen und Augenhintergruad normal. Verbandwechsel. In der Wundhöhle nicht Besonderes. Abends Nachlass der Kopfschmerzen.

10. Jnli. Patient soll in der Nacht etwas delirirt haben, hat aber mit Unterbrechungen geschlafen. Morgens keine Kopfschmerzen. Wohlbefinden. Die Kopfschmerzen treten im Lanfe des Tages mehrmals wieder auf, sind aber offenbar nie sebr stark. Puls regelmässig, meist über $100 \mathrm{p}$. M. Temp. $38,8^{\circ}-39,9^{\circ}$. Angenhintergrund normal.

11. Juli. Temp. $38,1^{0}-38,5^{\circ}$. Appetit gut. Zeitweise leichte Kopfschmerzen.

12. Juli. Temp. $37,2^{\circ}-38,1^{\circ}$ Puls $72-76$ p. M. Subjectives Woblbefinden. Verbandwechsel.

13. Juli. Temp. $37,0^{\circ}-39,2^{\circ}$.

14. Juli. Verbandwechsel. Woblbefinden und guter Appetit. Ab und zu Anfälle von Kopfschmerz vom operirten Our ausgehend und in die Schläfe und linke Stirnseite ausstrahlend. Augenhintergrund normal. Puls klein, etwas beschleunigt. Temp. $37,5^{\circ}-38,7^{\circ}$.

15. Juli. In der Nacht Durehfall obne Schmerzen. Im Laufe des Tages fortdauernd. Temp. $37^{\circ}, 7^{\circ}-38,2^{\circ}$.

16. Juli. Durchfall hat nachgelassen. Temp. $36,9^{\circ}-38,2^{\circ}$.

17. Juli. Temp, $36,9^{\circ}-38,2^{\circ}$.

18. Juli. Temp. $36,7^{\circ}-38,1^{\circ}$.

19. Juli. Temp. $37,1^{\circ}-37,7^{\circ}$.

20. Juli. Temp, $36,8^{\circ}-38^{\circ}$.

21. Juli. Temp. $36,7^{\circ}-3 \overline{7}, 9^{\circ}$.

22. Juli. Temp. $37,2^{\circ}-37,4^{\circ}$.

23. Juli. Temp. $37,3^{\circ}-38,2^{\circ}$.

24. Juli. Temp. $37,2^{0}-37,8^{\circ}$.

25. Juli. Temp. $36,8^{\circ}-37,9^{\circ}$

26. Juli. Temp. $36,8^{\circ}-37,8^{\circ}$

27. Juli. Temp. $36,5^{0}-37,1^{\circ}$

In diesen Tagen der gleiche Status. Kopfschmerzen treten noch zeitweise auf, nach Angabe des Patjenten ziemlich beftig, aber bald vorübergehend. 
28. Juli. Morgens einmal Erbrechen. Kopfschmerzen stärker als gewöhnlich und hänfiger anftretend. Augenhintergrund: Links Grenzen der Papille verwaschen. Differenz der Druckstärke der Hảnde, Dynamometer rechts ca. 20, links ca. 40. Giebt an, Rechtshänder zu sein. Appetit schlecht. KIopfempfindlichkeit der linken Schläfengegend und der Austrittsstelle der linken Trigeminusäste. Benennt alle vorgehaltenen Gegenstände richtig. Temperatur $36,7^{\circ}-37,4^{0}$, Puls 62 p. M.

29. Juli. Heute Kopfschmerzen stärker. Patient schläft viel. Sensorium im Wachen immer frei. Puls klein, Frequenz etwas herabgesetzt, doch nie unter 60. Kein Appetit. Patient fühit sich subjectiv schlechter, Temp. 36,9037,10. Gegen Beginn der Nacht Erbrechen. Stärkere Kopfschmerzen. Um 10 Uhr $38,0^{\circ}$. Patient sieht äusserst verfallen aus. Haut blass. Die Temperatur steigt in der Nacht noch auf $40^{\circ}$. Patient ist nur zeitweise bei Besinnung ohne ein Wort zu reden. Morgens $5^{ \pm / 2}$ Uhr Exitus letalis ohne Agonie unter Trachealrasseln.

\section{A uszug aus dem Sectionsprotocoll.}

Diagn os is post mortem. Abscess im linken Schläfenlappen. Meningitis purulenta. Hydrocephalus externus und internus. Erweichungsherde in den Basalganglien. Pleuritis adhaesiva. Folliculärer Katarrh des Dünndarms. Taenia saginata. Schwellung der Mesenterialdrisen. Multiple Abscesse in beiden Nieren.

Dura ziemlich straff gespannt, an der Innenflăche glatt, von hellrosarother Farbe, kleine Gefässe injicirt. Pia ziemlich blutreich, insbesondere auf der Höbe der Convexität. Beim Herausnehmen des Grosshirns findet sich der linke Schläfenlappen mit der Vorderseite des Os petrosum verklebt. Die Hirnhäute an dieser Stelle missfarbig gefärbt und hyperaemisch. In der Schädelørube sammelt sich nach Herausnahme des Gehims rejeblich eitrig seröse Flüssigkeit an. Im linken Schläfenlappen findet sich ein hühnereigrosser zweikammeriger Abscess, der von einer rothbraunen granulirenden Membran ausgekleidet ist. Er steht mit der erwähnten verfärbten Stelle am Os petrosum in Zusammenhang und enthält eine reichliche Menge grüngelben, stark riechenden Eiters. Er ist vom linken Seitenhorn durch eine dünne, in Erweicbung begriffene Wand getrennt. Tela chorioidea des linken Seitenhornes stark hyperämisch, an einigen Stellen mit eitrigem Secret bedeckt. Der hintere Theil des rechten Seitenventrikels stark erweitert, mit klarer seröser Flüssigkeit gefülit. Die Hirnsubstanz rechterseits im Bereich des hinteren Theiles der Basalganglien in Erweichung begriffen.

Oberfläche der linken Niere von graurother Farbe, zeigt überall zahlreiche grauweisse, stecknadeikopfgrosse Herde. Auf Durchschnitten finden sich dieselben Herde im änssersten Theil der Rinde.

Rinde und Mark sehr blutreich. Die reehte Niere verhält sich in allen Theilen wie die linke.

Section des linken Schläfenbeines. Der Sinus petrosus superior wird eröfinet und erweist sich leer. Seine untere Wand fehlt indess zum Theil und an deren Stelle liegt schmutzig gefärbter Knochen frei. Nach Ablösung der Dura zeigt sich an der Felsenbeinkante entsprechend der an der oberen Seite der Dura bemerkten Verfärbung und in Zusammenhang mit der oben erwähnten Stelle an der Wand des Sinus petrosus superior, eine aus. gedehnte Arrosion der Corticalis. Die Corticalis ist an dieser Stelle durchbrochen und scheinbar in ziemlicher Ausdehnung unterminirt. Die Ränder des Defectes sind unregelmässig gezackt, und in der weiteren Umgebung der Knochen weiss gefärbt. Der Defect befindet sich medialwärts vom Wulst des oberen Bogenganges und ist von dunkelrothen, theilweise verfarbten Granulationen angefüllt. Seine Grösse ist ungefähr die eines Kirschkernes. Die Operationshöble ist vollständig mit glatten, rothen Granulationen ausgekleidet. Die Epidermisirung vom Rande der Transplantationslappen hat be. reits begonnen. Von der medialen Wand des Antrums lässt sich ein feiner Fistelgang nach dem oben beschriebenen Knochendefect verfolgen. Die bei der Operation entstandene Kuochenliucke am Tegmen antri ist durch eine blasse Membran verscblossen, die Ränder reactionslos. Schnecke und Bogen- 
gänge frei. Der Defect an der Felsenbeinkante steht mit dem Labyrinth in keiner Verbindung.

Epikrise: Der Fall erweckte bei der Aufnahme keineswegs den Verdacht, dass eine intracranielle Complication vorliege, und auch bei der Operation war nichts gefunden worden, was darauf hätte hindenten können, dass der Process in die Schädelhöhle fortgeschritten war. Als am 3. Tage nach der Totalaufmeisslung unter gleichzeitigem Ansteigen der Temperatur heftige Kopfschmerzen eintraten, mussten diese nach der Anamnese und dem Operationsbefund unerwartet gekommenen Symptome auf eine beginnende Meningitis bezogen werden. Der protrahirte Verlauf, die wechselnden Symptome machten es unwahrscheinlich, dass eine eiterige Meningitis vorlag. Die Annahme einer tuberculösen Meningitis die hatte meiste Berechtigung, da. der Patient den Habitus eines Phthisikers darbot, obwohl keine manifesten Zeichen von Tuberculose nachzuweisen waren. Dass der Meningitis ein Hirnabscess zu Grunde lag, blieb uns verborgen. Erst am Tage vor dem Tode, als sich zum ersten Male eine leichte Parese des rechten Armes zeigte, wurde auch die Mögliehkeit eines Hirnabscesses in den Bereich der Erwägung gezogen, obwohl das gleiche Symptom auch Folge der Meningitis hätte sein können. Ein weiteres Symptom war nicht zu entdecken, ausser geringfügiger einseitiger Neuritis optica und nun auftretenden Erbrechens; alles konnte ebensogut auf die Meningitis bezogen werden. Vor der Operation hatten Kopfschmerzen, sowie jegliche cerebralen symptome gefehit. Der Puls war nie herabgesetzt. Bei der Unsicherheit der Diagnose hielten wir es für das beste, abzuwarten, zumal das allgemeine Befinden des Patienten sich eher besserte als versehlechterte. Aber am Abend des nächsten Tages trat plötzliche Temperatursteigerung ein, und unter zunehmender Apathie verschied der Kranke. Die Scetion ergab, dass ein Hirnabseess thatsächlich vorhanden war. Die Meningitis war vorwiegend serös, dagegen fanden sich keine Zeichen von Tuberculose. Es erscheint somit, dass sich, durch den bestehenden Hirnabscess veranlasst, eine zunächst seröse Meningitis entwickelt habe, die erst später, nach stärkerer Erweichung der Wand, die die Abscesshöhle von dem Seitenventrikel schied, zu einer eiterigen wurde. So könnte man die plötzlich einsetzenden Kopfschmerzen und das gleichzeitig auftretende Fieber wohl erklären, ebenso auch die späteren Remissionen. Da der Kranke aber vor der Operation 
angeblich nie Kopfschmerzen gehabt hat, ist die Frage nicht zu umgehen, ob nicht ein Zusammenhang zwischen dem operativen Eingriff und dem Auftreten der cerebralen Symptome bestehe. Wir müssen die Möglichkeit zugeben, dass die Meisselersehütterung die directe Veranlassung zu dem Durohtritt von Entzündungserregern aus dem Hirnabscess gewesen ist. Ob die Temperatursteigerung indess allein auf Rechnung der Entztindung der Hirnhäute zu setzen ist, kann zweifelhaft erseheinen in Anbetracht dessen, dass sich bei der Section metastatische Herde in den Nieren fanden, deren Ausgangstelle in dem stark arrodirten Sinus petrosus superior zu suchen ist, obwohl in demselben kein Thrombus mehr vorhanden war. Es ist nicht festzustellen, in welehem Grade jeder der gleichzeitig bestehenden Processe an der Fieberbewegung betheiligt waren. Nur das kurz vor dem Tode plötzlich erfolgende starke Ansteigen der Temperatur ist wohl allein auf die Meningitis $z$ beziehen, die aus ihrem bisherigen schleichenden Verlaufe infolge 'Austritts grösserer Mengen von Eitererregern durch die allmäblich durchlässiger gewordene Abscesswand, mit einem Male in das gefährliche letal endigende Stadium trat.

4. Carl Bock, 14 Jahre alt, Drechslerlehrling, Giebichenstein. Aufgenommen am 5. Juli 1898, gestorben am 11. Juli 1898. Pat. hat seit dem 6 . Lebensjahre rechtsseitige Ohreiterung nach Scharlach, doch ohne Besehwerden. Seit 3. Juli Auftreten eines stärkeren ,wässerigen" ubelrieckenden Ausflusses zugleich mit Schmerzen hinter dem Ohre, die in das Genick and die rechte Schlaffe ausstrahlten. Zuweilen dabei unerbeblicher Kopfschmerz. Appetit seit dieser Zeit schlecht. Am 5. Juli früh beim Aufstehen aus dem Bette vorübergehend Schwindel. Heute Morgen einmal Eirbrechen, nach seiner Angabe absichtlich herbeigefübrt durch Einführen des Fingers in den Hais. In dieser ganzen Zeit will er offters Fieber gehabt haben, auch einmal Frost. Der Stuhlgang sei immer normal gewesen.

Status praesens: Blasser, schmächtiger, schlecht genährter Knabe. Der Kopf wird nach rechts gebeugt gehalten. Die Bewegung des Kopfes um die verticale und transversale Axe frei, um die sagittale etwas behindert und schmerzhaft. Druckempfindlichkeit nur am Epistropheus nachzuweisen. Starker Foetor ex ore. Zunge belegt. Sensorium völlig frei. Pupillen gleichweit, eng, reagiren gut. Patellarieflexe normal. Papilla nervi optici besonders an der nasalea Seite etwas verwaschen, im übrigen nicht hyperämisch. Innere Organe ohne Befund. Urin ohne Zucker und Kiweiss.

Umgebung des Ohres: Rechts starke Druckempfindlichkeit der Spitze und des hinteren Theiles des Proc. mast. Ingularisgegend besonders stark druckempfindlich.

Gehörgang und Trommelfellbefund: Rechts Gehörgang nicht stenosirt. Vom Trommelfell steht nur ein oberer und unterer Saum. Unter dem oberen Saum hängt eine Granulation herab. Links normal.

Hörpr äfung: Uhr rechts ad concham, nicht vom Knochen. Flüstersprache rechts vor dem Ohre, links $5-6 \mathrm{~m}$. C $\mathrm{C}_{1}$ rechts vom Knochen schlechter als links, vom Scheitel nach links verstärkt. Rinne rechts negativ. Fis 4 rechts herabgesetzt. Beim Katheterism. t. rechts lautes Knattern, kein Perforationsgerāusch. Der linke Gaumenbogen steht höher als der rechte.

Temp. am 5. Juli Abends $3 \bar{i}, 1^{\circ}$, Puls 100 , regelmässig und kräftig. Um 10 Uhr Nachts $41,2^{\circ}$ unter leichtem Frösteln. Puls 134, sehr gespannt, 
ungleiche Elevationen. In der Nacht vom 5,-6. Juli Kopfschmerzen und Schmerzen im Genick.

6. Juli. Temp. Morgens $36,9^{\circ}$. 10 Uhr $40,5^{\circ}$. Befinden wie gestern. Lumbalpunction ergiebt klaren Liquor obne vermehrten Leakocytengehalt. Operation: Unterbindung der Vena jug. int. Freilegung der Mittelohrräume. Sinusoperation. Weichtheile normal, Corticalis blutreich; in den Mittelohrräumen zerfallener foetider Brei und schmutzige Granulationsmassen. Hammer und Aảboss cariös. Beim Eingehen auf die hintere Schãdelgrube quillt bei den ersten Meisselschlägen pulsirend branne Jauche hervor. Der Knochen um den ganzen Sinus herum morsch, die Knochenwand zwischen Antrum und Sinus schwarz und morsch. Mit der Knochenzange der Sinus sigm. und seine Umgebung in Kleinhandtellergrösse freigelegt. Seine Wand ist wie die umgebende Dura theils schwarz, theils speckig infiltrirt und exulcerirt; an der Grenze des Kranken ist die Dura mit älteren Blntextravasaten durchsetzt. Nun erst Unterbindung der Vena jugularis oberhalb der Abgangsstelle der Vena facialis communis. Eine grössere, der Venenscheide aufsitzende acut geschwollene Lymphdrüse musste entfernt werden. Weites A ufchlitzen des schon perforirtensinus. Zerfallene Thrombenmassen darin mit dem scharfen Lôffel entfernt. Beim Eingehen mit dem Löffel in das periphere Ende, worin der meiste jauchige Thrombenbrei sass, schliesslich starke, venöse Blutung, welche Tamponade des peripheren Endes mit Jodoformgaze nothwendig machte. Aus dem centralen Ende blutete es nicht.

Temp. am 6. Juli nach der Operation $40,9^{\circ}, 39,3^{\circ}$, (Puls 120), 39,6 $39,4^{\circ}, 39,2^{\circ}$.

7. Juli. Temp. $37,8^{\circ}$, (Puls 96), 38,50, (116), 39,20, (120), 390, 390, $39,5^{\circ}, 40,0^{\circ}, 41,2^{\circ}$. Auftreten starker Kopfschmerzen in der Stira. Oedem des rechten Augenlides.

8. Juli. Temp. $41,0^{\circ},(139), 37,1^{\circ},(130), 37,1^{\circ}, 36,9^{\circ},(84), 40,7^{\circ},(135)$ $40,50,37,5$. Morgens 7 Uhr Schüttelfrost mit folgender Temperatursteigerung auf $41,2^{\circ}$. Seit heute Morgen Stechen in der rechten Brustseite, vorn unten. Puls frequent, dünn, leicht unterdrückbar.

9. Juli, Temp. $37,1^{0},(96), 40,3^{\circ}, 40,2^{\circ}, 39,4^{\circ}, 39,7^{\circ}, 39,6^{\circ}, 39,8^{\circ}, 39,2^{\circ}$, $37,5^{\circ}$. Appetit schlechter als gestern. Stechen in der rechten Brust heftiger. Athemfrequenz beschleunigt, 54 pro Minute. Dämpfung rechts anten hinten nachweisbar. Von Zeit zu Zeit Kopfschmerzen. Pat. liegt meist apathisch da, ohne sich zu rühren. Ord. Decoct. Chin., Wein.

10. Juli. Temp. $36,8^{\circ}$, (108), $37,0^{\circ}, 39,6^{\circ}, 39,5^{\circ}, 38,2^{\circ},(120) 38,5$, $39,3^{\circ}, 40,0^{\circ}, 38,2^{\circ}, 39,5^{\circ}$. Puls besser, regelmäsaig und kräftig. Stechen in der rechten 'Brust noch stärker. Athemfrequenz bis 60 pro Minute. Allgemeinbefinden besser. Gegen Abend verschlechtert sich der Zustand. Athem oberfächlich und frequent. Pat, delirirt die ganze Nacht. Papillengrenze nasal beiders. verwaschen.

11. Juli. Temp. $39,9^{\circ},(152), 39,0^{\circ}, 39,5^{\circ}, 39,3^{\circ}, 38,9^{\circ}, 39,6^{\circ}$. Fortwährendes Deliriren; Pat. beginnt leicht blutig gefärbtes Sputum auszawerfen. Athemfrequenz wie gestern. Heute auch Schmerzen in der linken Brustseite. Infus, rad. Seneg. Verbandwechsel: Aus dem peripheren Sinusende nach Entfernung des Tampons starke venöse aber leicht stillbare Blutung, aus dem centralen Sinusende quillt bräunliche Jauche hervor, deren Menge sich bei Druck auf die obere Iugularisgegend noch mehr steigert. Spülung, Tamponade. Iugulariswunde gut aussehend. Kein Eiter.

Die Athembeschwerden nehmen immer mehr za. Auswurf ziemlich bedeutend. Einmal Erbrechen. Gegen Abend allmählicher Verfall. Gesichtsfarbe bläulich weiss. Von 10 Uhr an Trachealrasseln. $11^{1 / 2}$ Uhr Nachts Exitus letalis.

Auszug aus dem Sectionsprotokoll: Oberhalb der Ligatur in der rechten Vena jugul. int. eitrig zerfallene Thrombenmassen. Unterhalb der Ligatur flussiges Blut. In der Umgebung der Vena jugul. nirgends eitrige Massen. Im Sinus longit. Fibrin und flüssiges Blut. Dio weichen Häute der Convexität zart. Der rechte Sinus transy, verschlossen durch einen missfarbenen, grösstentheils erweichten Thrombus. Der linke Sinus transv. 
ist von diesen jauchigen Thromben nicht mehr erreicht, er ist wie der linke Sinus sigm, vôn frischem Blutgeriunsel erfüllt. Die jauchigen Thromben massen des rechten Sinus transv. setzen sich auf die ganze Ausdehnung tes rechten Sinus sigm. und Sinus rectus fort. Der rechte Bulbus venae von jauchig erweichten Massen erfüllt, ebenso im rechten Sinus pextos. inf. Thrombenmassen, wäbrend die Petrosi sup. frei von Thresobose sind. Zwerchfellstand beiderseits unterer Rand der vierten Ripro. Nach Fortnahme des Brustbeins die Lunge mässig retrahirt. Linke nunge in ganzer dusdehnung mit dem Thorax verwachsen. Rechte Lunge teicht löslich mit der Thoraxwand verklebt, in der rechten Pleuraboble wre ziemliche Menge trüber, mit Fibrinfocken untermischter Flussigkeit. Lwischen Zwerchfell und Pleura diaphragm. befindet sich eine abgesackte Höhle, mit fibrinöseitrigen Massen erfült. Pleura der linken Lunge von fibrinösen Massen bedeckt; Bronchialmucosa stark geröthet, mit schleimig-eitrigem Secret bedeckt. An der Basis der rechten Lunge einige etwa kirschgrosse Abscesse mit missfarbenem grünlichen Inhalt, einer davon mit einem Bronchialast in Verbindung stehend. Oberlappen der linken Lunge blass, ziemlich zäh und feucht, in den unteren Partien von einigen hellbraunen Streifen und Flecken durchsetzt. Luftgehalt bedentend herabgesetzt. Aus den Bronchien entleert sich reichlich eitriges Secret. Rechte Lunge, mit fibrinösen Massen bedeckt, ziemlich schwer. Bronehialmucosa. wie links. Anf dem Durchsehnitt des Oberlappens hellbraun, Iufhaltig, an den übrigen Partien dunkelbraun, von zahher Consistenz, feucht, herabgesetzter Luftgehalt. Unterlappen ebenso zäb, dunkelbraun, in den unteren Partien abgesehen von den erwähnten Abscessen, von leicht prominirenden Flecken durchsetzt. Luftgehalt aufgehoben. Milz etwas vergrössert. Kapsel blauviolett, etwas schlaff. Auf dem Durchschnitt Pulpa schmutzig bräunlich, ziemlich weich. Follikel vergrössert, jedoch undeatlich.

Linke Niere von mässigem Fettpolster umgeben. Fibrosa leicht löslich. Oberfläche gut injicirt, glatt. Auf dem Durchschnitt Markkegel hellbraun, wenig scharf. Rinde gelbbraun, leicht überquellend und von helleren Streifen durchsetzt. Organ vergrössert. Ebenso die rechte Niere. Mikroskopisch erweisen sich die Nierenepithelien stark verfettet.

Diagnosis post mortem: Eitrig janchige Thrombose des rechten Sinus transv., sigmoid. und petros. inf, des Sinus rectus, der Vena jugul. int. dext. in ihrem oberen Theile; Ligatur der Vena jugul. int. dext, metastatische Lungenabscesse. Pleuritis fibrosa, fibrinosa u. sero-purul. sinistra. Pleuritis sero-purul. dextr., Hyperämie der Lunge, Atelektase des rechten Unterlappens in seinem unteren Theil. Bronchitis catarrhalis. Milztumor. Nephritis parenchymatosa. Enteritis follicularis.

Epikritische Bemerkungen: Als Todesursache müssen wir in diesem Falle die ansgedehnten Lungenveränderungen metastatiseher Natur auffassen, deren Diagnose sehon in vita gesichert war. Bei der Aufnahme des Kranken war an den Lungen noch nichts Pathologisches nachweisbar. Erst am 2. Tage nach der Sinusoperation begann die Lungenerkrankung in die klinische Erscheinung zu treten. Indess ist wohl die Annahme berechtigt, dass die Aussaat infectiöser Keime, welche zu den Lungenmetastasen geführt, bereits zur Zeit der Aufnahme des Kranken, also vor der Sinusoperation, erfolgt war. Wenn auch die Prognose der Sinusthrombose im Wesentliehen abhängt von dem Nachweis schon bestehender Lungenmetastasen, so lehrt uns dieser Fall, dass ein negativer Lungenbefund zur Zeit der Sinusoperation noch nicht berechtigt, die Prognose günstiger zu 
stellen. Erst wenn melnere Tage nach der Operation vergangen sind, ohne dass abnorme Erscheinungen seitens der Lunge eintreten, haben wir die Sicherheit, dass die Anlage zu Lungenmetastasen nieht schon vor der Operation geschaffen war und dürfen wir in der Voraussetzung, dass es unserem operativen Eingriff gelungen, die Tendenz der localen Sinuserkrankung zu einer Allgemeininfection zu beseitigen, die Prognose wesentlich günstiger stellen.

5. Agnes Günther, 14 Jahre alt. Vater Cigarrenarbeiter, Delitzsch. Aufgenommen am 30. Juli 1898, gestorben am 2. August 1898.

Anamnese: Ohreiterung rechts seit Kindheit. Vor 14 Tagen Schmerzen in der rechten Ohrgegend, Kopfschmerzen und mehrtägiges Erbrechen. Vor 8 Tagen hatte Patientin nach ibrer Beschreibung einen typischen Schüttelfrost. Der Ausfluss aus dem $\mathrm{Ohr}$ soll geringfügig gewesen sein. Der behandelnde Arzt verordnete Blutegel hinter das Obr, Einstreuen von Borpulver und eine Eingiessung von Camillenthee. Seit 8 Tagen bält Pat. den Kopf schief und klagt über Schmerzeu im Genick. Appetit während der ganzen Zeit sehr gering, viel Durst, Ohrensansen, unruliger Schlaf. Pat. kommt zur Klinik wegen der Schmerzen und der Störung des Allgemeinbefindens.

Status praesens: Schlecht genährtes Mädchen, blasse Gesichtsfarbe, schwer krankes Aussehen. Passive Bewegungen des Kopfes erregen laute Schmerzäusserungen. Es besteht eine allgemeine Hyperästhesie der Kopfgegend, des Halses und Nackens. Ophthalmoskopisehe Untersuchung: Papillen beiderseits vollständig scharf. Rechts ist der nasale Theil der Papille etwas hyperämisch. Pupillen gleich weit, reagiren normal. Keine Paresen, Herz o. B.; Lungen: Percussion ergiebt negativen Befund. Das Athmungsgeräusch aber rechts schwächer als links.

Urin obne Zucker und Eiweiss.

Umgebung des Ohres: Hinter dem Obr Blutegelstiche. Geringes Oedem der rechten Finterhauptgegend. Starke Druckempfindlichkeit des Planum mast. und besonders der Spitze.

Gehőrgang - und Trommelf elib ef und: Gebörgang nicht stenosirt; beim Ausspritzen des in der Tiefe befindlichen Eiters kommen vielgeschichtete Epidermismassen mit zum Vorschein. Nur oberer Saum rom Trommelfell erhalten, die freiliegende Pankenhöhleninnenwand epidermisirt. Lin $\mathrm{k}$ : Narbe vora unten im Trommelfell.

Hörprüfung: Rechts wird nur laute Sprache verstanden. $C_{1}$ vom Scheitel nubestimmt. Fis 4 rechts nur bei starkem Fingerkuppenanschlag.

Temperatur bei der Anfnahme $37,5^{\circ}$, Puls 100 regelmässig. Resp. 50. 4 Ubr Nachmittags: Lumbalpunction ergiebt unter starkem Drucke in weitem Strahl abfliessende wasserklare Flüssigkeit, die mikroskopisch keine Formelemente enthält. Färbung ebenfalls negativ. Nach der Lumbalpunction wird der Puls frequenter, kleiner und etwas unregelmässig. Bald darauf ausgesprochener Schüttelfrost mit Ansteigen der Temperatur auf 40,0 $0^{\circ}$. Daner desselben etwa 10 Minuten. Danach leichter Schweissausbruch. Puls wird wieder voller und regelmässiger, $128 \mathrm{p}$. M.

In der Nacht vom 30.-31. Juli wieder Schüttelfrost mit folgender Temperatursteigerung auf $40,8^{\circ}$.

31. Juli. Temp, 37,0 $0^{\circ}$. Um 9 Uhr Schüttelfrost mit Temperatursteigerung auf $39,0^{\circ}$.

12. Uhr Operation: Weichtheile ödematös, Corticalis sehr blutreich. Der zunächst darnnter liegende Knochen weich, morsch, gelblich verfärbt. Nach einigen Meisselschlagen dringt von hinten her Eiter hervor. Dem Eiter nachgehend gelangt man in den sulcus sigmoideas, der mässig mit jauchigem Eiter angefüllt ist. Der sinus sigmoideus wird mit Meissel und Knochenzange etwa $5 \mathrm{~cm}$ in der Jünge freigelegt. Derselbe ist collabirt, so dass der sulcus 
fast leer ist. Die vorliegende Wand des Sinus ist schmutzig graugelb gefärbt mit schwärzlichen brandigen Stellen und zeigt nach unten eine etwa stecknadelkopfgrosse Perforation. Der Sinus erscheint nach oben verschlossen, von unten quillt auf Druck auf die Jugularis brăunliche Jauche hervor. Daher zunächst Aufsuchen der Vena jug. int. Dieselbe ist von normalem Aussehen und prall gefüllt. Unterbindung der Vena jugularis doppelt und Durchschneidung derselben zwischen den beiden Ligaturen. Ebenso Unterbindung der sehr hoch abgehenden Vena facialis comm. Freilegung der Mittelohrräume durch Fortnahme der hinteren knöchernen Gehörgangswand. Im Antrum viel cholesteatomatöse Massen, die sich nach aussen und hinten weit fortsetzen und bis in den Sulcus sigm. verfolgen lassen. Hammer entfernt, Amboss fehlt. Freie Eröffnung des Sinus von der Perforations stelle in demselben aus. Kein Inhalt. Excision der nekrotischen lateralen Sinuswand. Auf Druck auf den peripheren Jugularisstumpf dringt aus dem unteren sinusende zuerst noch Jauehe, dann Blut. Der Stumpf fullt sich wieder mit Blut. Naht des oberen Wundwinkels, der Halswunde und des hinteren T-Schnittes.

Temperatur post operat. $38,8^{\circ}$ (Puls 120 ), $38,7^{\circ}, 38.8^{\circ}, 38,5^{\circ} 38,2^{\circ}, 39,6^{\circ}$.

Nach der Operation Puls sehr schlecht; Aetherinjection, Wein. Nach. mittags erholt sich Pat. wieder. Sie klagt über starke Schmerzen im Genick und in der linken. Brust. Wenig Schlaf.

1. August. Temp. $39,0^{\circ}$ (Respiration 32), 39,2 $, 39,1^{\circ}$ (Puls 160) 40,6 $39,4^{0}, 40,8^{\circ}$.

Die Respiration auf 32 erhöht, Nasenflügelathmung. Zeitweise comatöser Zustand.

2. August. Temp. $40,0^{\circ}$. Morgeas kleiner werdender Puls. Pat. reagirt noch anf Anrufen. 9 $1 / 2$ Uhr Exitus letalis.

\section{Sectionsbericht.}

Diagnosis post mortem: Lungenoedem. Diffuse katarrhalische Pneumonie beider Lungen. Lungenabscesse. Serös-eitrige Pleuritis. Bronchitis catarrhalis. Splenitis acuta et Perisplenitis. Nephritis parenchymatosa. Jauchig-eitrige Thrombose des rechten Sinus transversus. Jauchige Infiltration der Wandung des rechten Sinus transversus. Jauchige Infiltration der Wandung des rechten Sinus sigm. und des Bulb. venae jugul. Ligatur der Vena jugul, und Thrombose des oberen Stüekes der Vene.

Gracil gebauter Körper eines jungen Mädchens mit blassen Hautdecken. Auf Brust und Abdomen zahlreiche stecknadelkopfgrosse wasserhelle Bläschen. In der rechten mittleren Halsgegend am oberen Rande des Sternocleidom. eine ca. $8 \mathrm{~cm}$ lange, in den obersten Theilen durch 2 Nähte vereinigte tiefe Incisionswunde, in deren Grunde die doppelt unterbundene Vena jugul. freiliegt. Pannic. adip. in geringem Grade entwickelt. Muscul, blass und trocken.

Darmserosa glatt, glänzend. Im kleinen Becken vermehrter flüssiger Inhalt, Leber überragt den Rippenbogen fingerbreit. Zwerchfellstand beiderseits unterer Rand der 4. Rippe. Nach Wegnahme des Sternum die Lungen gut retrahirt. Herzbeutel zum grossen Theil vorliegend, enthält ziemliche Mengen klares hellgelbes Serum. In der linken Pleurahöhle eine mâssige Menge trubgelber Flüssigkeit. In der rechten Pleurahöhle etwas weniger. Herz von entsprechender Grösse und ohne abnormen Befund. Die linke Lunge gross und schwer. Pleura im vorderen Abschnitt leicht getrübt und mit zahllosen kleinen subpleuralen kikchymosen bedeckt. Die utbrigen $\mathrm{Ab}$ schnitte der Pleura mit fibrinös-eitrigen Auflagerungen bedeckt. Im Unterlappen hinten unten ein etwa bohnengrosser Abscess, der nach aussen durchgebrochen ist und missfarbene schmutzig grüne Ränder hat. Die Bronchialmucosa ist leicht injicirt und mit schleimigem Secret bedeckt. Pulmonalarterienäste sind frei. Eine Bronchialdrüse stark vergrössert und verkalkt. Der Oberlappen ist auf dem Durchschnitt von braunrother Farbe, ziemlich derb mit trüber Schnittfläche, von welchen sich auf Druck reichliche, schaumige Flitssigkeit entleert. Der Unterlappen etwas dunkler, zeigt an einigen 
Stellen leicht hellbräunliche Verfärbung im Parencbym. In seinem unterstes und hintersten Theile ist der Luftgebalt aufgehoben, in den übrigen $A b$ schnitten stark reducirt. Rechte Lunge in ihrem äusseren Verbalten ähnlich wie links. Auf der Pleura des Unterlappens sind hinten zwei über erbsengrosse prominente missfarbene Stellen, welche beim Einschneiden missfarbenen grünen Inhalt aufweisen. Bronchialmucosa mit schleimig - eitrigem Secret bedeckt, im Uebrigen Befund wie links. Milz ist mit Umgebung fest verwachsen. Die Kapsel mit fibrösen Auflagerungen bedeckt von blăulich livider Farbe. Pulpa schmutzig braunroth, überquellend, von zerfliesslicher Consistenz, normaler Zeichnung.

Nephritis parenchymatosa.

Die übrigen Bauchorgane ohne Besonderheiten.

Schädeldach langoval, von entsprechender Dicke, Diploë erhalten. Auf der Höhe des Scheitels ist das Schädeldach durchscheinend. Aussenfäche der Dura glatt und glänzend. Im Sinus longit. wenig flüssiges Blut. Innenfläche der Dura glatt und glänzend. Die oberflächlichen Gefässe in mässigem Grade gefült. Bei Herausnahme des Gehirns entleert sich aus der grossen Schädelgrube eine geringe Menge klarer hellgelber Flüssigkeit. Dura der Basis stark injicirt, izber dem Clivus etwas missfarben. Dura in der rechten hinteren Schädelgrube über dem Sinus sigm. missfarbig, von grünlichem Eiter bedeckt. An einer Stelle, nahe dem lateralen Ende der oberen Felsenbeinkante zweimal perforirt in der Grösse ungefähr eines Bleistifts. Die umgebenden Partien der Dura von stärkerem Gefässhof umgeben. Im rechten Sinus transw. findet sich ein erweichter Thrombus, der in seinen Randpartien namentlich gegen den Sinus sigm. hin in missfarbenen Fetzen mit der Sinuswand zusammenhängt. Der Sinus petros. sup. ist frei. Der Sinus petros. int. enthält flüsiges Blut, das gegen den Sinus cavernos. hin missfarben ist. Im rechten Sinus cavernos. eitrige Massen, die sich durch den Türkensattel hindurch bis anf den linken Sinus cavernosus erstrecken Die linken Sinus petrosi sind frei. Im linken Sinus sigm. und transv. schwarze Blutgerinnsel. Sinus rectus ist frei. Nach Abzug der Dura findet sich die hintere äussere Fläche des Felsenbeins missfarben, am lateralen Ende der vorderen Felsenbeinfäche findet sich eine zackige, etwa linsengrosse Perforation, durch welche man nach aussen vor das obere Ende des Warzenfortsatzes gelangt. Nach Abzug der Dura vom Foramen magnum findet sich zwischen Occiput und 1. Wirbel das Gewebe auf der rechten Seite eitrig infiltrirt. Bei Erweiterung des in der rechten Halsgegend befindilichen Schnittes zeigen sich die Weichtheile in der Umgebung nirgends eitrig infiltrirt; das obere Ende der ligirten Vena jugul, int. gelullt mit einem sehwarzen, der Wand leicht anhaftenden, feuchtglänzenden Thrombus. Am Foramen jug. zeigt die Vene jauchig missfarbiges Infiltrat der Gefässwand. Im unteren Ende der Vena jug. findet sich ein schwarzes Blutgerinnsel; die Venenwand ohne Verănderungen. Die Basis des Gehims ist zart. Nur die rechte Kleinhirnhemisphäre zeigt an ihrer unteren äusseren Fläche eine missfarbene Partie und circumscripten eitrigen Belag. Auf dem Durchschnitt erstreckt sich die missfarbene Stelle noch eine kleine Strecke in die Hirnrinde hinein. Die Seitenventrikel enthalten einige Tropfen klarer Fiüssigkeit. Ihr Ependym ist zart und glănzend, ebenso das der übrigen Fentrikel. Sonst nichts Besonderes. Die Kapsel des rechten Atlanto-Occipitalgelenkes ist eitrig infiltrirt. Das Gelenk selbst frei. Die Gelenkfiäche des Schädels zeigt auf dem Durchschnitt die darunter liegende Spongiosa sehr blutreich. Das dicke Markgewebe quillt uber die Schnittlache. Labyrinth frei. Vom Steigbugel nur die Platte vorhanden.

Epikritische Bemerkungen: Der Tod der Patientin ist an pyämischer Allgemeininfection erfolgt, insbesondere an der metastatischen Lungenerkrankung. Die Sinnsoperation kam zu spät, als dass sie das Zustandekommen der Allgemeininfection hätte verhindern können; schon 8 Tage vor Aufnahme in die Klinik hatte die Kranke einen Sehüttelfrost gehabt. Aber auch 
wenn zur Zeit der Sinusoperation eine so ausgedehnte Aussaat infectiösen Materiales anf dem Wege der Blutbahn noeh nicht erfolgt wäre, so wären in diesem Falle doch, wie die Section lehrte, die Chancen zur Erhaltung des Lebens nur gering gewesen. Denn einmal waren die Krankheitskeime bereits dureh die Sinusinnenwand hindurchgegangen und hatten eine circumscripte Leptomeningitis der entsprechenden Kleinhirnfäche verursacht, die sich ja leicht zu einer diffusen, zum Tode führenden, hätte ausdehnen können, und zweitens bestand eine purulente Thrombose des rechten Sinus cavernosus, deren Entstehung man, da die beiden Sinus petrosi frei waren, mit dem cariösen Defect an der Vorderseite der Pyramidenspitze in Zusammenhang bringen muss. Wenn es möglicher Weise bei rechtzeitiger Operation gelungen wäre, durch die Operation die Thrombose in dem der Körperoberfäche nahe gelegenen und operativ zugängigen Sinus sigmoidens and transversus ihrer Gefährlichkeit zu entkleiden, so hätte doch die discontinuirlich von der Transversus-Thrombose entstandene Cavernosus-Thrombose mit grösster Wahrscheinlichkeit zum Tode geführt, weil die Erkrankung dieser Oertlichkeit unserem chirurgischen Vorgehen bisher nicht zugänglich ist. Von besonderem Interesse ist in diesem Falle noch die AtlantoOccipitalgelenkaffection, welche als Ursache der in vita vorhanden gewesenen starken Genickschmerzen und der Unbeweglichkeit des Kopfes angesprochen werden muss.

6. Albert Limburg, 38 Jahre alt. Handarbeiter aus Kl. Ostran. Aufgenommen den 21. August 1898. Gestorben den 13. September 1898.

Anamuese: Patient will erst seit 6 Jahren an linksseitigem Ohrenfluss, angeblich nach Erkältung leided. In den letzten Jahren wurde der Ausfluss stärker und stark riechend. Zu Pfingsten d. J. warde Patient von Schwindel und Kopfschmerzen befallen, die allmählich zunahmen. Er suchte einen Arzt auf, der Ausspülungen anordnete. Dies brachte Erleichterung. Patient konnte seine Arbeit wieder aufnehmen. Vor 8 Tagen bekam er anf dem Wege zur Arbeit wieder heftigen Schwindel. Er musste sofort nach Hause gehen und sich zu Bett legen. Es traten Kopfschmerzen anf und Erbrechen, oft 4 mal täglich obne Uebelhefinden. Der Appetit blieb gut. Stuhl hat er seit gestern vor 8 Tagen nicht mehx gehabt.

Status praesens: Schlecht genährter, blasser Mann. Zunge leicht belegt, geringer Foetor ex ore. Pupillen gleichweit, reagiren normal. Kein Nystagmus. Augenhintergrund normal. Starker Schwindel beim Gehen mit geschlossenen Augen. Gang auch bei geöffneten Augen unsicher. Das Aufstehen vom Stuhl missingt beim ersten Versuch. Innere Organe ohve Befund. Urin frei von Eiweiss und Zucker. Temp. 36,90. Puls 92 p. M.

Umgebung des Ohres: Ohne Befund.

Gehörgang und Trommelfellbefund: Rechts mehrere Narben im Trommelfell. Links: Der äussere Gehörgang durch Granulationen, die leicht bluten, yöllig verlegt. Die Sonde weist einen ausgedehnten Defect der hinteren knöchernen Gehörgangswand nach, der ganz lateral gelegen ist. 
Hörprüfung: Flüstersprache rechts $2 \mathrm{~m}$. Links nur laute Worte. Weber nach rechts. Fis 4 rechts normal, links bei Metallanschlag. Galtonpfeife rechts normal, links $5,5 \mathrm{~m}$.

22. August. Operation: Totalaufmeisselung links. Weichtheile und Corticalis normal. Nach der Vorklappung der obrmusehel zeigt sich ein Defect der ganzen knöchernen hinteren Gehörgangswand, welcher von Cholesteatommassen ausgefüllt ist. Eine schwarz verfärbte polypöse Granulation quillt aus dem Aditus hervor, sie hat, wie sich später zeigt, ibre Wurzel am Boden des Aditus. Die Mittelohrränme sind vollständig angefullt mit Cholesteatom. Theilweise ist die Matrix vom Knochen abziehbar. Oben liegt die Dura, hinten der Sinus frei, beide theilweise von Cholesteatommatrix bedeckt. Der horizontale Bogengang ist fistulös durchbrochen. Aus der Fistel lässt sich mit der Sonde Cholesteatom herausholen. Der Bogengang wird mit dem Meissel erweitert. Der Nervus facialis lag in Ausdehnung von ca. $1 \frac{1 / 2}{\mathrm{~cm}}$ frei, sein Perineurium rosaroth. Von Hammer und Amboss ist nichts zu finden. Spaltung. Offenlassen der retroauriculären Wunde.

In den Tagen nach der Operation normale Temperaturen. brechen.

27. August. Erster Verbandwechsel. Nach dem Verbandwechsel Er-

28. August. Abends mehrmals Erbrechen. Temp. $36,3^{\circ}-36,5^{\circ}$. Beim Aufsitzen stets starker Schwindel, meist von Erbrechen begleitet.

30. August. Kein Erbrechen mehr, doch starker Schwindel und Uebelkeit bei kleinen Bewegungen des Kopfes. T'emp. $36,4^{\circ}-36,6^{\circ}$.

4. September. Seit heute Morgen Kopfschmerzen in der Stirn. Schwindel unverändert. Brechneigung. Weniger Appetit.

5. September. Klopfempfindichkeit am Hinterkopf links. Linke Pupille vielleicht etwas weiter als die rechte, reagiren beide gut. Augenhintergrund unverändert. Dynamometer rechts 30 , links 20. Giebt an, Linkshänder zu sein. T'emp. nie über $36,5^{\circ}$. Meist $36,1^{\circ}$ bis $36,3^{\circ}$ Abends.

6. September. Fortwährend starke Kopfschmerzen in der Stirn. Linke Pupille deutlich weiter als die rechte. Temp. Abends $36,0^{\circ}$. Hochgradige Apathie. Stets gleiche Lage auf der rechten Seite.

7. September. Pupillendifferenz Morgens verschwunden, nach einigen Stunden wieder dentich nachweisbar. Augenhintergrund normal. Geringe Gesichtsfeldeinschränkung beiderseits. Puls wechselnd, 60-120 p. M. Schwindel bei jeder Koptbewegung.

Trepanation a d as Kleinhirn links. Sinus sigmoideus freigeleyt, derselbe ist mit plastischem Exsudat bedeckt. Kein Eiter zwischen Knochen und Sinus. Dura über dem Kleinhirn unverändert. Pia stark injicirt. Bei mehrmaligem Eingehen mit dem Scalpell und Dilataticn mit der Kornzange wird kein Eiter entleert.

Abends Sensorium frei. Starke Kopfschmerzen, kein Fieber, Puls gut, frequenter. Temp, $36,8^{\circ}$.

8. Septemper. Ziemliche Nachblutung aus der Wunde. Erneuerung der obersten Lagen des Verbandes. Patient giebt an, dass die Kopfschmerzen nachgelassen haben, dass es ihm aber ,dumm" im Kopfe sei. Temp. 37,2 bis $37,5^{\circ}$.

9. September. Kopfschmerzen geringer. Kein Schwindel mehr. Ausser Schmerzen in der Operationswunde keine Klagen mehr. Patient ist wieder hompungsvoll and spricht mehr.

10. September. Befinden im Allgemeinen gut. Appetit leidlich. Patient hat einmal zum Stubl das Bett verlassen, ohne Schwindel zu bekommen. Temp. Abends wieder über $37,0^{\circ}$.

11. September. Keine Kopfischmerzen mehr. Patient ist lebhafter und verändert seine Lage häutiger als früber.

12. September. Morgens wieder Klage über leichte Kopfschmerzen, die den Tag uber bestehen. Sie werden meist in die Stirn verlegt. Temperaturen wieder niedriger $36,3^{\circ}$ Abends. Bei der Abendvisite Puls häufig aussetzena, 100-110 p. M. Lässt Nachts einmal Urin unter sich gehen.

13. September. Morgens Puls wieder regelnässig. Klagt nur über geringen Kopfschmerz. Verbandwechsel. Beim Entfernen des in die Gehirm- 
substanz eingelegten Tampons quillt Eiter nach, etwa 2 Theelöffel. Einführung der Kornzange ohne weitere Entleerung. Bei Einführen eïes Drains nochmals Entleerung von blutig gefürbtem Eiter. Nach dem Verbandwechsel ist das Sensorium zunächst ungetrubt. Einige Zeit darauf reagirt Patient nicht mehr auf Anrufen, obwohl er die Augen offen hat. Um 3 Uhr Nachmittags wird der Arzt gerufen, da der Patient sebr unruhig sei und aus dem Bette springen wolle. Patient giebt auf Fragen richtige Antworten und benermt vorgehaltene Gegenstände richtig. Er erinnert sich, dass es kurz vorher geregnet bat. Klagt über stärkeren Kopfschmerz in der Scheitelgegend. Temp 36,19. Puls klein. Verfallenes Aussehen.

Um $3^{3 / 4}$ Uhr Nachmittags bemerkte die Wache Stocken der Athmung und meldet eingetretenen Tod, Leichenfarbe des Gesichtes. Keine Inspirationsbewegung, kein Cornealrefiex, doch deutlicher kleiner Puls zu fühlen. Künstiche Athmung, Aether- und Campherinjectionen. Reizung des Nervus phrenicus mit dem Inductionsstrom, Entfernung des Drains aus dem Gehirn. Es gelingt den Puls noch über $1 \frac{1}{2}$ Stunde, meist ganz kräftig zu erhalten, ohne eine einzige spontane Athenbewegung auszulosen. Um $5^{1 / 2}$ Uhr erlischt auch die Herzthătigkeit.

\section{Auszug aus dem Sectionsprotocoll.}

Diagnosis post mortem. Prolaps des Kleinhirns aus einer Trepanationsöffnung der hinteren Schädelgrube. Kleinhirnabscess. Hydrocephalus externus und internus. Hirnoedem. Anaemie des Gehirns. Chronische Leptomeningitis. Hypertrophie des Herzens. Himphysem des oberen Lungenlappens. Oedem der unteren Lappen. Staungsniere. Stauungsleber. Thrombose des linken Sinus sigmoideus.

Am linken Occiput und Warzenfortsatz eine ausgedehnte Wunde. Das mittlere Ohr und die linke hintere Schädelgrube eröffnet. Aus der letzteren Oeffinung dringt Kleinhirnmasse hervor, die eine Incisionswunde zeigt. Im Sinus longitudinalis nur in den hinteren Partien etwas flüssiges Mlat. Innenflache der Dura glatt, aber wenger glänzend als normal. Pia in den vorderen Partien mässig blutreich. Arachnoidea leicht getrubt. Windungen abgeflacht. Subarachnoideale Flüssigkeit vermehrt Das linke Kleinhirn ist mit der oberen Kante des Felsenbeins leicht verwachsen. Die vordere obere Fläche ziemlich stark injicirt. Bei Herausnahme des Gehirns entsteht auf der Oberfläche, nahe dem Wurm, etwa $1 \mathrm{~cm}$ vom vorderen Rande entfernt eive Oeffnung, aus der sich grängelber Eiter entleert. Die Seitenventrikel ziemlich stark erweitert. Darin klare seröse Flüssigkeit. Ependym überall glatt und glänzend. In der vorderen Hälfte des linken Kleinhirns findet sich ein etwa wallnussgrosser mit grüngelbem Eiter angeíüllter Abscess, dessen Wandungen glatt sind und von einer ziemlich derben Membran gebildet werden. Das Kleinhirngewebe in der Umgebung dieses Abscesses sowie der erwähnten Incisionswunde ist blutreich und zeigt zablreiche kleine Ekchymosen. Eine Verbindung des Abscesses mit der Incision ist nicht nachzuweisen. Graue und weisse Substanz des Gehirns zeigen geringen Blutgehalt und ziemlich derbe Consistenz. Dura der Basis ziemlich blutreich. Im linken Sinus sigmoidens findet sich ein alter derber Thrombus. In den übrigen Sinus nur fiüssiges Blut.

Section des linken Schläfeabeins. Nach Entfernung der reichlichen Granulationsmassen in der Paulkenhöhle sieht man den Nervus facialis in seinem ganzen Verlaufe durch die Paukenhöhle freiliegen, ebenso eine Strecke weit unterhalb des horizontalen Bogenganges. Der Wulst des hor:zontalen Bogenganges fehlt fast vollständig. Ein an seiner Stelle gelegener spaltförmiger Schlitz führt in das Vestibulum. Das Promontorium ist nicht mehr vorbanden. Es findet sich hier ein grosser Defect, der andeutungsweise die obere Grenze des ovalen und die untere des runden Fensters erkennen lässt. Das Dazwischenliegende fehlt, und gelangt die Sonde weit bis gegen die Schneckengegend, wo sich eine grössere Höhle sondiren lässt. Hier und im Vestibulum weiche blassrothe Granulationen. In der Gegend, wo die Schnecke liegen müsste, ausserdem viel Eiter. In den anfgemeisselten Bogengăngen sieht man ebenfalls blassrothe Granulationen. Die Aquaeducte an- 
scheinend frei. Porus acusticus internus ebenso. Im Tegmen antri ein linsengrosser Defect, durch eine blasse Membran verschlossen und mit reactionsloser Umgebung.

Epikrise. Der Tod des Patienten ist an einer reinen Complication des Kleinhirnabscesses, der Lähmung des Athem. centrums erfolgt. Der Kleinhirnabscess war richtig diagnosticirt, aber bei der Trepanation nicht gefunden worden. Schuld daran mag gewesen sein, dass der, durch die Vieldeutigkeit der hier vorliegenden Symptome gerechtfertigte Zweifel an der Sicherheit der Diagnose, diesmal besonders sehwer auf dem Operateur lastete und ihn hinderte, das Messer noch einige Millimeter tiefer einzufiuhren, wodurch er den Abscess sicher getroffen hätte. Die Unsicherheit war bedingt durch die Sohwierigkeit der Diagnose, da in diesem Falle die Symptome, die anf den Abscess hindeuteten, ebensogut vielleicht als Folgen der bereits nachgewiesenen Erkrankung hätten aufgefasst werden können. Die bei der Operation gefundene Labyrinthzerstörung konnte den vorhandenen starken Schwindel und das Erbrechen wohl erklären. Die Symptome, die uns auf den Hirnabseess leiteten, waren vor Allem die Kopfsehmerzen, dann die oft subnormalen Temperaturen, die zunehmende Apathie, die zeitweise rorhandene $\mathrm{Pu}$ pillendifferenz. Doch konnte man auch einen Extraduralabscess als Ursache dieser Erseheinungen annehmen. Als vor der Trepanation die hintere Schädelgrube eröffnet, um den Sinus herum und, nach Abhebung der angrenzenden Dura vom Knochen, auch hier kein Eiter gefunden wurde, selbst dann war noch nicht ausgeschlossen, dass nicht doch noch tiefer gegen die Spitze des Felsenbeines zu eine derartige Eiteransammlnng bestände. Diese Erwägung hielt auch den Operateur, nachdem das Messer seiner Ansicht nach in genugende Tiefe eingedrungen war, davon $a b$, dasselbe noch weiter vorzuschieben, in der Befürchtung, dass dadurch vielleicht der vermuthete Extraduralabseess getroffen werden und so eine Infection der Hirnhäute veranlassen könnte.

Die Section belehrte uns, dass die Incision in der ursprünglichen Richtung noch viel weiter hätte gehen können, ehe sie die gegenüberliegende Dura verletzt häite.

Ferner deckte die Section noch einen alten Thrombus im Sinus sigmoidens auf, der den Vermittlungsweg des Abscesses dargestellt haben kann, wenigstens konnte eine directe Weg-leitung der Erkrankung von dem zerstörten Labyrinth aus nicht festgestellt werden. Bemerkenswerth ist es, dass für das Be- 
stehen der Sinusthrombose weder in der Anamnese, noch in der ganzen Beobachtung des Falles sich je Anhaltspunkte fanden.

7. Gustar Martin, 19 jähr. Dienstknecht ans Wiedemar. Aufgenommen den 21. September 1898. Gestorben den 5. October 1898.

Anamnese: Pat. litt seit frühster Kindheit an Ohrenlaufen beiderseits. Seit 5 Jahren ist das rechte Ohr ständig trocken. Links bestand immer Eiterung ohne Beschwerden weiter.

In der vergangenen Woche erkrankte der Patient angeblich an Influenza. Zugleich traten Schwindel und Ohrenschmerzen links auf. Mehrmals traten Frôste auf. Appetitlosigkeit, vorübergehende Leibschmerzen, Die Eiterung links soll seit 8 Tagen aufgehört haben.

Status praesens: Mässig krättig gebauter, leidlich genährter junger Mann. Herpes der Mundwinkel. Blasse Gesichtsfarbe. Taumelt etwas beim Gehen mit geschlossenen Augen. Augäpfel stark hervortretend. Augenhintergrund normal. Pupillen normal. Innere Organe ohne Befund. Starke Druckempfindlichkeit im rechten Epigasirium. Urin frei von Eiweiss und Zucker. Temperatur abends $37,2^{\circ}$. Puls 96 , regelmässig.

Umgebung des Ohres: Ohne Besonderes.

Gebörgang und Trommelfellbefund: Rechts grosse Narbe in der hinteren Hälfte des Trommelfells. Links: Mattes Trommelfell. Ueber dem Processus brevis eine verdächtige Stelle, aus der aber kein Eiter kommt. und die anch für die Sonde durchgängig ist.

Hörprüfung: Flüstersprache rechts $15 \mathrm{~cm}$. Links laute Worte. $\mathrm{C}_{1}$ vom Scheitel nach rechts. Rinne beiderseits negativ. Fis rechts bei stärkstem Fingeranschlag, links bei Ieichtem Nagelanschlag.

Ergebniss bei Catheterismus tubae: Links Rasseln.

Paracentese entleert keinen Eiter. Danach kurze Zeit Ohrschmerzen.

22. Septernber. T'emp. $36,6^{\circ}-38,3^{\circ}$.

23. September. Temp. morgens $37,4^{\circ}$. Abends leichtes Frösteln. Ansteigen der Temperatur auf $38,90^{\circ}$. Nachts Steigerung auf $39,6^{\circ}$.

24. September. Morgens ausgesprochener Schüttelfrost. Temp. 39,6, $40,0^{\circ}$. Pat. klagt nur über Leibschmerzen. Stuhlgang war stets in Ordnung. Am Abdomen nichts Besonderes.

Operation: Weichtheile und Oberfläche der Corticalis absolut normal. Das Antrum wird typisch eröffnet. Der Knochen von Eifenbeinhärte, das Antrum abnorm tief und klein. Bei der Eröffnung desselben erscheint ein Tropfen Eiter. In der Spitze ist nur geschwollene Schleimhaut als Befund zu erwähnen. Beim Glätten der Knochenwunde stürzen plötzlich pulsirend von hinten etwa 2. Theeloffel Liter hervor. Es zeigt sich, dass die abnorm tief unter der Knochenoberfläche liegende Fossa sigmoidea eröfinet war. Beim Freilegen des extrasinuösen Eiterherdes, der abnorm tief lag und bei dem compacten ihn umgebenden Knochen sich sehr schwer aufdecken liess, wird in der grunlich verfärbten Sinuswand eine Fistelöffnung entdeckt, aus der Jauche hervorquillt. Nun wird zuerst die Vena jugularis aufgesucht und doppelt unterbunden, oberhalb und unterhalb der Einmündungsstelle der Vena facialis communis, die ebenso dick erscheint als die Jugularis. Letztere war nicht collabirt. Halswande mit Jodoformgaze tamponirt und offen gelassen. Nun wird der Sinus und die erkrankte Dura um thn herum breit freigelegt, der Sinus sigmoideus, das Knie und der Sinus transversns nach dem Torcular zu durch einen ca. $5 \mathrm{~cm}$ langen Schnitt von der Fistel aus breit aufgeschlitzt. Der darin befindliche zerfallene Thrombus mit dem seharfen Löffel entfernt und die brandig aussehende äussere Sinuswand excidirt. Stärkere Blatung tritt nicht ein. Nach oben und unten werden Jodo. formgazestreifen in den Sinus eingefübrt. Nähte in die Wundwinkel. Verband.

Nach der Operation Abfall des Fiebers.

25. September. Morgens fühlt sich der Patient wobl., Temp. $37,5^{\circ}$. Abends wieder Fieber bis $40,8^{\circ}$, ohne Frost.

26. September. Stechen links unten beim Athemholen. Athemfrequenz nicht erhöht. Temp. $37,1^{0}-40,7^{\circ}$. 
27. September. Stechen links oben und unten beim Athemholen. Leise Reibegeräusche über dem linken Thorax ungefähr in der Mamillarlinie. Temp. $37,3^{\circ}-40,0^{\circ}$.

28. September. Verbandwechsel. Jugulariswunde frei. Einige secundäre Nähte. Sinus nach unten leer. Auch bei Druck auf die Jugularisgegend entleert sich nichts. Von oben kommt etwas Eiter. Temp. $37,6^{\circ}$ bis $39,7^{\circ}$.

29. September. Temp. $38,1^{0}-40,5^{\circ}$.

30. September. Verbandwechsel. Aus den Sinusöffinungen kommt kein Eiter mehr. Keine Athembeschwerden mehr. Wirft etwas schleimiges Sputum aus. Temp. $38,9^{\circ}-41,0^{\circ}$.

1. October. Anschwellung an der rechten Halsseite hinter dem Processus mastoideus. Temp. $38,8^{\circ}-40,5^{\circ}$.

2. October. $38,5^{\circ}-40,5^{\circ}$.

3. October. Die Anschwellung an der rechten Halsseite ist stărker geworden, jetzt faustgross. In cision in Narkose. Oedem der Weichtheile über dem rechten Occiput. Muskelansätze infiltrirt. Speckige Infiltration des Periostes. Starke Blutung aus der angeschnittenen Vena jugularis externa.

Nach der Operation Collaps. Abends schlechter Puls. Aetherinjection. Injection von $1 / 21$ steriler Kochsalzlösung subcutan. Danach wird der Puls besser. Temp. $39,4^{\circ}-39,8^{\circ}$.

4. October. Morgens "Puls 120 p. M., ziemlich kräftig. Athem stertorös. Schaum auf den Lippen. Athem Tags über immer schlechter und frequenter. Puls bis Mittags noch kräftig, dann kleiner und frequenter. Temp. $38,8^{\circ}-39,3^{\circ}$.

5. October. Morgens $4 \mathrm{Uhr}$ Exitus letalis.

Auszug aus dem Sectionsprotokoll.

Diagnosis post mortem: Unterbindung der Jugularis interna linkerseits. Thrombophlebitis der Hirnsinus links. Vereiterung des Atlanto-Occipitalgelenkes. Pachymeningitis purulenta circumscripta. Leptomeningitis chronica. Hydrocephalus externus. Hirnoedem. Pleuritis exsudativa recens. Multiple metastatische Abscesse in beiden Lungen. Milztumor. Trübe Schwellung der Nieren.

Die Dura der Basis ist längs des Sinus transversus sowie des unteren Theiles des Clivus missfarbig, graugrün verfärbt, trübe. Im Cebrigen glatt und glänzend. Beim Eröffnen des Sinus finden sich im linken Sinus transversus, im unteren Sinus sigmoideus, dem Sinus petrosus inferior, sowie dem Confluens sinuum and im Anfangstheil des Sinus rectus eitrig zerfallene graurothe Thrombusmassen. Beim Lösen der Dura vom Clivus zeigt sich das Atlanto-Occipitalgelenk eitrig infiltrirt; von hier aus setzt sich die Eiterung in den Abscess an der rechten Halsseite fort. Der rechte Sinus transversus sowie der linke Sinus petrosus superior nnd die Sinus cavernosi sind frei. In der linken Pleurahöhle eine reichliche Menge blutig verfärbter, mit Fibrin̄flocken vermischter Flüssigkeit. In der rechten Pleuraböhle derselbe Inhalt. Oberlappen der linken Lunge mit punktförmigen subpleuralen Ekchymosen bedeckt. Unterlappen reichlich bedeckt mit derben grüngelben fibrösen Auflagerungen. Aus dem Bronchus quillt reichliche schaumige Flüssigkeit. Bronchialmucosa blassroth. Parenchym des Oberlappens graugelbroth, Luftgehalt herabgesetzt. Am vorderen Rande eine haselnussgrosse, mit grüngelbem Eiter gefüllte und von unregelmässigen fetzigen Wandungen ausgekleidete Abscesshöhle. Das nmgebende Lungengewebe ist grauroth, luftleer und derb infiltrirt. Am Unterlappen an mehreren Stellen kleinere und grössere mit Eiter gefüllte Cavernen.

Die Pleura des Oberlappens der rechten Lunge ebenfalls mit fibrinösen Auflagerungen bedeckt und von kleinen Blutungen durchsetzt. Ober- und Unterlappen zeigen an vielen Stellen rothgraue böckrige, kleine Prominenzen, denen auf den Durchschnitten kegelförmige Herde, im Innern grösstentheils eitrig zerfallen, entsprechen.

Section des linken Schläenbelnes: Trommelfell mattgrau. Im hinteren unteren Quadranten eine kleine runde Perforation (Paracentesenstelle). 
Hoch über dem Processus brevis ein kleiner Defect der Atticuswand am Rande des Ansatzes der Membrana Shrapnelli. Hammerkopf stark arrodirt; am Amboss der Körper und der lange Fortsatz cariös. In der Paukenböhle Eiter. Die Knöchelchen in succulente oedematöse Granulationen eingebettet. Vom Stapes ist nur die Platte vorhanden. Labyrinth und dessen nach der Schädelböhle führende Canäle normal. Bulbus venae jugularis frei von Thrombusmassen. Venenwand daselbst makroskopisch intact.

Epikrise. In diesem Falle war die Diagnose der Pyämie besonders dadurch erschwert, dass uns betreffs der otogenen $\mathrm{Na}$ tur der Erkrankung, abgesehen von den Angaben des Patienten, wenig Anhaltspunkte gegeben waren. Die otoskopische Untersuchnng lies uns diesmal über die Art und Ausdehnung der krankhaften Processe im Mittelohr im Unklaren. Aus dem Trommelfellbefunde - die Perforation in der Membrana Shrapnelli war zwar vermuthet, abex nicht dentlich nachzuweisen konnte eine ehronisehe Eiterung nicht diagnosticirt werden. Dazu kam, dass auch weitere, von der Complication der chronischen Otitis ausgehende Symptome in den ersten Tagen der Beobachtung ausblieben. Es muss hierzu bemerkt werden, dass wir, durch die Anamnese auf das eventuelle Bestehen einer otogenen Pyämie hingewiesen, nichts verabsäumt hatten, um uns Aufklärung zu verschaffen, insbesondere sind, wie es in unserer Klinik bei allen auf Complicationen verdächtigen Kranken geschieht, während der ganzen Beobachtungszeit regelmässige Temperaturmessungen alle 2 Stunden, auch Nachts, vorgenommen worden, ohne dass uns die beiden ersten Tage eine Entscheidung brachten. Das nachzuweisende geringe Fieber war zwar verdächtig, indessen hatte der Patient angeblich erst kürzlich InAuenza durchgemacht. Seine subjectiven Beschwerden beschränkten sich fast auf Leibschmerzen; es musste nahe liegen, an eine, wenn auch noch nicht objectiv nachweisbare abdominale Complication der Influenza zu denken und darauf die gesteigerte Temperatur zu beziehen. Erst am dritten Tage nach der Aufnahme zeigte sich Abends unter leichtem Frösteln ein stärkeres Ansteigen der Temperatur. Als am darauf folgenden Morgen nun ein ausgesprochener Schüttelfrost und Fieber bis 40,00 sich einstellte, ohne dass inzwischen eine abdominale Frkrankung manifest geworden war, entschlossen wir uns zur Aufmeisslung. Den Angaben des nicht sehr intelligenten Patienten ïber die Daner seines Ohrleidens nicht vertranend, nahmen wir des zweifelhaften Trommelfellbefundes halber an, dass vielleicht eine acute Infuenzaeiterung nach dem Sinus za fortgeschritten sei. Wir machten zunächst die typische Aufmeisslung, ohne hierbei 
einen Anhaltspunkt zur weiteren Diagnose oder eine Wegleitung nach dem Sinus zu finden. Erst bei weiterem Eingehen nach dem Sinus zu wurde ein perisinuöser Abscess gefunden und die Thrombose aufgedeckt. Bei dem Vergleich der geringfügigen pathologischen Veränderungen im Warzenfortsatz und der ausgedehnten Sinuserkrankung erscheint nun, nachdem die Section erwiesen, dass thatsächlich eine chronische Eiterung mit Caries der Gehörknöchelchen vorlag, der Verlanf doch so gewesen zu sein, dass eine secundäre acute Infection der chronisch entzlindeten Paukenhöhle, vielleicht im Anschluss an Influenza die geschilderte Erkrankung veranlasste, wobei trotzdem der Mangel jeder Wegleitung auffallend ist. Leider ist diesmal eine bakteriologische Untersuchung des Abscesseiters nicht vorgenommen worden; es wäre interessant gewesen, wenn wir auch in diesem Falle, der sich an eine chronische Eiterung anschloss, und der mit den uns nun zur Genuge bekannten aeuten Pneumokokkenerkrankungen in seinem Verlanfe so viel Aehnlichkeit darbot, Gelegenheit gehabt hätten, den Eitererreger kennen zu lernen.

Weshalb wir die Operation einige Tage aufschoben, erseheint hinlänglich begründet, nichtsdestoweniger ist indess die Verzögerung vielleicht für den Kranken verhängnissvoll geworden. Das septische Material hatte sich bis dahin in derartigem Umfange, besonders in den Lungen verbreitet, dass es nicht mehr gelang, durch die Operation das Leben zu retten. Dass auch nach der Operation noch septisehe Stoffe in die Blutbahn gelangt sind, ist ebenfalls ziemlich sieher, da die Thrombose gegen das Torcular zu nicht abgeschlossen war. Von Interesse ist in diesem Falle auch die Vereiterung des Atlanto-Oecipitalgelenks und der von diesem Gelenk ausgehende Senkungsabscess an der dem kranken Ohr entgegengesetzten Halsseite, welehen wir in vita für einen metastatischen gehalten hatten.

8. Anna $K u h$ fahl, $25 \mathrm{jähr}$. Lademeisterstochter aus Halle. Aufgenommen am 28. September 1898. Gestorben den 3.October 1898.

Anamnese: Die Patientin wurde am 28. September. Abends auf Veranlassung ihres Arztes der Klinik zugewiesen. Der letztere berichtete, dass er die Patientin seit 21/2 Wochen wegen Kopfschmerzen und unbestimmten anderen Klagen (Obstipation) in Behandlung gebabt habe, obne dass er zu einer Diagnose gekommen sei. Da eine Ohreiterung vorhanden sei, vermathete er ein vom Ohr ausgehendes Leiden. Seit den letzten Tagen sei zeitweise Bewusstlosigkeit und träger Puls eingetreten.

Die Schwester der Patientin giebt an, dass die letztere seit Kindheit an Obreiterung rechterseits leide. Seit $2^{1 / 2}$ Wochen bestehe Kopfschmerzen und Schmerzen in den Schultern. Manchmal auch Schmerzen hinter dem Ohre. Stets Stublverstopfung. Seit dem 10. September bettlägerig. Oefters Frösteln, 
schlechter Schlaf. Seit 3-4 Tagen schlafähnlicher Zustanả. Undeutliche Sprache. Kein Erbrechen.

Status praesens: Gut genährtes Mädchen. Reagirt auf Anrufen schwach. Antworten karz, meist richtig, doch tritt rasch wieder Somnolenz ein. Starke Hyperästhesie. Aufschreien bei starker Berührung irgend eines Körpertheiles. Besonders druckempfindliche Stellen sind nicht nachzuweisen. Leib etwas voll, Gelenke frei. Keine Paresen. Pupillen meist eng, reagiren träge. Augenhintergrund nicht zu untersuchen (Photophobie). Foetor ex ore. Zunge wenig belegt. Lebhafte Bewegung der Finger auf der Bettdecke. Urin frei von Eiweiss and Zucker. Temp. 37,7 . Puls 72, regelmässig.

Umgebung des Ohres: Ohne Besonderes.

Gehörgang-und Trommelfellbefund: Links: Narben. Rechts: Eiter im Gehörgang. In der Tiefe Krusten. Nach deren Entfernung sieht man vollständigen Defect der Membran. Die Paukenhöhle mit macerirter Epidermis ausgekleidet. Von hinten oben kommen einige hellrothe Granulationen.

Auf Essigklystier erfolgt reichlicher Stuhl. Pat. trinkt etwas Milch. In der Nacht zeitweise Delirien, aus denen die Patientin durch Anrufen leicht zu erwecken ist. Keine Klagen.

29. September. Im Algemeinen derselbe Zustand. Pat. ist schwer dazu zu bringen, eine Antwort za geben; jede Ueberlegung scheint ibr Ueberwindung zu kosten. Wenn man sie aber mit Fragen nicht in Ruhe lässt, antwortet sie meist richtig. Kann sie mit ja oder nein antworten, so sind ihre Angaben stets richtig. Ueber Zahlen nachzudenken scheint ihr besonders schwer za fallen. Sie giebt ihr Alter faisch an. Weiss nicht, wo sie wohnt. Benennt vorgehaltene Gegenstände erst nach einigem Drängen und nach ziemlicher Zeit der Ueberlegung richtig. Auch die Nahrungsaufnahme wird durch offenbar zwischen dem Schlucken eintretende Somnolenz gestört. Beim Aufrüteln und Anrufen trinkt sie weiter. Nachmittags klagt sie einige Zeit über Schmerzen in der Scheitelgegend, manchmal auch über Schmerzen im Leib. Temp. $36,9^{\circ}-36,3^{\circ}-36,5^{\circ}$. Puls gut, 80 p. M. Urin zeitweise spontan, zeitweise in's Bett. Heute ist es möglich, den Augenhintergruad zu antersuchen. Es findet sich beiderseits Neuritis optica (Dr. Schlodtmann 1. Assistent d. Kgl. Augenklinik bestatigt den Befund). Das obere Lid des linken Auges hängt zeitweise tiefer wie das rechte herab, kann aber vollständig gehoben werden.

30. September. Sensorium heute freier. Zeitweise Klagen über Kopfschmerzen. Hallucinationen, Pupillen hente ziemlich weit. Reaction träge. Lippen rissig. Zunge belegt. Nahrungsaufnahme gut. Blase stark gefült, muss mit dem Katheter entleert werden. Abends Zunahme der Somnolenz. Temp. $36,5^{\circ}-37,0^{\circ}$

1. October. Morgens Ptosis links deutlich. Somnolenz wechselnd in hohem Grade. Puls 8\%. Linke Pupille weiter als die rechte. Um $10 \mathrm{Uhr}$ Operation. Totalanfmeisselung rechts. Im Antrum etwas granuläre Schleimhaut, sonst nichts Pathologisches, ebenso im Atticus. Insbesondere ist das Tegmen tympani glatt und unverdächtig. "Darauf Trepanation auf den rechten Schläfenlappen. Mittelst der Kreissäge wird ein viereckiges Knochenstück aus der Squama ossis temporis geschnitten. Beim Einschneiden der Dura entleert sich kein Liquor. Bei mehrfachen Einstichen in das Gehirn mit dem Scalpell und stumpfer Dilatation mit der Kornzange wird kein Eiter gefunden. Die grosse Wunde wird durch einige Năhte verkleinert. Tamponade mit Jodoformgaze. - Während der Operation, schon vor der Eröffnung des Schadels, wird die linke Pupille maximal weit, die rechte bleibt eng. Der Puls geht während der Operation auf 68 herunter, steigt aber nach Beendigung der Narkose rasch wieder an.

Nach der Operation besteht links vollständige Ptosis. Abends Temperatur $37,5^{\circ}$. Puls $100 \mathrm{p}$. M.

2 October. Die Somnolenz hat zugenommen. Linke Pupille maximal weit, rechte Pupille mittelweit. Ptosis links fortdauernd. Temp. $36,6^{\circ}-36,6^{\circ}$.

3. October. Status idem. Manchmal Spasmen im linken Arm. Gegen Abend Trachealrasseln. Exitus letalis 11 Uhr Abends. 
Auszug aus dem Sectionsprotocoll.

Diagnosis post mortem. Eröfnung des Warzenfortsatzes und der mittleren Schädelgrube. Prolaps des rechten Temporallappens. Pachymeningitis und Leptomeningitis chronica fibrosa. Hyperämie der Pia und der Rinde. Hyperostose des Schädeldaches. Exostose der rechten Felsenbeinpyramide. Ependymitis granulosa. Subpleurale Hämorrhagien links. Frische miliare Tuberkeleruption in den Lungen. Bronchopneumonische Herde im linken, Hyperämie des rechten Unterlappens. Hyperämie der Nieren. Cervixkatarrh. Beiderseits Pyosalpinx.

Schädeldach verdickt. Breite $0,7 \mathrm{~mm}$. Dura wenig blutreich, durchscheinend, in den vorderen Partien getrïbt. Innenfläche der Dura glatt, ziemlich stark getrübt. Pia trocken. Gefässe prall gefüllt. Arachnoidea an einigen Stellen im Verlauf der Gefässe leicht milchig getrübt. Bei Herausnahme des Gehirns entleert sich etwas seröse Flüssigkeit. In der Gegend des Chiasma, der Pons und der vorderen Theile des Kleinhirns finden sich ziemlich reichliche zarte fibröse Verdickungen der Pia. In den Ventrikeln eine normale Menge seröser Flüssigkeit. Im Plexus chorioideus links finden sich einige erbsengrosse cystische Erweiterangen. Das Ependym der Seitenventrikel zeigt eine sehr fein granulirte Oberfläche. Hirnrinde und Basalganglien blutreich. Weisse Substanz von normalem Blutgehalt. Consistenz des Gehirnes etwas herabgesetzt. Die Spitze des rechten Temporallappens ist in eine graurothe Erweichungsmasse verwandelt, die sich durch eine zweimarkstückgrosse Trepanationsöftinung des Schläfenbeins nach aussen drängt. Dura der Basis ebenfalls verdickt, mit dem Knochen fest verwachsen. An der Felsenbeinpyramide findet sich nahe dem Clivus eine halbkugelige glatte Exostose. In den Sinus flüssiges Blut.

Linke Lunge ziemlich gross, vordere Partien gebläbt. Die Vorderfläche des Oberlappens zeigt ziemlich reicbliche flächenförmige subpleurale Hämorrhagien. Der Bronchus entleert auf Druck trübe schaumige Flüssigkeit. Mucosa blauroth injicirt. Parenchym des Oberlappens von graurother Farbe, gutem Luftgehalt. Auf der Schnittfäche zeigt sich eine Anzabl grauweisser miliarer Knötchen. Der Unterlappen von dunkelblaurother Farbe, starkem Blut- und Saftgehalt, Luftgehalt herabgesetzt. Ueber dem Parenchyra zerstreut finden sich ziemlich ausgedehnte luftleere infiltrirte Herde, ferner zablreiche Knötchen wie im Oberlappen. Ober- und Mittellappen der rechten Lunge gebläht. Unterlappen grauviolett, Pleura glatt. Bronchialschleimhaut blass, mit schleimigem Secret bedeckt. Der Oberlappen zeigt auf dem Durchschnitt dasselbe Ausseben wie links. Unterlappen blutreich und gut lufthaltig. An der rechten Tube findet sich der etwa $5 \mathrm{~cm}$ lavge Endabschnitt erweitert und mit grüngelben, rahmigen Eitermassen erfült. Links zeigt die Tube mehrfache Krümmungen, die durch bandartige Verdickungen der Aussenwand bedingt sind. Im Innern findet sich ebenfalls eingedickte rahmigkăsige grüngelbe Eitermasse. Schleimhaut verdickt, von grüngelber Farbe, mit eitrigen Massen infiltrirt.

Epikrise. Die Beurtheilung des vorliegenden Falles ist durch das Zusammentreffen dreier Umstände eine ganz besonders schwierige, einer unvollständigen Anamnese, erschwerter Beobachtung, und eines Sectionsbefundes, der weder die Todesursache zweifellos feststellte, noch eine hinreichende Erklärung für die klinischen Symptome gab. Wir sind daher auch jetzt nur in der Lage, Vermuthungen über die Art der Krankheit anzustellen. Vor allem scheint es wichtig, die Grunde darzulegen, die uns zur Operation des Ohres und zur Trepanation veranlassten: Die Kranke wurde uns in somnolentem Zustande tiberwiesen. Die vorher behandelnden Aerzte waren über die Natur ihres Leidens. 
nicht in's Klare gekommen. Soviel stand fest, dass ein schweres Leiden vorlag, dessen cerebralen Sitz man vermuthen musste. Die Patientin litt an einer chronisehen Ohreiterung, und so war den Aerzten der Gedanke an eine otogene cerebrale Complication gekommen und sie ordneten daher die Ueberführung der Patientin in die Ohrenklinik an. Die otoskopische Untersuchung bestätigte hier das Bestehen einer chronischen Eiterung des rechten Ohres. Für die weiteren Consequenzen konnte durch Untersuchung des Ohres nichts eruirt werden. Die Anamnese und die Berichte der Aerzte ergaben wenig Anhaltspunkte. Die weitere Untersuchung wurde nun durch die bestehende hochgradige Somnolenz änsserst erschwert. Die Prüfung der Function des Ohres z. B., der rohen Kraft, der Orientirungsfähigkeit, die Untersuchung des Augenhintergrundes waren zunächst unmöglich. Es war vorderhand nur festzustellen, dass ein geistiger Hemmungszustand vorhanden war, der die Somnolenz herbeifuhrte und die psyschischen Functionen der Patientin, auch wenn man letztere erweckte, nie zur vollkommenen Bethätigung kommen lies. Wie vorsichtig man unter diesen Umständen in der Dentung ron Symptomen sein musste, erhellt daraus, dass wir zuerst geneigt waren, eine hochgradige amnestische Aphasie bei der Patientin anzunehmen, die verschiedene Gegenstände anscheinend nicht benennen konnte. Dieselben Gegenstände benannte sie indessen, wenn man sie mit Fragen nicht in Ruhe liess und so den Hemmungszustand paralysirte. Die Mühe des Nachdenkens war ihr am Gesichte abzulesen, das bei jeder Frage deutlichen Unwillen verrieth. Immerhin fehlten einige Erinnerungsbilder, die es nicht gelang wieder aufzuwecken. Ebenso waren auch geringe Motilitätsstörungen bemerkbar, die einem Wechsel unterworfen waren, je nach dem Grade in dem es gelang den somnolenten Zustand der Patientin aufzuheben. Neben dieser Somnolenz und mangelhafter geistigen Reaction bestand aber andererseits ein unbewusster psychischer Erregungszustand, der sich in Delirien, Hallucinationen und lebhaften Bewegungen besonders der Arme äusserte, und eine Erhöhung der Sensibilität für materielle Reize. Dazu gesellte sich Obstipation und Blasenlähmung.

Wir mussten nach diesen ersten Befunden in gleicher Weise wie die vorher behandelnden Aerzte ein Leiden cerebraler Natur annehmen. Der Gedanke an Meningitis wurde erwogen. Dafür sprachen die Kopfschmerzen der Anamnese, dagegen das Fehlen des Fiebers. Die folgenden Tage machten die Diagnose der 
Meningitis unwallrscheinlicher, es bestand nie Fieber, im Gegentheil subnormale Temperaturen, und die krankhaften Erscheinungen nahmen eigentlich nicht zu, sondern liessen vielmehr zeitweilige Remissionen erkennen. Der Gedanke an eine Psychose tauchte jetzt auf. Zugleich stieg aber anch die Wahrsoheinlichkeit eines Hirnabscesses, durch zeitweise Klagen über Kopfschmerzen gestärkt. Die Diagnose einer Psychose, die bei dem somnolenten Zustande der Patientin nur auf Vermuthungen basiren konnte, wurde fallen gelassen, als wir in einem besseren Momente den Angenhintergrund der Patientin untersuchen konnten und in der beiderseitig constatirten Neuritis optica ein sicheres Zeichen von anatomisch nachweisbaren Veränderungen im Gehirn zu haben glaubten. Nach dem Stande der Beobachtung mussten wir nun einen Hirnabscess oder Tumor für das Wahrscheinlichste halten, und da eine alte Ohreiterung bestand, durften wir einen otogenen Hirnabscess für möglicherweise vorhanden annehmen. Als sich schliesslich noch die anfänglich fehlenden Herderscheinungen einzustellen schienen. (sicherer Nachweis der Oculomotoriusparese), so war ein Versucb des Anfsuchens des Herdes wohl berechtigt, besonders in der Erwägung, dass die Prognose beim Bestehen eines Abscesses noch am günstigsten, bei Vorhandensein anderer pathologischer Substrate (Tuberkel, Tumor, Syphilom) sehr ungünstig war. Die otogene Natur des Leidens wurde unwahrseheinlicher, als wir bei Freilegung der Mittelohräume nirgends eine cariöse Stelle an den vorliegenden Knochenwänden entdecken konnten. Auch die Trepanation verlief resultatlos. Es fand sich weder Eiter noch ein seröser Erguss.

Der Erfolg der Operation war dementsprechend anch negativ. Das Krankheitsbild änderte sich insofern, als bereits während der Operation (schon vor der Eröffnung des Schädels) maximale Erweiterung der linken Pupille auftrat, später auch vereinzelte Spasmen im linken Arm. Ferner nahm die Somnolenz $z n_{\text {, die }}$ Hallucinationen traten mehr in den Hintergrund, und es stellten sich Zeichen von Lungenerkrankung ein. Der Tod erfolgte am 2. Tage post operationem.

Unsere bis dahin noch immer festgehaltene Annahme, dass ein localer Krankheitsherd im Gehirn vorhanden sei, wurde durch die Section nicht bestätigt. Die geringen anormalen Befunde im Schädel, eine kleine Exostose am Tuberoulum jugulare und chronisch entzündliche Veränderungen der Gehirnhäute erklärten keineswegs die beobachteten schweren Gehirnerschei- 
nungen. Auch für die Oculomotoriuslähmung fand sich keine makroskopisch nachweisbare Ursache. Die durch die Operation gesetzte Hirnverletzung hatte den Bereich des Temporallappens nicht ubersehritten und war aseptisch verlaufen, so dass wir die Läsion des Oculomotorius nicht auf Rechnung der Trepanation setzen dürfen; ausserdem batte sie ja schon vor der Operation begonnen. Wir miissen demnach die Erscheinungen cerebraler Natur des Falles für unaufgeklärt halten. Vielleicht sind ihre Ursachen Veränderungen der Gehirnsubstanz, deren Erkennung nur mikroskcpiseh gelingt, oder solcher Art, dass sie mit den jetzigen Untersuchungsmethoden überhaupt nicht erkannt werden können. Letzteres ist ja oft bei den sogenannten Psychosen der Fall, und so müssen wir auch in unserem Falle mangels jeder anderen Erklärung für das Wahrseheinlichste balten, dass eine Psychose den von uns beobachteten Symptomen zu Grunde lag.

Der weitere Befund bei der Section war eine Bronehopneumonie und frische Tuberkeleruption in den Lungen. Die Lungenaffection ist höchst wahrscheinlich durch Aspiration im somnolenten Zustand der Patientin veranlasst worden. Für die Tuberkelbildung reicht diese Erklärung allerdings nicht ans. Doch ist eine Begtinstigung der Tuberkeleruption durch den bronchitischen Process wohl anzunehmen. Sonst ist keine Tubereulose im Körper gefunden worden; dass die Salpingitis tuberculöser Natur war, ist nicht festgestellt.

Der Befund in den Lungen war der am meisten hervortretende und muss als Todesursache angenommen werden. Immerhin waren die Lungenveränderungen nicht so hochgradig, wie man sie sonst bei letalen Ausgängen sieht. Wir müssen daher wohl eine allgemeine Herabsetzung der Lebensenergie der Patientin annehmen, wenn wir die Lungenerkrankung als Causa mortis behaupten wollen. Man könnte als Todesursache auch Operationscbok in Erwägung zieben, doch spricht dagegen, dass nach der Operation keine auffallenden Erscheinungen dazu gekommen sind und der letale Ausgang ist hierfür eigentlich anch zu spät erfolgt.

Die Gründe, die uns zum Eingreifen veranlassten, sind oben. angeführt. Wenn wir nach Betrachtung des Sectionsbefundes uns die Punkte unserer Diagnosenstellung und den negativen Befund nebeneinander halten, können wir uns trotzdem von dem Vorwurf unüberlegten Handelns freisprechen. Das etwaige Vorhandensein einer Psychose war von uns allerdings nicht in ge- 
nügender Weise in Rechnung gezogen worden. Bei der Schwierigkeit der Untersuchung war das aber entschuldbar, zumal sich die Zeichen für einen localen Herd mehrten. Müssen wir auch zugeben, dass Lähmung eines einzelnen Gehirnnerven und Neuritis optica auch einmal ohne greifbaren Befund im Gehirn vorkommen könne, so war das Zusammentreffen dieser Symptome mit den cerebralen Erscheinungen und den Kopfschmerzen, unter Berücksichtigung des acuten Verlaufes der Krankheit doch so auffallend, dass der Gedanke an eine Psychose in den Hintergrund treten musste. Zudem litt die Patientin an einer alten chronischen Ohreiterung und wir sind über die Bäufigkeit otogener Hirnabscesse jetzt zur Genïge unterrichtet.

Geschadet haben wir der Patientin durch die Operation wohl kaum. Der Eingriff am Ohr kann jedenfalls als irrelevant betrachtet werden. Operationschok ist unwahrseheinlich. Der Eingriff könnte also höchstens beschleunigend auf den letalen Ausgang hingewirkt haben, und selbst dafür fehlen uns Anhaltspunkte. Die Trepanation verlief aseptiseh. Die Oculomotorinslähmung muss, wie oben sehon erwähnt, als von der Operation unabhängig betrachtet werden. Die Narkose kann bei dem somnolenten Zustand der Patientin fur das Entstehen oder Fortschreiten der Pncumonie nicht verantwortlich gemacht werden. Der Einfluss der Operation kann höchstens darin bestanden haben, dass letztere die Kräfte der ohnehin schon geschwächten Patientin noch mehr herabsetzte. Die Unterlassung bätte aber den letalen Ausgang wohl nicht rerhüten können.

9. Rob. Deutschman n, 47 Jahre alt, fürstl. Stolberg'scher Haushofmeister zu Rossla a. H. Aufgenommen am 10. October 1898, gestorben am 13. October 1898.

An am nese: Vor 14 Tagen mit "Influenzasymptomen" (Busten, Mattigkeit, Appetitlosigkeit) erkrankt. Seit 8 Tagen starke Schmerzen des linken Ohres, zeitweise eitriger Ausfluss aus diesem Ohre. Seit 6. October starke Kopfschmerzen und mehrmaliges Erbrechen. Die Temperatur ist nach Aussage des behandelnden Arztes, Herrn Dr. Stark-Rossla, meistentheils erhöht gewesen.

Status praesens: Sensorium rollkommen frei. Durch die $21 / 2$ stündige Eisenbahnfahrt stark angegriffen, Klage über linksseitige Ohrenschmerzen und Schmerzen in der linken Kopfhälfte. Appetitlosigkeit. Mattigkeit. Zunge stark belegt, Foetor ex ore. Kein Schwindel objectiv nachweisbar. Pupillen gleich weit, reagiren gut, Temperatur $37,9^{\circ}$, Puls 100 , regelmässig.

Der linke Gehörgang geröthet, nicht stenosirt. Extravasat an der unteren Gehörgangswand. Trommelfell geröthet, sugillirt, Eiter nicht sichtbar. Hinter dem Obr kein Oedem, aber die Spitze des Warzenfortsatzes druckempfindlich.

Functionsprüfung: Leise Flüstersprache links einige $\mathrm{cm} . \quad \mathrm{C}$ rom Scheitel nach links.

Therapie: Die sofort vorgenommene Paracentese lässt einen Schuss Eiter hervorstürzen. Eisbentel hinter das Ohr. 0,3 Calomel, Klystier, Bett- 
ruhe. Nach der Paracentese grosse Erleichterung, Kopfschmerz ver schwunden, ebenso die Ohrenschmerzen, Appetit beginnt sich zu regen. Temperatur normal.

Am 11. October Abends Schmerzen im linken Ohr und ganzen Kopf. Temp. $38^{\circ}$. Kein Stuhlgang. Klystier.

In der Nacht rom 11. zum 12. October Jactation, aus dem Bett gesprungen.

12. October. Morgens Temp. 39,2 ${ }^{\circ}$. In der verflossenen Nacht ausgesprochenen Schüttelfrost gehabt, frühmorgens rudimentärer Schüttelfrost. Schmerzen und Unbeweglich beit in der Kreuz-Lendengegend (,Hexenschuss"); beschleunigte Athmung, $30-40$ pro Minute. Paracentese wiederholt, ohne dass neuer Eiter dabei entleeert wird. Mittags Temp. 36, $7^{\circ}$. Von Mittag bis Abend steigt die Temperatur auf $38,4^{\circ}$. Von Mittag an stetig zunehmende Somnolenz. Abends reagirt er noch, drückt auf Anweisung mit. der rechten Hand die Hand des Arztes und blickt auf Aufforderung nach rechts. Die Bewregung der Augäpfel nach links nur bis zur Mittellinie möglich. Die rechte Pupille weiter als die linke und schneller reagirend. Antworten nur selten aber correct. Starker Schweiss, Puls 152. Temp. in der Mundhöhle 37,8 ${ }^{\circ}$, Resp. 52, keuchend. Beginnender Herpes labialis. Kein Husten. Links: motorische Parese und Hypaesthesie. Die linke Hand fällt beim passiven Erheben schlaff herunter. Daumen und Zeigefinger der linken Hand in Streckstellung, die anderen in Beugestellung. Temporalarterien stark geschlängelt und gefült.

Ordin: Eisbeutel auf den Kopf und blutige Schröpfköpfe an den Schläfen.

13. October. Früh $3 / 48$ Uhr Coma, stertoröse Athmung, Puls 180. Lässt unter sich. Ophthalmosk. beids. Cataracta incipiens. Temp. 36,10, Der linke Arm ist völlig schlaff, während er mit dem rechten Arm noch spontane Bewegungen ma.cht. 10 Uhr Exitus letalis.

Die Section ergab eine diffuse eitrige Leptomeningitis; der eitrige Belag ist besonders stark ausgesprochen am motorischen Rindengebiete der rechten Gehirnconvexităt. Congenitale Dehiscenz an der oberen Fläche des Schläfen: beins, eine Verbindung $z$ wischen Paukenhöhle und Sehädelhöhle darstellend. Section des linken Schláfenbeines: Trommelfell stark injicirt, der hintere obere Quadrant stark geröthet und geschwollen. Ueber die hintere obere Trommelfellpartie verläuft eine etwa $3 \mathrm{~mm}$ lange, leicht verklebte Schnittwunde. Die Pankenhöhle ist mit dickem, zähem, hellgelbem Eiter, der mit einigen Blutstreifen untermischt ist, vollstăndig angefüllt. Die bei der Schädelsection gefundene congenitale Dehiscenz an der oberen Fläche des Schläfenbeines führt in die Paukenhöble, Das Antrum mastoideum ist nach unten $\mathrm{zu}$ enorm erweitert; es reicht nach unten bis etwa in das Niveau des Bodens des äusseren Gehörganges. Antrum und Warzenzellen mit Eiter vollständig angefüllt. In der Spitze ein grösserer Eiterherd von anscheinend confluirenden Zellen gebildet. Sinus stark vorgelagert. Sulcuswand intact. Auch einzelne periphere Mastoidzellen im Ansatz der Schuppe und an der hinteren Pyramidenfläche enthalten Eiter. Ossicula intact. Labyrinth und dessen nach der Schädelhöhle führende Canäle von normalem Aussehen. Corticalis des Warzenfortsatzes kräftig entwickelt.

Epikrise. Die Ursache des so schnellen Eintrittes der letalen eiterigen Meningitis ist in diesem Falle die Begünstigung der Entzändungsfortleitung nach der Schädelhöhle in Folge einer congenitalen, Pauken- und Sohädelhöhle frei verbindenden Dehiscenz der oberen Fläche des Schläfenbeins. Vielleicht wäre der fatale Ausgang verhütet worden, hätte man sofort bei der Aufnahme des Patienten, wo sichere Zeichen einer Meningitis noch nicht vorhanden waren, ausser der Paracentese des Trommelfelles auch die breite Eröffnung des Warzenfortsatzes vor- 
genommen. Indess war für uns eine Indication zu dieser Operation nicht vorhanden, da aus der Druckempfindlichkeit an der Spitze des Warzenfortsatzes allein nicht auf ein Empyem des Warzenfortsatzes geschlossen werden konnte. Stenose des Gehörgangs, äusseres Oedem war nicht vorbanden.

Klinisch war an dem Falle das geradezu apoplektiforme Einsetzen der Meningitis interessant, welches im Verein mit dem Symptomencomplex den Gedanken an eine Hemiplegie in Folge von Haemorrbagia cerebri in das Bereich unserer Erwägung ziehen liess. An diese Möglichkeit musste umsomehr gedacht werden, als der corpulente untersetzte Mann einen apoplektisehen Habitus hatte, sein Gesicht dunkelroth verfärbt war and die strotzend gefüllten Temporalarterien auffallend stark geschlängelt waren (Arteriosklerose).

10. Martha Krause, $1^{3 / 4} \mathrm{Jahr}$ ait, Fischerskind ans Halle. Aufgenommen am 21. November 1898, gestorben am 22. November 1898. Das schwächliche, schlecht genăhrte und entwickelte Kind wurde am Nachmittag des 21. November aufgenommen. Es zeigte verfallenes Ausssehen. Athem sehr beschleunigt. Am ganzen Körper Abschuppung. Nach Angabe der Eltern war das Kind seit einiger Zeit an Scharlach erkrankt. In der letzten Zeit trat Ohreiterung auf und seit einigen Tagen Anschwellung hinter dem rechten Obre.

$\mathrm{U} \mathrm{mgebung}$ des $0 \mathrm{hres}$ : hinter dem rechten Ohre ausgebreitetes Oedem. Fluctuation am Ansatz der Muschel.

Gehörgangs- und Trommelfellbefund: Beiderseits stinkende Eiterung. Grosse Defecte in den Trommelfellen. Abends Temp. $41,1^{\circ}$. In der Nacht steigerten sich die Athembeschwerden und am nächsten Morgen $7^{1 / 2}$ Uhr trat Exitus letalis ein unter den Anzeichen der Lungeninsufficienz.

Die Section ergab als Todesursache ausgedehnte hypostatische Pnetmonie. Der subperiostale Abscess über dem rechten eitrig entzündeten Warzenfortsatz war ohne Durchbruch der Corticalis entstanden.

11. Gertrud Stockmann, 1 Jahr alt, Fabrikarbeiterskind aus Halle. Aufgenommen am 27. Januar 1899, gestorben am 29. Januar 1899.

Anamnese. Nach Angabe der Mutter ist das Kind seit etwa vier Wochen erkrankt, zunächst an Ohreiterung links. Es soll aber vorher schon mitunter an das $0 \mathrm{hr}$ gegriffen haben. Vor 14 Tagen bekam es Krämpfe, dabei Nackenstarre (von einem Arzte sicher beobachtet). Seitdem ist das hind ganz theilnahmslos, trinkt nnr auf Aufforderung. Stuhl in Ordnung. Hitze und Fröste. Erbrechen ist nur einmal aufgetreten.

Status praesens. Gut genährtes Rind in tiefem Coma. Pupillen gleich weit, von mittlerer Weite, starr, ohne jede Reaction. Déviation conjugée. Augenhintergrund normal. Manchmal Spasmen im rechten Arm. Kopf in Zwangsstellung auf die linke Schulter geneigt. Keine Nackenstarre. Extremitäten rechts starr. Temp. $37,9^{\circ}$

Umgebung des Ohres ohne Besonderes.

Gehörgang und Trommelfellbefand. Links reichliche stinkende Eiterung. Perforation mittelgross im hinteren unteren Quadranten. Keine Stenose.

Am Tage der Aufnahme worde die Lumbalpunction vorgenommen, die klare, unter vermehrtem Druck stehende Flüssigkeit zu Tage förderte. Mikroskopisch fanden sich die Leukocyten etwas vermehrt, doch keine Bakterien. Hierauf A u fmeiss elung. Warzenzellen normal. Im Antrum 
kein Eiter. Primäre Naht. Durch die Operation wird das Betinden nicht verändert. Nachts Steigerung der Temperatur bis $39,8^{\circ}$,

28. Januar. Temp. 37,8-39,2 ${ }^{\circ}$. Deutliche Contracturstellung der rechten Extremitäten. Sonst Status idem.

29. Januar. Temp. 39,7-40,3 ${ }^{\circ}$. Das Kind schluckt seit der vergangenen Nacht nicht mehr. Die linken Extremitäten gelähmt. Puls klein und schwach. Mittags 3; 2 Uhr Exitus letalis.

Die Section ergab ausgedehnte tuberculöse Meningitis, starken $\mathrm{Hy}$ drocephalus externus und internus.

Epikrise: Dass wir trotz des desolaten Zustandes, in dem das Kind in unsere Behandlung kam, noch eine Operation wagten, lag darin, dass wir noch nicht jede Hoffnung anf Rettung für ausgeschlossen hielten, falls das Leiden otogener Natur gewesen wäre. Nach dem protrahirten Verlaufe war eine eiterige Meningitis auszuschliessen. Es konnte sich nur um eine seröse oder tuberculöse Meningitis handeln. Für letztere gab die Lumbalpunction keine Anbaltspunkte, wesshalb wir es unternahmen, die Aufmeisselung des Antrum zu machen, um vielleicht die Ursache der Meningitis zu finden. Die Section erwies, dass thatsächlich eine tuberculöse Meningitis bestand, die mit der Ohreiterung in keiner Beziehung stand.

12. Fritz Nagel, $3^{1 / 2}$ Jahr alt, V. Wagemeister ans Oppeln. Anfgenommen am 14. Januar 1899, gestorben am 19. Februar 1899.

Anamnese. Vor 5 Wochen Scharlach. Starke Durchfälle. Seit 14 Tagen Ohreiterung beiderseits. Schüttelfröste. Kein Erbrechen. Einigemale sind Zuckungen der Extremitäten beobachtet worden.

S tatus praesens: Blasses, schwerkrank aussehendes Kind. Schuppt. stark ab. Parese des linken Mundfacialis sehr ausgesprochen, das linke Augenlid kann nur balb geschlossen werden. Hustet viel. Athemfrequenz etwas gesteigert. Dämpfung links hinten unten nachweisbar. Temp. $38,0^{\circ}$, Resp. 24-37 pro Minute. Urin frei von Eiweiss und Zucker.

Umgebung des Ohres ohne Besonderes.

Gehörgang und Trommelfellbefund. Beiderseits starke stinkende Eiterung. Keine Stenose. Grosse Defecte in beiden Trommelfellen. Die Die Hammergriffe ragen frei in die Defecte hinein,

Ordination: Ausspülungen. Codein innerlich. Temp. vom 14. bis zum 17. Januar hochnormal, dann normal.

21. Januar A uf m eisselung links. Weichtheile kaum verändert, etwas speckig infiltrirt. Corticalis äusserlich unverändert. Bei den ersten Meisselschlägen quillt stinkender Eiter aus dem Warzenfortsatz. Alle Zellen des zellenreichen Processus mit Secret angefullt bis weit an die Peripherie nach oben hinten und unten. Die Spitze wird breit eroffinet. Die Schleimhaut der Spitzenzellen ist eitrig zerfallen. Durchspülung nach der Yaukenhöhle, wobei der Amboss ausgespült wird.

Nach der Operation keine Temperatursteigerung.

25. Januar. Erster Verbandwechsel. Das Spülwasser geht gut durch das Antrum und die Paukenhöhle.

29. Jannar. Es ist Oedem hinter dem rechten Ohre anfgetreten. Der Ausfluss rechts trotz häufiger Spülungen stets stinkend.

30. Januar. Hente ist Fluctuation hinter dem rechten Ohr nachweisbar. A ufme isselung rechts. Der retroanriculäre Abscess wird gespalten. Die Spitze des Warzenfortsatzes nekrotisch, aber noch nicht sequestrirt. Oberhalb der nekrotischen Partie ein fistulöser Durchbruch im Planum. Die Spitze wird entfernt, das Antrum breit eröffnet. Aus dem Antrum kommt Fiter hervor. 
Der Sinus wird in ziemlicher Ausdehnung freigelegt. Seine Wand sieht normal aus. Am Abend nach der Operation Fieber bis $39,7^{\circ}$.

31. Januar. Allgemeinbefinden gut, Appetit gut. Das Kind schläft viel. Husten wie sonst. Resp. 28 pro Minute. Temp. $38,3-38,4^{\circ}$. In der linken Operationswunde zeigt sich ausgedehnte Nekrose des freigelegten Knochens an der Spitze.

1. Februar. Temp. 37,4-37,50.

2. Februar. Temp. $37,2-3 \bar{i}, 4^{\circ}$.

3. Februar. Temp. $37,0-36,9^{\circ}$.

4. Februar. Temp. $36,8-36,7^{\circ}$.

5. Februar. Temp. 36,7-36,8

6. Februar. Temp. Abends $40^{\circ}$. Allgemeinbefinden nicht gestört. Schläft viel. Appetit gut.

7. Februar. Temp. $40,2^{\circ}, 39,0^{\circ}, 40,1^{\circ}, 39,8^{\circ} .39,2^{\circ}$. Es ist Angina aufgetreten. Appetit gut, im Ưrin kein Eiweiss.

8. Februar. Temp. $40,9^{\circ}, 38,8^{\circ}, 39,6^{\circ}, 38,4^{\circ}, 37,3^{\circ}$. Appetit schlechter. Abends zwei mal Erbrechen.

9. Februar. Temp. $38,1^{\circ}, 40,4^{\circ}, 37,9^{\circ}, 40,3^{\circ}, 40,7^{\circ}, 39,2^{\circ}$. Angina vorüber. Keine Schmerzen. Trinkt viel Milch.

10. Februar. Temp. $39,6^{\circ}, 39,3^{\circ}, 39,8^{\circ}, 39,4^{\circ}, 38,7^{\circ}$. Drei dünne hellbraune Stühle. Befinden unverändert.

11. Februar. Temp. $39,6^{\circ}, 39,3^{\circ}, 38,5^{\circ}, 39,9^{\circ}$. 4 Stühle. Tannalbin 0,5 .

12. Februar. Athemfrequenz gesteigert, bis 60 pro Minute. Temp. $39,3-40,4^{0}$.

13. Februar. Temp. 39,6-40,0 . Dampfung links unten hinten ausgedehnter, Athem sehr beschleunigt. Appetit schlechter.

16. Februar. Temp. $40,0-40,5 \circ$. Schmerzen in der rechten Schulter, Die rechte Schulter leicht verdickt. Gelenk gut beweglich. Keine Röthung noch deutliche Schwellung. Im Liegen leichter Opisthotonus. Keine Schmerzen im Genick. Jodanstrich der Schulter. Husten stärker und freier.

17. Februar. Wieder auffällig die stets gleichbleibende Lage mit zurückgebogenem Kopf. Die linke Schulter ist schmerzhaft und wird kaum bewegt. $D$ ie linksseitige Facialisparese ist ausgesprochener. Temp. 39,7 bls $39,4^{\circ}$.

18. Februar. Puls schlechter. Athem noch frequenter, bis 80 pro Minute. Nahrungsanfnahme gut. Trinkt viel Milch und Wein. Sensorium stets ungetrübt. Temp. $38,9-37,4^{\circ}$.

19. Februar. Puls immer schlechter. Warme Bàder mit kalten Uebergiessungen. Morgens $38,9^{\circ}$. Nach dem ersten Bade Puls besser. Etwa drei Stunden nach dem zweiten Bade ist der Puls ganz klein, nicht zu zählen. Temp. $35,5^{\circ}$ im Anus. Nach Aufahahe von Wein, unter Einbüllung des Kindes in Decke, Wărmeflasche, wird die Temperatur langsam höher. Puls nun etwas besser, aber immer fadenförmig, unregelmässig. Der Athem wird immer mühsamer, der Husten immer schwächer. Gegen 10 Uhr Abends Trachealrasseln. 11 Uhr Exitus letalis.

\section{Auszugaus dem Sectionsprotokoll.}

Diagnosis post mortem. Fibrinö-eitrige Pleuritis. Embolische Infarkte in den Lungen. Bronchitis catarrhalis. Dilatation des Herzens. Otitis media et interna purulenta. Theilweise erweichte Thrombose des Sinus sigmoideus und der Vena jugularis. Nephritis parenchymatosa acuta. Enteritis chronica. Hydrocephalus externus et internus. Oedem des Gehirns.

Im Sinus longitudivalis ziernlich viel dünnflüssiges Blut. Die weichen Häute der Convexităt zart, etwas vermehrte subarachnoideale Flüssigkeit, die hinteren Gefässe etwas stärker gefüllt. In der hinteren Schädelgrube ziemlich viel klare, farblose Flüssigkeit. Dura der Basis glatt und glänzend. An der Uebergangsstelle des rechten Sinus sigmoideus findet sich ein gelblich verfärbter, erweichter Thrombus, der an einigen Stellen in eitriger Schmelzung sich befindet. Die Wand des rechten Sinus sigmoiceus ist zum Theil mit eitrigen Massen bedeckt. Beim Abziehen der Dura findet sich rechts im Sulcus sigmoidens eine etwa kirschkerngrosse Perforation des Knochens, die 
hier freiliegende Dura ist mit blassen Granulationen auf der Aussenseite bedeckt. Am Ende des Sinus sigmoideus findet sich an der Hinterfläche der Pyramide der Knochen in erbsengrosser Ausdehnung erweicht und mit gelblich erweichten Zerfallsmassen erfültt. Auch auf der Vorderseite der lateralen Seite der Felsenbeinpyramide findet sich ein fiacher, unregelmässiger Substanzverlust des Knochens. Auf der linken Seite finden sich auf der lateralen Seite der Felsenbeinpyramide ebenfalls flache, oberfläcbliche Substanzverluste des Knochens und ebensolche im Sulcus sigmoideus. Der oben genannte Thrombus setzt sich etwa $4 \mathrm{~cm}$ in die Vena jugularis fort. In den Seitenventrikeln vermehrte Flüssigkeit, ebenso im dritten Ventrikel. Das Ependym sămmtlicher Ventrikel ist glatt und glänzend. Plexus chorioidei blass. Consistenz des Gehirns weich, Rinde sehr blass, Schnittfläche feucht.

Bei der Eröffinung der Brusthöhle entleert sich aus beiden Pleurahöhlen eine reichliche Menge truber, eitriger Flüssigkeit. Die rechte Lunge ist seitlich und nach binten mit der Thoraxwand verwachsen, die linke Lunge ziemlich retrahirt. Der Herzbeutei enthält klare gelbliche Flüssigkeit in vermebrter Menge. Endokard und Klappen des Herzens ohne Veränderungen. Muskulatur blassbraun, doch ziemlich kräftig. Linke Lunge ziemlich schwer. Pleura in ganzer Ausdehnung getrubt, mit Fibrinauflagerungen bedeckt, am vorderen unteren Rande des Unterlappens eine etwa markstückgrosse graue, derbe, etwas missgefärbte Stelle, die sich keilförmig in die Tiefe erstreckt und auf dem Darchschnitt von trübgelber Farbe ist. In den Broncbien eine vermehrte Menge Secret. Auch die Pleura der rechten Lunge mit zahlreichen fibrinösen Auflagerungen bedeckt. Unter der Oberfiäche mehrere kleine próminente Partien, die sich beim Einschneiden als Eiterherde erweisen. Bronchien wie links. Milz erheblich vergrössert. Beim Einschneiden in das rechte Schultergelenk erscheinen die Muskelfasern gelblich, trocken, verfärbt. Das Gelenk selbst ohne Besonderes. Das rechte Schläfenbein wird in situ anfgemeisselt. Mittelohr und Labyrinth mit dünnen Eitermassen erfüllt. Das linke Schläfenbein wird ganz berausgenommen.

Section des linken Schläfenbeines, Die Spitze des Warzenfortsatzes nekrotisch, lässt sich leicht ablösen. Die Nekrose reicht nicht bis zum Canalis facialis, sondern umfasst lediglich den äusseren Theil der Spitze. Nach der Auslösung zeigt sich ganz unten noch eine mit Eiter vollständig angefülte Zelle. Die Wände der Paukenböble sind mit Granulationen hedeckt. Der Amboss fehlt. Hammer und Steigbugel intact. Ueber dem Foramen ovale eine Dehiscenz des Facialcanales von ziemlicher Ausdehnung und mit glatten Rändern. Der freigelegte Facialis zeigt hyperämisches Perineurium. An der Dehiscenz geringe Granulationsbildung. Labyrinth intact.

Epikrise: An den verderblichen Folgen einer acuten Scharlachotitis ist das Kind zu Grunde gegangen, ohne dass die Aufmeisselung den verhängnissvollen Ausgang hat verhüten können. Die Erkrankung des rechten Schläfenbeines war die schwerere, uns musste indess die linksseitige Otitis der Facialislähmung wegen als die gefährlichere erscheinen, wesshalb wir, da der bereits bei der Aufnahme bestehende herabgekommene Allgemeinzustand des Kindes eine gleichzeitige Operation beider Obren nicht rathsam erscheinen liess, zunächst nur links operirten, zumal rechts stricte Indicationen für einen operativen Eingriff nieht vorhanden waren. Nach einigen Tagen veranlasste nun auftretendes Oedem hinter dem rechten Ohr uns zur Operation auch dieser Seite, doch kam die bereits bestehende Thrombose des Sintus nicht mehr zur Ausheilung, Obwohl die Thrombose im 
rechten Sinus sigmoideus lange latent geblieben war - sie documentirte sich zum ersten Male direct nach der Operation des rechten Ohres durch kurzdauernde Temperaturerhöhung müssen wir ihr Bestehen ziemlich weit zurückdatiren. Möglicherweise hat sie schon bei der Aufnahme bestanden. Wir müssen berücksichtigen, dass Symptome der von der Thrombose indueirten Pleuritis damals bereits vorhanden waren. Auffallend bleibt indess das lange Ausbleiben typischer pyämischer Erscheinungen. Auch das nach der zweiten Operation auftretende Fieber, das wir als pyämisches auffassen müssen, hielt nur zwei Tage an, um dann wieder 5 Tage lang normalen Temperaturen Platz zu machen. Erst am 7. Tage nach der zweiten Operation manifestirte sich die Pyämie wieder deutlich durch hohes Fieber; das aber auch auf die gleichzeitig sich einstellende Angina bezogen werden konnte. Bald indess kamen pyämische Durchfälle, Infiltration der rechten Sehulter und Zunahme der Lungensymptome hinzu, so dass jeder $Z$ weifel an der Art der verhängnissvollen Complication sohwinden musste. Die Section zeigte, wie grosse Knochenzerstörungen die verhältnissmässig kurz bestehende Ohreiterung gemaeht hatte, und wie machtlos unsere therapeutischen Eingriffe solchen Wirkungen des Scharlachgiftes gegenüber sind. Das uns zuerst und am meisten imponirende Symptom der Facialislähmung hatte seine Ursache nicht in der Erkrankung des Knochens, sondern seiner Entstehung lag eine congenitale Dehiscenz im Canalis Fallopiae za Grunde, wodureh die Entzündung von der Paukenhöhlensehleimhaut direct auf den Nervenstamm fortschreiten konnte.

13. Christian Braunsdorf, 58 Jahre alt. Futterknecht aus Pratan. Aufgenommen den 17. Februar 1599. Gestorben den 21, Februar 1899.

Anamnese: Der Patient wurde vor ca. 3 Wochen von einem Stiere angegriffen, zu Boden geworfen und mehrfach verletzt. Er war längere Zeit bewusstlos. Nach dem Unfall blutete er aus der Nase nnd ans dem rechten. Ohr. Er wurde wegen Verdachtes auf Schädelbasisfractur in die chirurgische Universitätsklinik gebracht. Nach 5 Tagen warde er von dort wegen Mangel weiterer Symptome entlassen. Vor einigen Tagen wurde er wieder in die chirurgische Klinik aufgenommen wegen Kreuzschmerzen, fur die eine Unterlage nicht gefunden werden konnte. Ausserdem bestand noch Hämatom am rechten Unter- und Oberschenkel. Eiterung des Ohres wurde nun erst bemerkt. Der Patient gab an, dass er ror dem Unfall keine Ohreiterung gehabt hätte, doch habe er im Jabre 1892 nach Influenza Obrschmerzen rechts gehabt. Seit dem 16. Abends ist Fieber aufgetreten, das am Morgen des folgenden Tages noch fortdauerte. Da das Fieber als von der Ohreiterung ausgehend aufgefasst werden musste, wurde der Patient in die Ohrenklinik verlegt. Auf Befragen giebt er noch an, dass er nach dem Unfall beim Kauen im rechten Obre Schmerzen gehabt hatte.

Status praesens: Leidlich genährter Mann. Ausgedehnte blutunterlaufene Stellen am rechten Unterschenkel. Kleinere in der Lendengegend 
der Wirbelsäule. Sensorium etwas benommen. Antworten nicht immer richtig. Sprache etwas undeutlich. Pupillen gleichweit, reagiren gut. Augenhintergrund normal. Einzelne Rasselgeränsche über den Lungen vorn, keine Dămpfung. Herztöne dumpf, aber rein. Zunge trocken, belegt. Keine Klagen über Schmerzen. Temp. 40,5\%. Puls 136 p. M. Der Crin enthält Spuren von Eiweiss.

Umgebung des Ohres: Oedem hinter dem rechten Warzenfortsatz. Geringe Druckempfindlichkeit daselbst.

Gehörgang und Trommelfellbefund: Geringe Schwellung der vorderen Gehörgangswand. Am Boden des Gehörgangs im knöchernen Theile einige kleine Granulationen. Das nur zum Theil sichthare Trommelfell zeigt vorn unten einen pulsirenden Reflex. Epidermislage fencht, gelockert. Viel eitriges Secret im Gehörgang.

Gehörprüfung: Des stets etwas benommenen Sensoriums halber ist die Hörprufung nicht einwandsfrei vorzanehmen. Weber nach rechts. Fis 4 wird beiderseits bei starkem Fingerkuppenanschlag gehört.

18. April. Sensorium noch benommen wie gestern. Keine Kopfschmerzen. oedem hinter dem rechten Ohre kaum nachzuweisen. Drackempfindlichkeit besteht am vorderen Rande des Warzenfortsatzes in der Mitte. An der Spitze keine Druckempfindlichkeit. Starke Druckempfindlichkeit an der linken unteren seiclichen Thoraxparthie. Athemfrequenz 40 p. M. Puls 120 bis 124 p. H. Hohe Elevationen, regelmässig. $C_{1}$ wird beute vom Scheitel nicht lateralisirt. Patient hat einmal Urin unter sich gehen lassen. Temp. $38,6^{\circ}$ bis $39,8^{\circ}$.

19. Februar. Allgemeinzustand wenig verändert. Hat etwas zu sich genommen. Stuhl gestern auf Klystier. Morgens Schüttelfrost mit nachherigem Schweiss. Sensorium noch benommen. Ataktische Bewegungen der Hände beim Greifen. Trommelfellbild heute dentlich. Mittelgrosse Perforation vorn unten mit granulirenden Rändern. Heute ist die Schmerzhaftigkeit am Warzenfortsatz gering, dagegen besteht starke Drackempfindlichkeit vor dem Tragus. Starke Schmerzen in der linken Thoraxseite und in der Herzgegend. Dämpfung in der hinteren unteren Thoraxparthie. Abgeschwächies Athemgeräusch links in der gedämpften Partie, Abends wird Anschwellung beider Ellenbogengegenden bemerkt. Starke Schmerzhaftigkeit derselben. Die rechte Ellenbogengegend zeigt ausgedehnte Röthe. Links ist nur der Condylus internus geröthet und schmerzhaft. Abends starker Schweissausbruch ohne vorherigen Frost. Temp. $39,2^{\circ}-41,0^{\circ}$.

20. Februar. In der vergangenen Nacht verschiedene rudimentäre Schüttelfröste. Gegen Morgen wird der Athem frequenter und flacher. Morgens Temp. 39, $4^{\circ}$. Pals sehr schwach. Athem oberflächlich, manchmal stertorös. Patient nimmt noch etwas za sich. $10 \mathrm{Uhr}$ Trachealrasseln. Puls nicht mehr zu fühlen. 11 Uhr Exitus letalis.

\section{Auszug aus dem Sectionsprotokoll.}

Diagnosis post mortem. Fibrinös-eitrige Pleuritis. Hypostatische Pneumonie links hinten unten. Hyperämie und Atelelitase der Lungen. Emphysem der Lungen. Schleimig-eitrige Bronchitis. Dilatation des rechten Herzens. Endocarditis chronica fibrosa papillaris. Oedem der Nieren. Contusion beider Orbitallappen. Zertrümmerung des Orbitaldaches beiderseits Fissur der Schädelbasis rechts. Myositis septica.

Im Sinus longitudinalis Cruor. Die weichen Hänte zart, glänzend, in den subarachnoidealen Raumen etwas vermehrte klare Flüssigkeit. In der vorderen Schädelgrube finden sich auf der Innentäche der Dura flache Blutauflagerungen, rechts stärker als links, sowie jederseits über dem Orbitaldach trübgelbliche weiche Massen. An den entsprechenden Stellen des Orbitallappens finden sich oberfiächliche, unregelmässige erweichte, gelbbräunliche Hirnpartien. Auch in der Schädelgrube einige flache Blutauflagerungen. Die grossen Sinus frei. Nach Abzug der Dura findet sich jederseits das Orbitaldach zertrümmert and zieht rechterseits eine vom Orbitaldach aus über die Keilbeinflïgel in das Foramen ovale und rotundum sich erstreckende, den hinteren Theil der Pyramide querende, in den Sulcus transversus und 
die Squama ossis ocipitalis verlaufende schmale Fissur. Sinus der Basis frei. In den Seitenventrikeln geringe Mengen klarer Flüssigkeit. Consistenz des Gehirns gut. Schnittfäche feucht.

Der rechte Oberarm ist angeschwollen. Beim Einschneiden entleert sich aus dem Gewebe trübröthliche Flüssigkeit. Muskeln erweicht, von trübbräunlicher Farbe. Auf dem Ausstrichpräparat zablreiche Streptokokken und Staphylokokken.

Section des Schläfenbeines. (Siehe Fig. 1 u. 2, Seite 159. )

Das fracturirte Schläfenbein zerfält nach seiner Herausnabme in 2 Theile. Es zeigt sich, dass die Fractur sich quer durch den Warzenfortsatz unterhalb der Spina fortsetzt und die vordere und hintere Wand des knöchernen Gehörgangs in der Längsrichtung bis in den Sulcus tympanicus gespalten ist. Die vordere Gehörgangswand zeigt ausserdem am Uebergang in die untere noch eine Längsfractur, die am äusseren Rande in die erstgenannte Bruchstelle mündet, so dass ein Stück Knochen ganz lose und beweglich ist. Das Trommelfell ist vorn unten perforirt. Perforation nierenförmig. An der Schädelfäche verläuft die Fractur durch die vordere Wand der Pyramide von der Gegend des. Foramen lacerum an durch das Tegmen tympani und antri und durchquert den Sulcus sigmoideus in der Gegend des Uebergangs in den Sulcus transversus.

Die Sinuswand ist ron normalem Aussehen, sowohl aussen als innen. Im Bulbus venae jugularis Blutgerinnsel, an der oberen Hälfte etwas adhärent. Diese adhärente Stelle gelbröthlich, der übrige Theil dunkelroth. An der Venenwand im Bulbus jugularis kann nichts Abnormes entdeckt werden.

Die mikroskopische Untersuchung der adhärenten verfärbten Partie des Gerinnsels ergiebt indess Thrombusmasse, worin zahlreiche Staphylokokken und Streptokokken eingelagert sind.

Im Warzenfortsatz jauchig zerfallener Bluterguss. In der Paukenhöhle etwas Serum. Ossicula und Chorda tympani intact. Labyrinth intact.

Fig. 1 zeigt den Verlauf der Fissur durch den Warzenfortsatz und den äusseren Gehörgang.

Fig. 2 zeigt den Verlauf der Fissur uber das Tegmen tympani und antri in den Sulcus sigmoideus.

Epikrise: Nach dem Sectionsbefund kann kein Zweifel daruber bestehen, dass trotz der anderweitigen festgestellten sehweren Verletzungen die Todesursache lediglich in der Complication von Seiten des verletzten Ohres zu suchen ist. Die Fraetur des Sehläfenbeines war eine so ausgedehnte, dass der Mangel ausgesprochener localer Symptome unmittelbar nach dem Unfall auffallend ist. Trotz der Fissuren im änsseren Gehörgang, die ein Knochenstïek an der vorderen Wand vollständig losgesprengt hatten, war die Kaufähigkeit nicht aufgehoben, sondern nur dureh geringe Schmerzhaftigkeit beeinträehtigt. Die nach dem Unfall eingetretene Blutung aus dem Ohre war das einzige Symptom, das mit Sicherheit auf eine Betheiligung des Ohres hinwies. Erst später stellte sich Ohreiterung ein. Mangels der Aufnahme eines Ohrbefundes sofort nach dem Unfall müssen wir versuchen, den Verlauf nach der Anamnese, unseren kurzen Beobachtungen und dem Sectionsbefund zu reconstruiren. Es erscheint danach am wahrscheinlichsten, dass die Contusion eine 
Jahresbericht d. Kgl. Universitäts-Ohrenklinik zu Halle a. S. 1898/99. 159

Fig. 1.

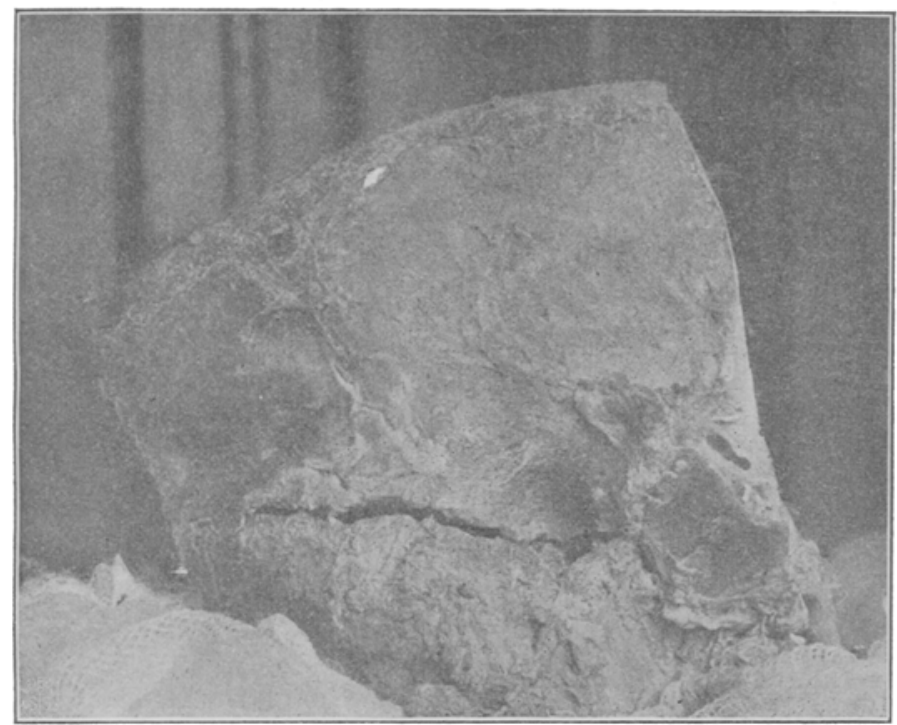

Fig. 2.

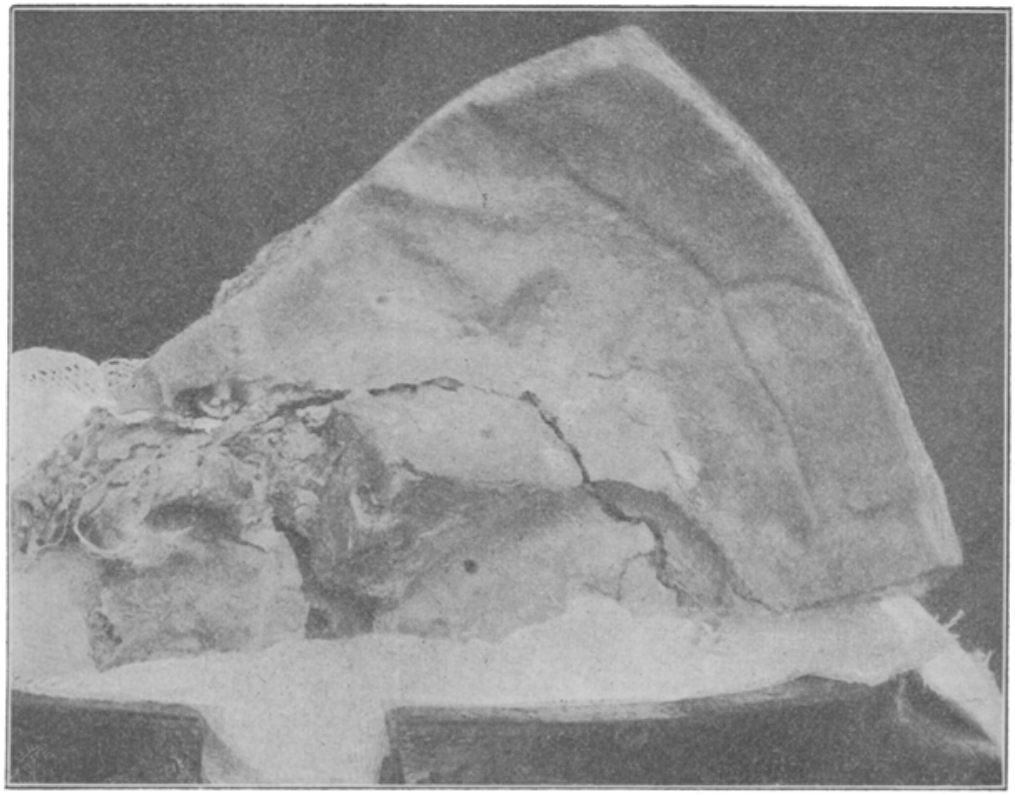


Trommelfellruptur herbeifübrte, die späterhin zu einer Infection des Mittelohres Veranlassung gab. Doch lässt der Sectionsbefund auch die Mögliohkeit $z \mathfrak{z}$, dass die festgestellte Perforation des Trommelfells eine alte war (vielleicht von einer fruheren Influenzaotitis herrührend) und dass die Fractur des Schläfenbeines dann entweder eine Exacerbation einer alten Otitis, oder das Fortschreiten einer solchen im Gefolge hatte. Die Todesursache war eine Septicopyämie, deren Ausgang von dem erkrankten Ohre bezw. Sinus uns nur durch Zufall einwandsfrei festzustellen gelang. War doch im Sinus selbst, anch an der der Fracturstelle anliegenden Wand niehts Pathologisches zu entdecken und selbst das im Bulbus venae jugularis gefundene Gerinnsel wäre ohne mikroskopische Untersuchung sicher für ein postmortales gehalten worden, zumal auch hier die Venenwand intact zu sein schien. Durch die mikroskopisohe Untersuchung indess gelang es, nachzuweisen, dass wir die Reste eines infectiösen Thrombus vor uns hatten. Diese Beobachtung lässt den Fall in klarstem Lichte erscheinen. Die Infection ist vom Mittelohr, wo ihr die den Sulous sigmoideus durchquerende Fractur Gelegenheit dazu bot, nach dem Sinus fortgeschritten. Die hier entstehende Thrombose blieb zunächst latent, löste sich jedenfalls später ab und gelangte in die Blutbahn. Schon vorher mag sich vielleicht auf embolischem Wege ein kleiner Thrombus im Bulbus venae jugularis gebildet haben, der aber auch bereits im Begriff war, sich abzulösen und den wir das Gliick hatten, bei der Section noch zu finden. Dieser Fall lebrt uns, dass die anscheinend intacte Sinuswand nicht als Beweis dafür gelten kann, dass eine Pyämie ohne Vermittlung durch Sinusthrombose entstanden ist, sondern dass die Regeneration der Intima nach Los. lösung der Thromben rasch und vollständig eintreten kann.

14. Ernst Weiss, 1 ) 61 Jahre alt. Fabrikarbeiter aus Seehausen. Aufgenommen den 12. Januar 1899. Gestorben den 15. Januar 1899 an Meningitis.

15. Bertha Nethge, 38 Jahre alt. Zỉmmermannsfrau aus Halle. Aufgenommen den 2. März 1899. Gestorben den 7. März 1899.

Anamuese: Die Patientin ist als Kind scrophulös gewesen und hat damals an Ohreiterung and Augenkrankheit in einem Krankenhause längere Zeit gelegen. Auch seither war das linke Obr öfters feucht. Vor 4 Tagen traten heftige Schmerzen im linken Ohr auf. Den folgenden Tag starke Kopfschmerzen und Schwindel, so dass sie nicht mehr gehen konnte. Die Schmerzen beschränkten sich auf die linke Kopfhälfte. Appetitlosigkeit. Mehrfaches Erbrechen. Stuhlgang in Ordnung. Die Patientin hat vor 4 Monaten geboren (das fünfte Kind) und stillt noch.

1) Zeroni, Ueber das Carcinom des Gehörorgans. Dieses Archiv. Bd. XLVIII. S. 150 . 
Status präsens: Gut genährte Frau. Klagt über heftige Schmerzen in der linken Kopfhälfte. Kopfbewegungen frei. Keine Druckempfindlichkeit am Genick. Spricht viel. Manchmal fehlen ihr bestimmte Worte, was sie selbst bemerkt. Allgemeine Hyperästbesie, Reflexe nicht gesteigert. Innere Organe ohne Besonderes. Urin frei von Eiweiss uud Zucker. Temp. 38,30. Puls in gleichen Intervallen nicht ron gleicher Frequenz. $80-90$ p. M. Respiration regelmässig $20 \mathrm{p}$. M. Augenhintergrund normal. Pupillen normal.

Umgebung des Ohres: Jodanstrich in der Umgebung der linken Obrmuschel. Mässige Druckempfindlichkeit des linken Warzenfortsatzes. Stärkere Druckempfindlichkeit am Uebergang des Warzenfortsatzes auf das Occiput. Klopfempfindlichkeit der ganzen linken Schädelhälfte.

Gehörgang und Trommelfell befund: Links: Im Gehörgang viel Eiter. Die Tiefe verlegt durch Schwellung der Gehörgangswănde, besonders der oberen. Rechts. Grosser Defect des Trommelfells.

Hörprüfung: Weber unbestimmt. Fis 4 links stark herabgesetzt.

In der Nacht vom 2. bis 3 . Mărz wenig Schlaf. Stets Klagen über furchtbaren Kopfschmerz links.

3. Mărz. Morgens $37,7^{\circ}$. Puls 80. Die Unfähigkeit, bestimmte Worte zu finden, scheint zugenommen zu haben.

Sie benennt z. B. folgende Gegenstände: Schlüssel - man macht damit auf. Ring - zuerst: ich habe auch so ein Ding, dann nach längerem Nachdenken richtig. Bürste - nicht, auch Gebrauch unverständlich ausgedrückt. Buch - mein Bruder hat auch eines. Dynamometer rechts 2, links 13. Keine sonst nachweisbaren Paresen. Die Beine werden gut bewegt. Keine Anästhesien. Zunge weiss belegt, trocken. Pupillen verengt, reagiren auf Lichteinfall gleichmässig, aber etwas träge. Keine Druckempfindlichkeit der Jugularisgegend. Ausgesprochene Percussionsempfindlichkeit über dem linken Ohr. Die Patientin ist bei der Untersuchung in wechselnder psychischer Verfassung. Manchmal von gutem Humor, anfallsweise laute Klagen über Kopfschmerzen.

Um 12 Uhr Mittags ausgesprochener Schüttelfrost. Austeigen der Temperatur auf $40,4^{\circ}$. Nachher Delírien.

Um 1 Uhr Operation: Die Lumbalpunction ergiebt unter starkem Druck stehende wasserklare Flüssigkeit. Keine Leukocytenvermehrung, keine Bakterien. Totala ufmeis selung rechts. Weichtheile normal. Corticalis osteosklerotisch. In einer Tiefe von ca. $1 \mathrm{~cm}$ ist der Knochen mit Eiter durchsetzt und wird eine grössere, mit Detritusmassen erfüllte Höhle eröffnet. Hammer gesund. Amboss cariôs. Die Mittelohrräume von zerfallenen Cholesteatommassen erfüllt. Der knöcherne Gehörgang ist durch concentrische Hyperostose verengt. Der Boden der Paukenhöhle ist weit excavirt. Granulationsmassen und lappige fleischige Massen befinden sich daselbst. Ein wenig Eiter kommt centralwärts oben aus der Schädelhöhle. Die hier in Bleistiftdicke freigelegte Dura mit fibrösem Belage versehen und mit spärlichen Granulationen besetzt. Der Sinus sigmoideus wird in ziemlicher Ausdehnung freigelegt, derselbe ist äusserlich unverändert. Trepanation auf den linken Schläfenlappen. Die freigelegte Dura pulsirt nicht, die Pia ist unverändert. Es wird in mehreren Richtungen mit dem Scalpell nnd Kornzange eingegangen, ohne dass man auf einen Abscess stösst. Schliesslich wird nach hinten, gegen das Tegmen antri zu, noch eingestochen. Dabei entleeren sich etwa 2 K̇affeelöffel dünnflüssigen jauchigen Eiters und schwarze nekrotische Hirnmassen. Durch ein grosses Drain wird die Höhle mit Sublimat 1: 10,000 ausgespült, ohne dass noch Eiter nachfliesst. Drainage der Abscesshöhle. Tamponade des Mittelohres mit Jodoformgaze.

Nach der Operation Puls 132, klein. Temp. 38, $7^{\circ}$. Pat, ist nicht ganz bei Besinnung.

4. März. Temp. $37,1^{0}-38,3^{0}$. Puls besser. Sensorium frei. Die Klagen über Kopfschmerzen sind geringer. Pat. trinkt viel Wasser. Gegen Nahrungsaufnahme besteht Widerwille. Gegen Abend nimmt sie etwas Milch und Bouillon zu sich.

כ. März. Morgens Temp. 37,4 . Nahrungsaufnahme besser. Verbandwechsel. Ausspülung des Abscesses. Nachmittags relatives Wohlbe- 
finden. Pat. isst etwas. Abends wieder Klagen über Kopfschmerzen. Temperatur $39,9^{\circ}$. Nachts ist die Patientin sehr unruhig.

6. März. Temp. 37, $7^{\circ}-38.5^{\circ}$. Starke Kopfschmerzen. Die Patientin schreit ofters laut auf. Morph, subet. 0,02. Eisblase. Nachmittags Sensorium leicht getrübt. Pat, antwortet nicht mehr. Leichte Delirien. Appetit noch vorbanden, Pat. trinkt 11 Milch im Laufe des Tages. Abends wieder heftiges Schreien, unterbrochen von lautem Singen.

7. März. Temp. Morgens $38,7^{\circ}$. Trachealrasseln von 4 Uhr Morgens an. Trotzdem noch Nahrungsaufnahme. Die Besinnung kehrt zeitweise wieder, abwechselnd mit tiefem Coma.

12 Uhr Mittags Exitus letalis.

Auszugas dem Sectionsprotokoll.

Diagnosis post mortem. Jauchiger Hirnabscess im linken Temporallappen. Hirnprolaps. Perforation des Abscesses in das Unterborn des linken Seitenventrikels. Bluterguss i. Ventrikel. Verjauchte Thrombose des linken Sinus sigmoideus. Lungenödem. Bronchitis. Dilatation des rechten Herzens. Aussenfäche der Dura stark gespannt, glatt und glänzend, ebenso die Innenflache. In Sinus longitndinalis Cruor. Die weichen Häute der Convexität sind trocken. Gyri abgeplattet. Sulci verstrichen. Die Dura der Basis findet sich links im Bereich der mittleren schädelgrube mit schmutzig-röthlichen Blutmassen bedeckt und zum Theil schwärlich verfärbt. Im linken Sinus sigmoideus ein zum Theil grünlich verfärbter verjauchter Thrombus, am Ende des linken Sinus transversus ein grauröthlicher kleiner Thrombus. In den ubrigen Sinus zum Theil Cruor, zum Theil sind sie leer. Beim Abziehen der Dura reisst diese im Bereich des linken Schläfenbeins bäufig ein. Auf der vorderen Seite der linken Felsenbeinpyramide findet sich missfarbiger abwischbarer Belag. Am lateralen Ende des Felsenbeines auf der vorderen und hinteren Fläche je eine etwa bleistiftdicke Perforation des Knochens, von denen die hintere durch Operation entstanden, die vordere, deren Rănder etwas missfarbig erscheinen, spontan entstanden ist. An den ubrigen Theilen der Schädelbasis nichts Besonderes. An der Gehirnbasis findet sich auf der Unterfläche des linken Schläfenlappens ausgedehnte schmutzig-gränliche Verfärbung. In den mittleren Theilen des Lappens ragen aus dem zertrümmerten Gehirn schmutzig-bräunliche Zerfallsmassen hervor. Beim Auseinanderklappen findet sich eine ziemlich grosse, mit ebensolchen Massen erfullte Höhle, deren Wandungen ehenso schmutzig-grünlich verfärbt sind. Die umgebenden Gehirntheile sind sehr weich. Auch in den binteren Partien finden sich verfarbte Stellen, vor allem zu beiden Seiten, namentlich links von der Medulla und hinter dem Chiasma. Anf dem Durchschnit durch die thelriechende Zerfallmasse findet sich das umgebende Gehirn grüalich verfärbt und erweicht. Abscessmembran nicht vorhanden. In der Tiefe des Abscesses findet sich eine etwa federkieldicke Perforation, welche in das Unterhorn führt. Im linken Seitenventrikel finden sich missfarbene Cruormassen; das Ependym ist schmutzig-grünlich verfärbt; in dem rechten Seitenventrikel findet sich etwas trübe Flüssigkeit, auch hier ist das Ependym schmutziggrünlich. Im 3. Ventrikel ebenfalls Cruor, welcher sich durch den Aqnae. ductus Sylvii bis in die Rantengrube fortsetzt. Das Ependym sämmtlicher Ventrikel missfarben, bis in die weisse Markmasse des Kleinhirns hineinerstreckt sich die Verfärbung. In den grossen Ganglien, Pons, Medulla nichts Besonderes.

Section des Schlafenbeines: Knochen uberall hyperämisch; das Labyrinth enthalt klare, leicht röthlich gefärbte Flüssigkeit; einzelne Theile desselben gut erkenubar. Die Wege rom Labyrinth nach der Schädelhỏhle sind frei.

Epikrise. Die versehiedenartigen Complieationen dieses Falles in ihren Symptomen auseinanderzuhalten, fällt auch nachträglich schwer. Als Symptome mit klarer Ursache können wir nur diejenigen betrachten, die als reine Fernsymptome des Hirn- 
abscesses auftraten und uns zur Diagnose der letzteren hinleiteten: Die Aphasie und die verminderte Kraft des rechten Armes. Schwieriger ist es, die Fieberbewegung zn erklären, die sowohl von einer Complication des Hirnabscesses, dessen nachgewiesener Communication mit dem Seitenventrikel, als auch von der festgestellten Thrombose des Sinus herrühren konnte; doch ist es auch möglich, anzunehmen, dass beide Processe sich an der Temperaturerhöhnng betheiligten.

Die erste plötzliche stärkere Temperatursteigerung unter gleichzeitigem Schüttelfrost wurde von uns auf beginnende Meningitis bezogen. Da uns das Bestehen eines Hirnabscesses damals sehon als sicher ersehien, schritten wir nun unverzüglich zur Trepanation, als dureh die Lumbalpunotion eine diffuse eitrige Meningitis nicht erkennbar war. Jetzt indessen scheint es nicht uns ausgeschlossen, dass der Schüttelfrost ein pyämischer gewesen ist. Doch ist gleichzeitig zu bedenken, dass der Hirnabscess keineswegs abgekapselt war, dass sich vielmehr dessen Wand, besonders diejenige, die ihn rom Seitenventrikel trennte, in hohem Grade erweicht war. Es war so die Möglichkeit gegeben, dass infectiöse Stoffe und Bakterien von dem Abscess in die Ventrikelflïssigkeit gelangten, was bei der Deutung des Fiebers nicht ausser Acht gelassen werden darf. Wann die Perforation der erweichten Wand erfolgt ist, lässt sich nicht genau angeben; doch erscheint es ausgesehlossen, dass dies ror der Operation bereits gesehehen war, denn von den prägnanten Symptomen, die einen Abscessdurchbruch sonst zu begleiten pflegen, war nichts beobachtet worden. Dies erseheint nur so erklärbar zu sein, dass zur Zeit der Bildung der Communication, die durch allmäligen Zerfall einer circumseripten erweichten Partie der Scheidewand erfolgt sein wird, sich kein, oder nur wenig Eiter mehr in der Abscesshöhle befand. Mit einiger Wahrscheinlichkeit kann man den Abend des 2. Tages post operationem als den kritischen Zeitpunkt betrachten, wo sich unter wiederkehrenden Kopfschmerzen und schnellem Ansteigen der Temperatur das Krankheitsbild, das sich vorher zur Besserung hinzuneigen schien, rasch änderte. In diesen Symptomen documentirte sich wohl der Beginn der Ventrikelentzündung, die dann den Tod bald herbeifithrte.

16. Karl Ulrich, 26 Jahre alt, aus Roda im Harz. Aufgenommen am 20. März 1899 wegen Empyems sämmtlicher Nebenhöhlen der Nase, gestorben am 9. Juli 1899 . 
Anamnese: Seit 3 Jahren Gefuhl ron Nasenverstopfung. Verschiedentlich Polypen aus der Nase entfernt. Seit Sommer 1898 täglich Kopfschmerzen. Weihnachten 1898 Bildung eines Abscesses über dem rechten Auge, welcher von einem Arzte incidirt wurde. Seit 1/2 Jahre eitriger Ausfluss aus der Nase.

Sta tus pra esens: Hochgradige Anämie, Ektropion des rechten oberen Augenlides. Anscheinend fistulöser Durchbruch der rechten unteren Stirnhöblenwand. Urin ohne Zucker und Eiweiss.

Nas en be fu nd: Beiderseits hochgradige Muschelhypertrophie; viel Eiter in beiden Nasenhöhlen, vielfach blossliegender Knochen in allen Theilen der Nase sondirbar.

20. Mărz: Operative Eröfnung der rechten Stirnböhle: Weichtheilschnitt durch die Augenbrauen, um den medialen Orbitalwinkel herum bis etwa zur Hälfte der seitlichen knöchernen Nasenwand herabreichend. Eine Weichtheilfistel, welche direct unter den Augenbrauen, und zwar in der Mitte des Arcus snperciliaris nach aussen mundete, und zu Ektropion geführt hatte, wurde durch den Schnitt nicht berührt. Die Weichtheilfistel führte, wie es sich nach Freilegung des Knochens ergab, in eine feine Knochentistel im medialen Drittel des Árcus superc. Beim Aufmeisseln der Stirnhöhle quoll eine grosse Menge grünen foetiden Eiters unter Pulsation hervor. Nach breiter Eröfinung der Stirnhöhle durch Fortnahme der überhängenden lateralen Wand ergab sich, dass die mediale knöcherne Stirnhöhlenwand vollkommen fehlte und dass median von der Stirnhöhle eine wallnussgrosse Extraduralabscesshöhle vorlag. Die Dura leicht geröthet und mit kleinen Granulationen besetzt. Ein grösseres missfarbenes Granulationspolster schloss die Stirnböble nach der Nasenhöhle zu vollkommen ab. Von der Stirnhöhle aus direct auf das Siebbeinlabyrinth zugegangen. Dasselbe ist vollkommen cariös, mit missfarbenen Granulationen und vielen Sequestern erfüllt. Entfernung des ganzen rechten Siebbeinlabyrinthes erforderlich. Von dex rechten Stirnhöhle aus liess sich eine Sonde in die linke Stirnhöhle führen, da das Septum aufgezehrt war. Beim Einführen der Sonde quoll reichlich Eiter aus der linken Stirnhöhle hervor, so dass dieselbe auch von aussen breit eröfinet wurde. Sie enthielt Eiter und ein dickes missfarbenes Granulationspolster. Die in Narkose bei aberhängendem Kopfe ausgeführte Operation musste hier abgebrochen werden, da die lange Dauer derselben in Verbindung mit dem grossen. Blatverlust eine Vollendung des operativen Fingriffes nicht unbedenklich erscheinen liess. Tamponade der freigelegten Höhlen mit Jodoformgaze.

4. April. Erötfuung der linken Siebbeinzellen, welche einen entsprechenden Befund wie rechts darboten. Die rechte Highmorshöhle wurde von der rechten Fossa canina aus breit eröfnet, es fand sich ein fötides Empyem und dickes Granulationspolster darin. In der ebenfalls eröffneten linken Highmorshöhle fand sich nur ein dickes Polster granulär entarteter Schleimhaut.

Eine intercurrente acute linksseitige Mittelohreiterung wurde gut überstanden, die Kopfschmerzen zeigten zwar Remissionen, traten aber immer wieder von Neuem auf.

Am 7. Juni war die operative Entfernung der linksseitigen mittleren Nasenmuschel nöthig, sowie die Wiedereröfinung der linken Highmorshöhle, in welcher sich nun ein erhebliches Empyem vorfand.

In der Nacht vom 7.-8. Juni Eintritt von Fieber. Am 8. Juni Nachmittags Schüttelfrost und Temperatursteigerung auf $40,8^{\circ}$. In der folgenden Nacht heftige Kopfschmerzen.

9. Jani. Geringe Rothe und Infiltration der Stirn- und Wangenhaut rechts. Allgemeinbefinden schlechter wie Tags zuror. Grosse Unrube, Kopfund Nackenschmerzen. Cheyne-Stokes-Athmen beginnend, gegen Abend ausgesprochen. Sensorium frei bis ungefähr 9 Uhr Abends. Exitus letalis 12 Uhr.

\section{Auszug aus dem Sectionsprotokoll.}

Innenflache der Dura rechts in grosser Ausdehnung mit eitrigen Massen bedeckt, links glatt und glänzend. Auf der Oberfläehe des Gehirns rechts dicke eitrige grünliche Massen, links an mehreren Stellen des Scheitellappens 
leichte milchige Trübungen. Vor der vorderen Centralwindung die weichen Häute leicht mit eitrigen Knötchen bedeckt. Auch an der Basis des Gehirns, namentlich am Chiasma, den Fossae Sylvii und Pons eitrige Massen. Dura der Basis im Bereich der vorderen und, mittleren Schädelgrube mit Eiter bedeckt. Nach Abzug der Dura in der vorderen Scbädelgrube ein uber wallnussgrosser Defect im Stirnbein und in der angrenzenden Orbita, Knochenränder glatt und die umgebenden Knochenpartien nach innen hervorgedrängt. Der Körper des Keilbeins ist hervorgewölbt, verdünnt, an mehreren Stellen ist die dünne Knochenlamelle vollständig zerstört, so dass hier die sulzige ödematöse Schleimhaut frei vorliegt. In der rechten mittleren Schädelgrube findet sich im Bereich des grossen Keilbeinflügels nach hinten von der Pyramide, nach vorn von der Fissura superior begrenzt, ein kleinwallnussgrosser Knochendefect, dessen Ränder abgestumpft und glatt sind. In dem Sinus sphenoidalis die Schleimbaut zum Theil eitrig gefärbt und daneben ein kleinwallnussgrosser gelber, gallertig weicher Polyp, der nach der Nasenhöhle hin einen festeren Zusammenhang mit dem Gewebe zeigt. Trennung der Schädelbasis durch einen Sagittalschnitt; es präsentiren sich nun die erweiterten und mit Gallertpolypen ausgekleideten Reilbeinhöhlen.

Die übrige Körpersection stellte noch fest: Bronchitis catarrhalis, Hyperämie und Oedem der Lungen, Splenitis acuta.

Epikrise. Wegen des anatomischen Interesses, welches er darbietet, haben wir diesen Fall intracranieller Complication einer allgemeinen Nebenhöhleneiterung der Nase ausführlicher angeführt, obwohl er nicht otologischer Natur ist. Der Weg, auf welchem die terminale Meningitis purulenta zu Stande gekommen ist, war nicht zu ersehen, da das Sectionsergebniss (s. dieses) mehrere Möglichkeiten offen lässt.

17. Fritz K., 46 Jahre alt, a. Z. Aufgenommen am 28. Juli 1898, gestorben am 28. Januar 1899. Rechtsseitige Ohreiterung in der Kindheit acquirirt; 20 Jahre lang sei das $\mathrm{Ohr}$ dann trocken gewesen. Seit den letzten fünf Jahren besteht die Eiterung ununterbrochen fort. Oft im Anschluss an Borsäurepulvereinblasungen Sistirung des Ausflusses und, ,schweren Kopl". Nach Wiedereintritt des Ausflusses der Kopf wieder frei. In der letzten Zeit vor der Aufnahme viel Eingenommenheit des Kopfes, zwei mal früh $\mathrm{Schwindel-}$ anfälle. Nie Erbrechen, aber zeitweise geringe Nansea. Wiederholt Schmerzen im rechten Obr gehabt. In den letzten Jahren viel chronisch rheumatische Beschwerden gehabt.

Status praesens rom 28. Juli 1898: Grosser, kräftiger Mann, Herz und Lunge gesund. Objectiv keine Gleichgewichtsstörungen nachweisbar. Pupillen gleich weit, resp. eng, reagiren gut auf Lichteinfall. Puls 102 regelmässig. Körpergewicht 72,2 Kilo. Urin ohne Zucker und Eiweiss.

Umgebung des Ohres: Narben hinter dem Ohr (früherer Spontandurchbruch oder Incision?)

Gehörgang und Trommelfellbefund vom 28. Mai. (Erste Untersuchung). R.: Gehörgangshaut macerirt; in der Tiefe zwischen Borsäurepulverkrusten ein dicker Eitertropfen vou oben kommend. Nach Entfernung der Krusten eine von oben kommende Granulation sichtbar. Am 28. Juli oben der Hammerstummel sichtbar. L. normal.

Hörprüfung: Leise Flüstersprache rechts handbreit, links 6 Meter. C. vom Scheitel nicht lateralisirt; Fis rechts kaum herabgesetzt. Temp. am 28. Juli früh $37,2^{\circ}$.

28. Juli. Totalaufmeisslung rechts: Weichtheile auf dem Planum mässig oedematös. Die ganzen Mittelohrräume erfüllt mit einzelnen Jauche enthaltenden Zellen. Im Antrum grosses zerfallenes Cholesteatom. Hammer und Amboss rudimentär. Oben stürzt vom Tegmen antri aus Jauche zwischen Dura and Knochen hervor. Dura, theilweise schon freiliegend, wird in der Ausdebnung des ganzen Tegmen antri und tympani freigelegt。 
Ebenso der Sinus sigm. freigelegt, welcher grünlich grau verfärbt erscheint. Da eine Fistel oder erweichte Partie in der Dura nicht gefunden wird, wird von einer Spaltung der letzteren Abstand genommen. Fistel im horizontalen Bogengange sondirbar, aber kein Eiter daraus hervorquelllend. Spaltung etc.

10. Juli. Verlauf bisher reactionslos; starker Foetor bedingt durch drei nekrotische Knochenstückchen, welche noch nachträglich aus dem hinteren unteren Theil der Paukenhöhle entfernt wurden. In der Zeit vom 19. August bis 6 September, also 19 Tage lang, ein Erysipelas migrans mit 4 Fieberexacerbationen entsprechend dem successiven Befallenwerden von Kopf, Rücken, Rückffäche der Oberschenkel, linkem Arm.

Während des Erisypels auffällige Trockenheit der Operationswunde; ein günstiger Einfuss auf den Heilungsverlauf der Wunde, wie wir thu in anderen Fällen beobachtet, hier indess nicht bemerkbar.

12. September. Hartnäckige Granulationsbildung am Dache der Wundhöble sowie vom medialen Theile der vorderen Gehörgangswand ausgehend.

12. December. Ein paar mal nach Katheter Eiter aus der Tubengegend vorgekommen. Seit zwei Tagen "erkältet". "Rheumatische" Schmerzen auf der Brust, rechtsseitiger Kopfschmerz; besondere Druckscbmerzpunkte in der rechten Schlafen- und Warzenfortsatzgegend. Temp. Mittags $38,4^{\circ}$. Zwischen Granulationen ein kleiner Recess im hinteren oberen Theile der Operationswunde mit Eiterverhaltung darin. Auftamponiren des Recesses. Temp. Abends $38,4^{\circ}$, Puls 84.

In der folgenden Nacht nur bis 12 Uhr gut geschlafen, dann wieder Kopfschmerzen; Zunge belegt. Temp. in der Nacht $37,9^{\circ}, 37,0^{\circ}$.

14. December. Höchste Temp. gestern $37,9^{\circ}$. Noch viel Schmerzen. Periostitische Anschwellung vom hinteren Wundrande an nach dem Occiput zu.

15. December. Fieberfrei. Schmerz unverändert.

17. December. C. vom Seheitel nach links, Flüsterworte rechts unsicher direct. Fis 4 rechts nur bei stärkstem Nagelanschlag. Kein Schwindel.

18. December. Fieberfrel, immer noch Schmerzen. R. Facialparese der unteren Aeste; Augenhintergrund normal.

27. December. Seit drei Tagen wegen der Schmerzen mit jetzt deatlich neuralgiformem Charakter Abends Morph. subcutan. Fieberfrei. Puls zwischen 78 und 99 . Augenhintergrund normal.

12. Januar: Die Schmerzen bisher unverändert, die Facialisparese vom 7. Januar an zurückgehend. Leise Flüstersprache rechts unsicher direct. c. vom Scheitel nach links. Fis 4 rechts herabgesetzt. Temp. nicht über $37,9^{\circ}$, im Mittel $37,5^{\circ}$.

15. Januar. Letzte Spur der Facialparese noch vorhanden. Im 21. Lebensjahre Olcus am Frenulum penis gehabt, desgleichen ein ,Horn an der Stirn", welches spontan wieder geheit ist. Zwei, speckige Geschwure" am linken Unterarm gehabt, die der behandelnde Arzt als ,sonderbar" erklät hat, welche aber nach 14 Tagen wieder heilten. Kal. jodat. in Pillenform, pro die 2 gr. verabreicht.

18. Januar. Die rechtsseitigen Kopfschmerzen werden intensiver; Temperaturen hochnormal, objectiv an Wunde und Umgebung keine Veränderungen. nungen.

19. Januar. Gestern Abend $38,8^{\circ}$, sonst keine verdüchtigen Erschei-

$\mathrm{Z}$ weite Operation: Wieder vollkommene Freilegung der Mittelohrräume. In der ziemlich compacten aber nicht osteosklerotischen Spitze ein höchstens erbsengrosser Herd von grauer, cholestearinglänzender Schleimhaut ansgekleidet. Die Dura von lappigen fibrösen Granulationen bedeckt. Das hinter der abnorm tiefstehenden Dura liegende Antrum ist mit schmutzigen Granulationsmassen erfullt, seine morsche, mediane Wand wird zum grossen Theil entfernt. Mit der Sonde dringt man von hier aus tief in die Labyrinthhöhle hinein, ohne dass Kiter aus derselben hervorquillt. Nach Auskratzung der die Paukenhöhle theilweise erfüllenden Gramulationen liegt das verfärbte Promontorium frei, auf seiner Höhe eine Fistel sichtbar, durch welche die Sonde in die Labyrinthhöhle eindringt, ohne dass Eiter nachquillt. Trotzdem 
breite Erweiterung der Fistel. Tamponade der grossen Operationshöhle ohne Anlegung von Nähten.

20. Januar. Gestern Abend Temp. 38,5 ${ }^{\circ}$. Angina follic. Schmerz geringer, Kopf freier, ,die tiofen bohrenden Schmerzen sind fort".

21. Januar. Nacht leidlich. Im Uebrigen Status idem.

22. Januar. Tiefe Schmerzen geringer. Von gestern Nachmittag an Klage über diffuse Kopfscbmerzen. Unruhe, Abends Erbrechen nach dem Genusse von Caviar, der" ihm, ,widerlich" ist. Temp. bis $38^{\circ}$.

23. Januar. "Tiefe" Schmerzen gar nicht. Kopfschmerzen im ganzen Kopfe. Nachmittags Nausea.

24. Januar. Seit gestern Abend ganz fieberfrei; Puls nichts Abnormes zeigend; Nachts wegen der Kopfschmerzen kaum geschlafen. Heute Morgen bei nüchternem Magen erbrochen.

25. Januar. Viel Kopfschmerzen vom Hinterkopf ausgehend und nach dem Schädel ausstrahlend. Erbrechen. Beim Erwachen "steht jedesmal die rechte Wand tiefer und ich liege schief". Fieberfrei $\left(36,6^{\circ}\right)$, Puls 66 .

26. Januar. Temp. gestern Abend $36,7^{\circ}$, heute Morgen $36,6^{\circ}$, Puls 57. Seit gestern Abend Doppelbilder übereinander stehend, Kopfschmerzen heute etwas geringer.

27. Januar. Gestern Abend Temp. 36, $4^{\circ}$, Puls ca. 56-58. Zeitweise nicht ganz klar. Leichte mussitirende Delirien. Motilität und Sensibilität intact. Infolge der leichten Somnolenz klagt er nicht mehr über Kopfschmerzen. In der Nacht soll er nach der Aussage seiner bei ihm wachenden Gattin wiederholt durch Fassen mit der Hand nach dem Kopfe seinem Kopfschmerz Ausdruck gegeben haben. Keine Nausea mehr geklagt, aber seit den letzten Tagen absoluter Widerwille gegen jegliche Speisen. Seit heute Morgen 6 Uhr nach Aussage der Fran soporös, auch soll er mehrere Male "mit dem ganzen Körper gezuckt haben".

$73 / 4$ Uhr morgens: Tiefster Sopor, an Koma grenzend. Rechte Pupille etwas grösser als die linke, Reaction auf Lichteinfall träge, aber noch deutlich. Reagirt noch beim Stechen des Armes, der Hände und der Fusssoblen mit der Nadel.

11 Uhr Operative Entleerung eines rechtsseitigen Kleinhirnabscesses im tiefsten Koma. Flockenlesen auf dem Operationstisch. Ohne Narkose operirt.

Befund: Die Schädeldecke sehr dick; bei einzelnen Meisselschlăgen convulsivische Zuckungen des linken Armes und Beines, auch des rechten Beines. Spannung der freigelegten Dura erhöht. Beim Einschneiden der Dura quillt die Hirnmasse hervor. Drei mal mit dem Scalpell in $3 \mathrm{~cm}$ Tiefe eingedrungen, ohne auf Eiter zu stossen. Schliesslich noch einmal mit der Kornzange 6-7 cm tief in der Richtung nach der Pyramidenspitze vorgedrungen, dabei etwa drei Esslöffel stinkenden Eiters entleert. Ausspülung der Abscesshöhle mit Borsäurelösung; Drain.

Nach der Operation Steigerung der Temperatur auf $38,6^{\circ}$ (Nachmittags), dana $37,8^{\circ}$, Puls 90-96, tiefes Koma, Flockenlesen. In der Nacht rom 27. zum 28. noch einige Male geschluckt und coordinirte Bewegungen gemacht, z. B. überlaufende Milch vom Barte abgewischt.

28. Januar. Früh $1 / 28$ Uhr beginnt das Trachealrasseln. Rechte Pupille eng, linke ad maximum erweitert.

12 Uhr Exitus letalis.

Auszug aus dem Sectionsprotokoll (Kopfsection):

Leichte Trübungen der Pia; hie und da Hirnwindungen abgeplattet. Etwas vermehrte klare Flüssigkeit in den Hirnventrikeln. Keine eitrige Meningitis. Wallnussgrosser Abscess im rechten Kleinhirn, von Abscessmembran eingeschlossen. Farbe des Abscesseiters grüngelb. Die umgebende Hirnsubstanz in 2-3 mm Dicke mit Extravasaten durchsetzt. Die peripher davon gelegene Hirnsubstanz nicht erweicht, sondern fest. Beim Herausnehmen des Kleinhirns riss die an der Rückfläche der Pars petrosa des Schläfenbeines angewachsene Dura mit der Abscesswand ein, dabei entleert sich ein Schuss Eiter. Wo die Verwachsung an der Pars petrosa festgesessen hatte, liess sich nachher 
nicht genau feststellen, wabrscheinlich aber in der Gegend der Mündung des Aquaeductus vestibuli. In den grossen Basalsinus überall frisches Gerinnsel. Das Drain lag in der Abscesshöhle, aber es war noch viel Eiter darin zurückgeblieben.

Labyrinth höh le voll Granulationen und Eiter. Auch in der Schnecke Eiter. Die Knochenoberfläche der Pyramide geröthet und nicht von normaler Glătte.

Epikrise: Es erseheint uns zweekmässig, bei der retrospectiven Betrachtung dieses Falles uns an die chronologische Reihenfolge der einzelnen uns entgegentretenden abnormen Erscheinungen zu halten. Bei der Aufnahme des Patienten war kein Symptom vorhanden, welches an die Möglichkeit des sehon Vorhandenseins einer intracraniellen Complieation denken liess. Die von ihm angegebenen zwei Schwindelanfälle, sowie geringe Nausea im Verein mit der Functionsprüfung liessen uns nur an das Vorhandensein irgend einer Labyrinthveränderung denken, deren anatomisehe Natur zunächst unbekannt blieb. Dass in der That das innere $\mathrm{Ohr}$ nicht intact war, wurde bei der zuerst vorgenommenen Totalaufmeisslung sichergestellt: im horizontalen Bogen gange fand sich eine Fistelöffnung, aus welcher aber beim Sondiren kein Eiter hervorquoll. Wir glaubten uns somit zu der Annahme berechtigt, dass der chronische Erkrankungsprocess im inneren Ohre bereits seinen Abschluss gefunden habe, hatten wir es doch hier mit einem Befunde zu thun, der uns nicht selten bei der Totalaufmeisslung: entgegentritt and gewöhnlich für den weiteren Verlauf belanglos ist.

Der Verlauf nach der Operation war in den nächsten Wochen nicht beunruhigend; ein hartnäckiges Wandererysipel wurde gut iiberstanden, die Ausheilung der Operationswunde wollte indess keine rechten Fortschritte machen. Dieses Stadium der zögernden Heilung, in welchem Patient keinerlei Beschwerden und keine Störung des Allgemeinbefindens darbot, wurde im 2. Drittel des 5. Monats nach der Operation abgelöst durch ein Stadium, dessen wesentlichste Signatur mehr oder minder heftige Kopfsehmerzen auf der operirten Seite, leichte Temperatursteigerungen, leichte Störung des Allgemeinbefindens war. Der locale Ohrbefund liess zunächst an Eiterretention denken, welche ja anch in der That bestand. Als aber nach Beseitigung der Eiterverhaltung das Krankheitsbild sich nicht änderte, die Schmerzen allmählich einen intensiveren und bohrenden Charakter annahmen, die leichten Fieberbewegungen fortbestanden, periostitisehe Schwellung am hinteren Wundrande hinzutrat, da wurde es immer wahr- 
scheinlicher, dass eine intracranielle Complication im Entstehen oder schon vorhanden sei; für die Bestimmung der Natur und des Sitzes derselben boten sich allerdings keinerlei objective Anhaltspunkte dar. Die dem erkrankten Ohre entsprechende leichte, rasch wieder schwindende Facialislähmung konnte zur topischen Diagnostik nicht verwandt werden, der Augenhintergrund blieb normal; das von der ersten Hörprüfung abweichende Resultat einer erneuten Functionsprüfung legte uns allerdings den Gedanken nahe, dass ein friseher entzündlicher Process auf dem Wege des Labyrinths fortgeschritten sei, ein Umstand, der uns an die Möglichkeit des Vorhandenseins eines sogenannten tiefen, von einer Labyrintheiterung her inducirten Extraduralabscesses denken liess. Dass der Schmerz ein einfach neuralgiseher sei, haben wir trotz seines zeitweise neuralgiformen Charakters und trotz des Findens bestimmter mit Nervenaustrittstellen zusammenfallender Druckpunkte nie ernstlich erwogen, ebenso liessen wir den Gedanken an das Bestehen einer luetisehen Schädelknochenerkrankung, auf welche uns eine nachträgliche anamnestische Angabe führte, rasch wieder fallen, als eine eingeleitete specifische Therapie nutzlos blieb. Dies war die Sachlage, als wir uns dureh die qualvollen, trotz reichlicher Anwendung von Narkoticis jede Nachtruhe raubenden Schmerzen des Kranken, sowie durch das Ansteigen der Temperatur auf $38,8^{0}$ gedrängt, zu dem zweiten probatorischen operativen Eingriffe entschlossen. Das Resultat dieser zweiten Operation befriedigte insofern, als wir in der noch vorbandenen ausgedehnten Knochenerkrankung, insbesondere auch der Labyrinthkapsel, die Ursache des tiefen bohrenden Sehmerzes in einer Labyrintbnekrose gefunden zu haben glaubten.

Der den Schmerz mildernde Effect dieses Eingriffes war indess nur ein schnell vorübergehender. Bald änderte sich das Krankheitsbild so, dass es möglich war, mit grosser Wabrscheinlichkeit die Diagnose eines Kleinhirnabscesses zu stellen. Die Kopfschmerzen wurden mehr auf den Hinterkopf und als von hier auf den Scheitel ausstrahlend verlegt, Erbrechen trat mehrfach hinzu, eine ausgesprochene Pulsverlangsamung und Augenmuskelstörungen stellten sich ein, die Temperatur wurde subnormal. Mit Rücksicht auf den neben diesen Erscheinungen bestehenden Labyrinthbefund kam als Diagnose in erster Linie Cerebellarabscess in Betracht. Diese Diagnose fand durch die in bereits tiefem Koma des Kranken vorgenommene Trepanation ihre volle 
Bestätigung. Der aufgefundene Kleinhirnabscess sass in der Nähe der Pyramidenspitze und ist, wie der Sectionsbefund des Schläfenbeines mit Sicherheit erwies, durch die vorhanden gewesene Labyrintheiterung inducirt worden, wobei jedenfalls der Aquaeductus vestibuli die Rolle des Entzündungsfortleiters gespielt hat. Das Sectionsergebniss ist nach mehreren Richtungen interessant; zunächst überraschte uns das Fehlen einer Meningitis, hatten uns doch die mussitirenden Delirien, das Flockenlesen, die Steigerung der Temperatur auf $38,6^{0}$ nach der Operation, das Vorhandensein einer terminalen eiterigen Meningitis erwarten lassen. Aber auch von einer serösen Meningitis war keine Rede; wenn auch die klare Ventrikelflüssigkeit mässig vermehrt war, so konnte man von einem Hydrocephalus internus doch nicht sprechen, wiewohl die stellenweise deutliche Abflachung der Hirnwindungen vor Herausnahme des Gehirns für das Vorhandensein eines solchen zu sprechen schien.

Es bleibt die wichtige Frage übrig, welches Moment denn die unmittelbare Todesursache gewesen ist.

Dass der Patient durch Lähmung des Athmungscentrums in Folge von Druck des Abscesses auf dasselbe gestorben ist, kann ausgeschlossen werden, wenn auch hinter dem in die Abscesshöhle eingeführten Drain sich bei der Section eine gewisse Eiterverhaltung vorfand. Dje Annahme der diabetischen oder urämischen Natur des terminalen Koma's ist unzulässig, weil der kurze Zeit vor dem Tode untersuchte Urin zucker- und eiweissfrei war. Es bleibt für uns somit zur Erklärung nur die Annahme übrig, dass es sich um ein toxisches Koma gehandelt hat. Diese Auffassung von der Herkunft des Koma's in unserem Falle erscheint uns desshalb nicht unberechtigt, weil wir auch in Fällen von Leptomeningitis purulenta den Eintritt des Todes im Koma geseben haben, wo der eiterige Belag ein äusserst spärlicher war, wo lebenswichtige Theile des Gehirns nicht in das Bereich der Entzündung mit hineingezogen waren und wo auch der Gedanke einer allgemeinen Druckwirkung auf das Gehirn als Ursache des terminalen Koma's durch den Sectionsbefund ausgeschlossen war. 
Jahresbericht d. Kgl. Universitäts-Ohrenklinik zu Halle a. S. 1895/99. 171

Mastoidoperationen.

\begin{tabular}{|c|c|c|c|c|c|c|c|}
\hline 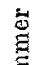 & Name & $\approx$ & Diagnose, & $\begin{array}{r}\mathrm{Da} \\
\text { der Beh }\end{array}$ & $\begin{array}{l}\text { uer } \\
\text { andlung }\end{array}$ & Besnltat & Bemerkuncen \\
\hline$\tilde{E}$ & & $=$ & resp. Bet & $\begin{array}{l}\text { in der } \\
\text { Elinik }\end{array}$ & tuberhaupt & & \\
\hline 1 & $\begin{array}{l}\text { Theodor } \\
\text { Röhr. T. }{ }^{1} \text { ) }\end{array}$ & 36 & Links: Cholesteatom. & 3 Mon. & 3 Mon. & Gebeilt. & - \\
\hline 2 & $\begin{array}{l}\text { Fran } \\
\text { Zeidler. T. }\end{array}$ & 36 & Links: Cholesteatom. & 11 Tage. & - & $\begin{array}{l}\text { Nicht } \\
\text { geheilt. }\end{array}$ & $\begin{array}{l}\text { Fistel im hor. } \\
\text { Bogengang u. } \\
\text { Cholest.darin. }\end{array}$ \\
\hline 3 & $\begin{array}{l}\text { Hans } \\
\text { Hiller. } \mathrm{T} .\end{array}$ & 8 & Links: Cholesteatom. & 8 Tage. & 3 Mon. & Gebeilt. & $\begin{array}{l}\text { Sinusoperat., } \\
\text { Jugul.-Onter- } \\
\text { bindung. }\end{array}$ \\
\hline 4 & $\begin{array}{l}\text { Reinhold } \\
\text { Zack. T. }\end{array}$ & 15 & Reohts: Chron. Caries. & 1 Mon. & 3 Mon. & Geheilt. & - \\
\hline 5 & $\begin{array}{l}\text { Valent. } \\
\text { Badina. T. }\end{array}$ & 21 & Links: Cholesteatom. & 4 Mon. & 4 Mon. & $\begin{array}{l}\text { d. Bhdlg. } \\
\text { entzogen. }\end{array}$ & - \\
\hline 6 & $\begin{array}{c}\text { Reinbold } \\
\text { Wiebecke. T. }\end{array}$ & 25 & $\begin{array}{l}\text { Rechts: Caries m. Cho- } \\
\text { Iesteatom. }\end{array}$ & $3^{1 / 2}$ Mon. & $31 / 2$ Mon. & $\begin{array}{l}\text { Noch in } \\
\text { Behndlg. }\end{array}$ & $\begin{array}{l}\text { In der Dépen- } \\
\text { dance. }\end{array}$ \\
\hline 7 & $\begin{array}{c}\text { Paul } \\
\text { Rippe. } \mathrm{T} .\end{array}$ & 10 & $\begin{array}{l}\text { Links: Caries m. Cho- } \\
\text { lesteatom. }\end{array}$ & $\begin{array}{l}\text { circa } \\
3 \text { Mon. }\end{array}$ & $\begin{array}{l}\text { circa } \\
3 \mathrm{Mon} .\end{array}$ & Geheilt. & - \\
\hline 8 & Rob. Apel. T. & 18 & $\begin{array}{l}\text { Links: Caries m. Cho- } \\
\text { lesteatom. }\end{array}$ & $11 / 2$ Mon. & $\begin{array}{l}\text { circa } \\
2 \text { Mon. }\end{array}$ & Geheilt: & - \\
\hline 9 & $\begin{array}{c}\text { Clara } \\
\text { Schmidt. } \mathrm{T} .\end{array}$ & 10 & Links: Caries. & $\begin{array}{l}\text { circa } \\
4 \text { Mon. }\end{array}$ & - & Ungeheilt. & $\begin{array}{l}\text { Stricturope- } \\
\text { ration. }\end{array}$ \\
\hline 10 & $\begin{array}{c}\text { Otto } \\
\text { Wiesener. T. }\end{array}$ & 13 & Links: Caries. & 18 Tage. & $\begin{array}{l}\text { circa } \\
2 \text { Mon. }\end{array}$ & Geheilt. & - \\
\hline 11 & $\begin{array}{c}\text { Meta } \\
\text { Schwamm- } \\
\text { baeb. T. }\end{array}$ & 7 & $\begin{array}{l}\text { Rechts: Caries u. Cho- } \\
\text { lesteatom. }\end{array}$ & $2 \ell$ Tage. & 8 Mon. & Geheilt. & - \\
\hline 12 & $\begin{array}{l}\text { Frieda } \\
\text { Hans. T. }\end{array}$ & 40 & $\begin{array}{l}\text { Nekrose der hinter. Ge- } \\
\text { börgangswand. }\end{array}$ & & - & $\begin{array}{l}\text { unbe- } \\
\text { kannt. }\end{array}$ & - \\
\hline 13 & $\begin{array}{c}\text { Ernst } \\
\text { Meger. T. }\end{array}$ & 17 & Reohts: Chron. Caries. & 1 Mon. & - & Geheilt. & - \\
\hline 14 & $\begin{array}{l}\text { Elisabeth } \\
\text { Erfurt. T. }\end{array}$ & 5 & Rechts: Chron. Caries. & 1 Mon. & 一 & $\begin{array}{l}\text { Nicht } \\
\text { geheilt. }\end{array}$ & - \\
\hline 15 & $\begin{array}{c}\text { Marie } \\
\text { Mansfeld. }\end{array}$ & 13 & $\begin{array}{l}\text { Rechts: Diffuse Mastoi- } \\
\text { ditis. }\end{array}$ & - & - & Geheilt. & - \\
\hline 16 & $\begin{array}{c}\text { Otto } \\
\text { Wagner. T. }\end{array}$ & 10 & Links: Chron. Caries. & $\begin{array}{c}\text { circa } \\
21 / 2 \text { Mon. }\end{array}$ & $\begin{array}{c}\text { cirea } \\
21 / 2 \text { Mon. }\end{array}$ & Geheilt. & - \\
\hline 17 & $\begin{array}{l}\text { Albert Ruhle- } \\
\text { mann. } T \text {. }\end{array}$ & 11 & Rechts: Ohron. Caries. & 2 Mon. & $\begin{array}{l}\text { circa } \\
2 \text { Mon. }\end{array}$ & Geheilt. & - \\
\hline 18 & $\begin{array}{c}\text { Paul } \\
\text { Larisch. T. }\end{array}$ & 2 & Links: Chron. Caries. & $11 / 2$ Mon. & - & $\begin{array}{l}\text { unbe- } \\
\text { kannt. }\end{array}$ & - \\
\hline 19 & $\begin{array}{l}\text { Willi } \\
\text { Hartich. }\end{array}$ & $\begin{array}{l}1 / 1 / 2 \\
\text { Jahr }\end{array}$ & Rechts: Acute Caries. & 7 Tage. & $\begin{array}{l}\text { circa } \\
11 / 2 \text { Mon. }\end{array}$ & Geheilt. & - \\
\hline 20 & $\begin{array}{l}\text { Franz } \\
\text { Meylink. }\end{array}$ & 7 & $\begin{array}{l}\text { Rechts: Acutes Em- } \\
\text { pyem. }\end{array}$ & $2^{1 / 2}$ Mon. & 21/2 Mon. & $\begin{array}{l}\text { unbe- } \\
\text { kannt. }\end{array}$ & - \\
\hline 21 & Derselbe. & 7 & Links: Aont. Empyem. & & & $\begin{array}{l}\text { unbe- } \\
\text { kanut. }\end{array}$ & - \\
\hline 22 & $\begin{array}{l}\text { Heinr. Wald- } \\
\text { vogel. T. }\end{array}$ & 46 & Rechts: Chron. Caries. & 3 Mon. & $\begin{array}{l}\text { circa } \\
3 \text { Mon. }\end{array}$ & Geheilt. & - \\
\hline
\end{tabular}

1) Bedeutet: Totalaufmeisselung. 


\begin{tabular}{|c|c|c|c|c|c|c|c|}
\hline 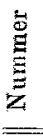 & Name & 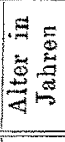 & $\begin{array}{l}\text { Diagnose, } \\
\text { resp. Befund }\end{array}$ & $\begin{array}{l}\quad \text { Da } \\
\text { der Beb } \\
\text { in der } \\
\text { Klinik } \\
\end{array}$ & $\begin{array}{l}\text { aer } \\
\text { andlung } \\
\text { uberhaupt }\end{array}$ & Resultat & Bemerkungen \\
\hline 23 & $\begin{array}{l}\text { Hermann } \\
\text { Ladewig. } \mathrm{T} \text {. }\end{array}$ & 36 & Rechts: Cholesteatom. & - & - & Geheilt. & - \\
\hline 24 & $\begin{array}{c}\text { Otto Narden- } \\
\text { bach. T. }\end{array}$ & 8 & Links: Chron. Caries. & 1 Mon. & 4 Mon. & Geheilt? & - \\
\hline 25 & $\begin{array}{c}\text { Hermann } \\
\text { Mauer. T. }\end{array}$ & 10 & Rechts: Cholesteatom. & $\begin{array}{l}\text { ciroa } \\
3 \text { Mon. }\end{array}$ & $\begin{array}{c}\text { circa } \\
3 \text { Mon. }\end{array}$ & Geheilt. & - \\
\hline 26 & $\begin{array}{l}\text { Karl Fichen- } \\
\text { topf. T. }\end{array}$ & 33 & Reohts: Caries. & $3^{1 / 2}$ Mon. & $3^{1 / 2}$ Mon. & $\begin{array}{l}\text { unbe- } \\
\text { kannt. }\end{array}$ & Strictur. \\
\hline 27 & $\begin{array}{l}\text { Christian } \\
\text { Dabne. }\end{array}$ & 65 & Reohts: Aent. Empyem. & 2 Mon. & 2 Mon. & Geheilt. & $\begin{array}{l}\text { Extradural- } \\
\text { abscess. }\end{array}$ \\
\hline 28 & $\begin{array}{c}\text { Paul } \\
\text { Walther. T. }\end{array}$ & 8 & Links: Chron. Caries. & $11 / 2$ Mon. & - & $\begin{array}{l}\text { unbe- } \\
\text { kannt. }\end{array}$ & Osteosklerose. \\
\hline 29 & $\begin{array}{c}\text { Minna } \\
\text { Schmidt. T. }\end{array}$ & 18 & $\begin{array}{l}\text { Rechts: Caries u. Cho- } \\
\text { lesteatom. }\end{array}$ & 9 Tage. & 9 Tage. & Gestorben. & Meningitis. \\
\hline 30 & Carl Ehrt. T. & 21 & Rechts: Caries. & 21/2 Mon. & - & $\begin{array}{l}\text { unbe- } \\
\text { kannt. }\end{array}$ & Strictur. \\
\hline 31 & $\begin{array}{l}\text { Karl Teich- } \\
\text { mann. }\end{array}$ & 62 & $\begin{array}{l}\text { Rechts: Acutes Em- } \\
\text { pyem. }\end{array}$ & 1 Mon. & - & Geheilt. & 一 \\
\hline 32 & $\begin{array}{c}\text { Karl } \\
\text { Meissner. T. }\end{array}$ & 45 & $\begin{array}{l}\text { Rechts: Nekrose d.vor- } \\
\text { der. Gehörgangswand. }\end{array}$ & 1 Mon. & - & Geheilt. & - \\
\hline 33 & $\begin{array}{l}\text { Emilie } \\
\text { Büttner. T. }\end{array}$ & 15 & Links: Cholesteatom. & $11 / 2$ Mon. & - & Geheilt. & - \\
\hline $3 \pm$ & $\begin{array}{l}\text { Karl } \\
\text { Book. T. }\end{array}$ & 14 & Reehts: Chron. Caries. & 6 Tage. & 6 Tage. & Gestorben. & $\begin{array}{l}\text { Sinusoperat. } \\
\text { Unterbindg. } \\
\text { der Jugul. }\end{array}$ \\
\hline $3 \tilde{3}$ & $\begin{array}{l}\text { Hermann } \\
\text { Reichardt. } \mathrm{T} \text {. }\end{array}$ & 17 & $\begin{array}{l}\text { Rechts: Chron. Caries } \\
\text { u. Cholestcatom. }\end{array}$ & 23 Tage. & 23 Tage. & Gestor ben. & $\begin{array}{l}\text { Hirnabscess; } \\
\text { Meningitis. }\end{array}$ \\
\hline 36 & $\begin{array}{l}\text { Louis } \\
\text { Frick. T. }\end{array}$ & 15 & $\begin{array}{l}\text { Links: Chron. Caries } \\
\text { u. Cholesteatom. }\end{array}$ & $\begin{array}{l}\text { circa } \\
3 \text { Mon. }\end{array}$ & $\begin{array}{l}\text { circa } \\
3 \text { Mon. }\end{array}$ & $\begin{array}{l}\text { unbe- } \\
\text { kannt. }\end{array}$ & - \\
\hline 37 & Otto Wolf. T. & 5 & Rechts: Nekrose. & 3 Mon. & 3 Mon. & $\begin{array}{l}\text { unbe- } \\
\text { kannt. }\end{array}$ & - \\
\hline 38 & $\begin{array}{l}\text { Mädchen, } \\
\text { Kaiser. T. }\end{array}$ & 11 & Rechts: Cholesteatom. & 21/2 Mon. & 21/2 Mon. & Gebeilt. & $\begin{array}{l}\text { Pachym. pu- } \\
\text { rul. externa. }\end{array}$ \\
\hline 39 & $\begin{array}{l}\text { Otto } \\
\text { Göbel. }\end{array}$ & 6 & $\begin{array}{l}\text { Links: Aeute Schar- } \\
\text { lachotitis. }\end{array}$ & - & - & $\begin{array}{l}\text { Nooh in } \\
\text { Behandlg. }\end{array}$ & $\begin{array}{l}\text { Sinusoperat,; } \\
\text { Unterbindg.; } \\
\text { der V. jugul. }\end{array}$ \\
\hline 40 & Derselbe. & 6 & $\begin{array}{l}\text { Rechts: Acute Mastoi- } \\
\text { ditis. }\end{array}$ & 6 Woch. & 6 Woch. & Geheilt. & - \\
\hline 41 & $\begin{array}{l}\text { Robert Naun- } \\
\text { dorf. T. }\end{array}$ & 19 & Rechts: Cholesteatom. & 1'/2 Mon. & - & Geheilt. & - \\
\hline 42 & $\begin{array}{c}\text { Paul } \\
\text { Schlegel. T. }\end{array}$ & 12 & Links: Chron. Caries. & 1//2 Mon. & 一 & Geheilt. & - \\
\hline 43 & $\begin{array}{l}\text { Franz } \\
\text { Heoht. T. }\end{array}$ & 9 & Links: Cholesteatom. & 1 Mon. & - & $\begin{array}{l}\text { unbe- } \\
\text { kannt. }\end{array}$ & $\begin{array}{l}\text { Pachym. pu- } \\
\text { rul. externa. }\end{array}$ \\
\hline 44 & $\begin{array}{c}\text { Agnes } \\
\text { Gunther. } T \text {. }\end{array}$ & 14 & Rechts: Chron. Caries. & 4 Tage. & 4 Tage. & Gestorben. & Pyämie. \\
\hline 45 & $\begin{array}{l}\text { Alfred } \\
\text { Krause. T. }\end{array}$ & 3 & Links: Chron. Nekrose. & 2 Mon. & 2 Mon. & Gestorben. & $\begin{array}{l}\text { In die medi- } \\
\text { on. Rlinik } \\
\text { verlegt. } \\
\text { Tuberculose. }\end{array}$ \\
\hline
\end{tabular}


Jahresbericht $d$. Kgl. Universitäts-Ohrenklinik zu Halle a. S. 1898/99. 173

\begin{tabular}{|c|c|c|c|c|c|c|c|}
\hline$\stackrel{\Xi}{E}$ & Yame & $\approx \sigma$ & Diagnose, & $\begin{array}{r}\mathrm{Da} \\
\text { der } \mathrm{Beh}\end{array}$ & $\begin{array}{l}\text { uer } \\
\text { andlung }\end{array}$ & Recrilt tot & Remerk nnoen \\
\hline$\stackrel{\Xi}{\xi}$ & Arasero & 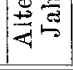 & resp. Befund & $\begin{array}{l}\text { in der } \\
\text { Klinik }\end{array}$ & iiberhaupt & & ont \\
\hline 46 & $\begin{array}{l}\text { Marie } \\
\text { Hotze. T. }\end{array}$ & 15 & Reehts: Chron. Caries. & $11 / 2$ Mon. & - & $\begin{array}{l}\text { unbe- } \\
\text { kannt. }\end{array}$ & - \\
\hline 47 & $\begin{array}{l}\text { Hulda Kud- } \\
\text { deritseh. T. }\end{array}$ & 26 & Links: Cholesteatom. & 4 Mon. & 4 Mon. & Geheilt. & - \\
\hline 48 & $\begin{array}{l}\text { Wilhelm } \\
\text { Richter. T. }\end{array}$ & 26 & Links: Chron. Caries. & 4 Mon. & 4 Mon. & Geheilt. & $\begin{array}{l}\text { Extradural- } \\
\text { absoess. }\end{array}$ \\
\hline 49 & $\begin{array}{c}\text { Albert } \\
\text { Limburg. } \mathrm{T} .\end{array}$ & 38 & Links: Oholesteatom. & 23 Tage. & 23 Tage. & Gestorben. & $\begin{array}{l}\text { Kleinhirn- } \\
\text { abscess. }\end{array}$ \\
\hline 50 & $\begin{array}{c}\text { Gustay } \\
\text { Althaus. T. }\end{array}$ & 6 & Rechts: Cholesteatom. & 4 Mon. & - & $\begin{array}{l}\text { unbe- } \\
\text { kannt. }\end{array}$ & - \\
\hline 51 & $\begin{array}{l}\text { Hulda Kod- } \\
\text { deritsch. T. }\end{array}$ & 26 & $\begin{array}{l}\text { Rechts: Oaries u. Oho- } \\
\text { lesteatom. }\end{array}$ & 2 Mon. & 2 Mon. & Geheilt. & - \\
\hline 52 & $\begin{array}{l}\text { Frau } \\
\text { Wille. T. }\end{array}$ & 39 & Reohts: Chron. Caries, & 1 Mon. & - & $\begin{array}{l}\text { unbe- } \\
\text { kannt. }\end{array}$ & - \\
\hline 53 & $\begin{array}{l}\text { Therese } \\
\text { Osterwald. }\end{array}$ & $\begin{array}{l}3^{1 / 2} \\
\text { Jahr }\end{array}$ & Links: Caries. & - & - & $\begin{array}{l}\text { unbe- } \\
\text { kannt. }\end{array}$ & - \\
\hline 54 & $\begin{array}{l}\text { Frau } \\
\text { Gluth. } \mathrm{T} .\end{array}$ & 25 & $\begin{array}{l}\text { Reehts: Chron. Caries } \\
\text { u. Cholesteatom. }\end{array}$ & $一$ & $3 / 4$ Jahr. & Geheilt. & $\begin{array}{l}\text { Ambulato- } \\
\text { risch. }\end{array}$ \\
\hline 55 & $\begin{array}{c}\text { Oscar } \\
\text { Schmidt. } T .\end{array}$ & 21 & Diffuse Caries. & 1 Mon. & - & $\begin{array}{l}\text { unbe- } \\
\text { kannt. }\end{array}$ & $\begin{array}{l}\text { Eixtradural- } \\
\text { abscess. }\end{array}$ \\
\hline 56 & $\begin{array}{l}\text { Bertha } \\
\text { Ertel. T. }\end{array}$ & 11 & Reehts: Cholesteatom. & 10 Tage. & $\begin{array}{l}\text { circa } \\
4 \text { Mon. }\end{array}$ & Geheilt. & - \\
\hline 57 & $\begin{array}{l}\text { Clara } \\
\text { Schütze. T. }\end{array}$ & 4 & Rechts: Nekrose. & 7 Tage. & $\begin{array}{l}\text { circa } \\
5 \text { Mon. }\end{array}$ & Geheilt. & - \\
\hline 59 & $\begin{array}{l}\text { Hermann } \\
\text { Ohlberg. }\end{array}$ & 19 & $\begin{array}{l}\text { Rechts: Acute Eiterg. } \\
\text { Sinusthrombose. }\end{array}$ & 6 Mon. & 6 Mon. & $\begin{array}{l}\text { Nicht } \\
\text { geheilt. }\end{array}$ & $\begin{array}{l}\text { Sinusoperat.; } \\
\text { Jugul-Enter-- } \\
\text { bindung. }\end{array}$ \\
\hline 59 & Derselbe. T. & - & Rechts: Caries. & - & - & Geheilt. & Nachoperat. \\
\hline 60 & $\begin{array}{l}\text { Otto } \\
\text { Schmidt. }\end{array}$ & 20 & $\begin{array}{l}\text { Acute Scharlachmastoi- } \\
\text { ditis. }\end{array}$ & - & 3 Mon. & Geheilt. & Med. Klinik. \\
\hline 61 & $\begin{array}{l}\text { Otto Schnei- } \\
\text { der. T. }\end{array}$ & 2 & Rechts: Diffuse Caries. & - & 4 Mon. & Geheilt. & - \\
\hline 62 & $\begin{array}{c}\text { Robert } \\
\text { Ziegenhorn. }\end{array}$ & 20 & Links: Empyem. & 2 Mon. & - & Geheilt. & - \\
\hline 63 & $\begin{array}{c}\text { Simon } \\
\text { Israel. } \mathrm{T} .\end{array}$ & 39 & $\begin{array}{l}\text { Rechts: Chron. Caries } \\
\text { m. Cholesteatom. }\end{array}$ & $\begin{array}{l}\text { circa } \\
3 \text { Mon. }\end{array}$ & - & Geheilt. & Osteosklerose. \\
\hline 64 & Fise Mullez. & 13 & Links: Acut. Empyem. & 1 Mon. & - & Geheilt. & - \\
\hline 65 & $\underset{\text { Bodin. }}{\text { Karl }}$ & 18 & $\begin{array}{l}\text { Links: Caries u. Cho- } \\
\text { lesteatom. }\end{array}$ & 3 Mon. & 3 Mon. & $\begin{array}{l}\text { unbe- } \\
\text { kannt. }\end{array}$ & - \\
\hline $66^{2}$ & $\begin{array}{c}\text { Robert } \\
\text { Naundorf. } T .\end{array}$ & 19 & $\begin{array}{l}\text { Links: Caries u. Cho- } \\
\text { lesteatom. }\end{array}$ & 4 Mon. & 4 Mon. & Geheilt. & - \\
\hline 67 & $\begin{array}{c}\text { Gustay } \\
\text { Martin. T. }\end{array}$ & 19 & $\begin{array}{l}\text { Links: Acute Kiterung. } \\
\text { Caries. }\end{array}$ & 14 Tage. & 14 Tage. & Gestorben. & $\begin{array}{l}\text { Sinusthrom- } \\
\text { bose, Pyämie. }\end{array}$ \\
\hline 68 & $\begin{array}{l}\text { Anna Kub- } \\
\text { fahl. T. }\end{array}$ & 25 & $\begin{array}{l}\text { Reohts: Chronisehe Ei- } \\
\text { terung. }\end{array}$ & 6 Tage. & 6 Tage. & Gestorben. & $\begin{array}{l}\text { Probat. Ope- } \\
\text { ration. }\end{array}$ \\
\hline 69 & $\begin{array}{l}\text { Ida } \\
\text { Herold. T. }\end{array}$ & 12 & $\begin{array}{l}\text { Links: Caries u. Cho* } \\
\text { lesteatom. }\end{array}$ & 2 Mon. & 2 Mon. & Geheilt. & - \\
\hline 70 & $\begin{array}{l}\text { Else } \\
\text { Arndt. T. }\end{array}$ & 10 & Caries $\mathfrak{u}$. Cholesteatom. & 2 Mon. & 4 Mon. & Geheilt. & - \\
\hline
\end{tabular}




\begin{tabular}{|c|c|c|c|c|c|c|c|}
\hline 总 & Name & 焉题 & $\begin{array}{l}\text { Diagnose, } \\
\text { resp. Befund }\end{array}$ & $\begin{array}{l}\text { Dar } \\
\text { der Beh } \\
\text { in der } \\
\text { Klinik } \\
\end{array}$ & $\begin{array}{l}\text { uer } \\
\text { andlung } \\
\text { uaberbaupt }\end{array}$ & Resultat & Bemerkungen \\
\hline 71 & Willi Bohne. & 4 & Nekrose des Proc. mast. & - & - & Geheilt. & 一 \\
\hline 72 & $\begin{array}{l}\text { Mädohen, } \\
\text { Rosahl. }\end{array}$ & 10 & Links: Scharlachotitis. & $21 / 2$ Non. & - & Gehellt. & $\begin{array}{l}\text { Perisinuöser } \\
\text { Abscess. }\end{array}$ \\
\hline 73 & $\begin{array}{l}\text { Marg. } \\
\text { Eessler. }\end{array}$ & 8 & $\begin{array}{l}\text { Rechts: Acutes Schar- } \\
\text { lachempyem. }\end{array}$ & $2^{1 / 4}$ Mon. & 4 Mon. & Geheilt. & Pyämie. \\
\hline 74 & $\begin{array}{l}\text { Gustay } \\
\text { Asehe. T. }\end{array}$ & 18 & $\begin{array}{l}\text { Rechts: Caries a. Cho- } \\
\text { lesteatom. }\end{array}$ & 3 Mon. & 3 Mon. & $\begin{array}{l}\text { uabe- } \\
\text { kannt. }\end{array}$ & - \\
\hline 75 & $\begin{array}{c}\text { Rudolf } \\
\text { Belger. T. }\end{array}$ & 19 & Links: Chron. Caries. & 3 Mon. & 3 Mon. & Geheilt. & - \\
\hline 76 & $\begin{array}{c}\text { Paul } \\
\text { Schmidt. T. }\end{array}$ & 29 & $\begin{array}{l}\text { Rechts: Chron. Caries } \\
\text { u. Cholesteatom. }\end{array}$ & 2 Mon. & 6 Mon. & Geheilt. & - \\
\hline 77 & $\begin{array}{l}\text { Gustar } \\
\text { Schneider. }\end{array}$ & 14 & $\begin{array}{l}\text { Links: Acute Mastoi- } \\
\text { ditis. }\end{array}$ & 6 Woch. & 6 Woob. & Geheilt. & 一 \\
\hline 78 & $\begin{array}{l}\text { Anna } \\
\text { Noack. T. }\end{array}$ & 6 & Links: Cholesteatom. & 21/2 Mon. & $21 / 2$ Mon. & Goheilt. & - \\
\hline 79 & $\begin{array}{l}\text { Herm. } \\
\text { Römer. T. }\end{array}$ & 21 & Rechts: Chron. Caries. & 4 Mon. & 4 Mon. & Geheilt. & - \\
\hline 80 & Derselbe. $\mathrm{T}$. & 21 & Links: Chron. Oaries. & & & Geheilt. & Stricturoper. \\
\hline 81 & $\begin{array}{l}\text { Johannes } \\
\text { Koch. T. }\end{array}$ & 13 & Links: Cholesteatom. & 4 Mon. & - & $\begin{array}{l}\text { Nioht } \\
\text { geheilt. }\end{array}$ & $\begin{array}{l}\text { Extrasinuöser } \\
\text { Abscess. }\end{array}$ \\
\hline 82 & $\begin{array}{l}\text { Richard } \\
\text { Reuss. T. }\end{array}$ & 16 & Links: Caries. & - & 一 & $\begin{array}{l}\text { unbe- } \\
\text { kannt. }\end{array}$ & Dépendance. \\
\hline 83 & $\begin{array}{l}\text { Emilie } \\
\text { Mietb. }\end{array}$ & 39 & Links: Acut. Empyem. & 1 Mon. & 1 Mon. & Geheilt & - \\
\hline 84 & $\begin{array}{l}\text { Wilh. } \\
\text { Zeymer. T. }\end{array}$ & 12 & Rechts: Cholesteatom. & 3 Mon. & - & $\begin{array}{l}\text { unbe- } \\
\text { kannt. }\end{array}$ & $\begin{array}{l}\text { Extrasinuöser } \\
\text { Abscess. }\end{array}$ \\
\hline 85 & Mathias. T. & 45 & Links: Cholesteatom. & - & - & $\begin{array}{l}\text { unbe- } \\
\text { kannt. }\end{array}$ & Dépendance. \\
\hline 86 & $\begin{array}{l}\text { Holdine } \\
\text { Goldsehildt. }\end{array}$ & 2 & Links: Empyem. & $1 / 2$ Mon. & $\begin{array}{l}\text { circa } \\
3 \text { Mon. }\end{array}$ & Geheilt. & - \\
\hline 87 & $\begin{array}{c}\text { Otto Harten- } \\
\text { haver. T. }\end{array}$ & 16 & $\begin{array}{l}\text { Rechts: Caries u. Cho- } \\
\text { lesteatom. }\end{array}$ & $2^{3 / 2}$ Mon. & $21 / 2$ Mon. & $\begin{array}{l}\text { unbe- } \\
\text { kannt. }\end{array}$ & $n, 7$ \\
\hline 88 & $\begin{array}{l}\text { Ida Hart- } \\
\text { mann. }\end{array}$ & 4 & Rechts: Caries. & - & $4^{1 / 2}$ Mon. & $\begin{array}{l}\text { unbe- } \\
\text { kannt. }\end{array}$ & Dépendance. \\
\hline 89 & $\begin{array}{l}\text { Karl } \\
\text { Maier. T. }\end{array}$ & 10 & Links: Chron. Caries. & 3 Mon. & 3 Mon. & Geheilt. & - \\
\hline 90 & $\begin{array}{l}\text { Heinrieh } \\
\text { Jost. }\end{array}$ & $9 \mathrm{j}$. & $\begin{array}{l}\text { Acute Eiterung rechts. } \\
\text { Aufmeisselng ausser- } \\
\text { halb. Sinusverletzg. }\end{array}$ & 2 Mon. & - & Geheilt. & $\begin{array}{l}\text { Sinusoperat.; } \\
\text { Jugularisun- } \\
\text { terbindung. }\end{array}$ \\
\hline 91 & $\begin{array}{c}\text { Karl } \\
\text { Sehiedt. T. }\end{array}$ & 17 & Rechts: Nekrose. & 2 Mon. & 3 Mon. & Geheilt. & - \\
\hline 92 & $\begin{array}{l}\text { Richard } \\
\text { Reuss. T. }\end{array}$ & 10 & Rechts: Ossiculacaries. & - & - & $\begin{array}{l}\text { unbe- } \\
\text { kannt. }\end{array}$ & $\begin{array}{l}\text { Excis. } v . \text { Ge } \\
\text { hörgange aus } \\
\text { misslungen. } \\
\text { Dépendance. }\end{array}$ \\
\hline 93 & $\begin{array}{l}\text { Minna } \\
\text { Hörning. }\end{array}$ & 23 & Links: Aout. Empyem. & 22 Tage. & 30 Tage. & Geheilt. & - \\
\hline 94 & Weimann. & 20 & Links: Caries. & - & - & $\begin{array}{l}\text { unbe- } \\
\text { kannt. }\end{array}$ & Dépendance. \\
\hline
\end{tabular}


Jahresbericht d. Kgl. Universitäts-Ohrenklinik zu Halle a. S. 1898/99. 175

\begin{tabular}{|c|c|c|c|c|c|c|c|}
\hline 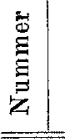 & Name & 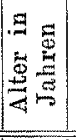 & $\begin{array}{l}\text { Diagnose, } \\
\text { resp. Befund }\end{array}$ & $\begin{array}{l}\quad \text { Dar } \\
\text { der Beh } \\
\text { in der } \\
\text { Klinik }\end{array}$ & $\begin{array}{l}\text { aer } \\
\text { andlung } \\
\text { überbaupt }\end{array}$ & Resultat & Bemerkungen \\
\hline 95 & Karl Apel. T. & 13 & $\begin{array}{l}\text { Rechts: Caries a. Cho- } \\
\text { lesteatom. }\end{array}$ & 3 Mon. & 4 Mon. & Geheilt. & - \\
\hline 96 & $\begin{array}{c}\text { Bertha } \\
\text { Dúring. }\end{array}$ & 15 & $\begin{array}{l}\text { Links: Acute Mastoi- } \\
\text { ditis. }\end{array}$ & - & 2 Mon. & Geheilt. & Dépendance. \\
\hline 97 & Arthur Horn. & $11 / 2$ & Links: Nekrose. & 16 Tage. & 16 Tage. & $\begin{array}{l}\text { Der Be- } \\
\text { handlung } \\
\text { entzogen. }\end{array}$ & - \\
\hline 98 & $\begin{array}{l}\text { Willi } \\
\text { Köhler. T. }\end{array}$ & 18 & Rechts: Caries. & 3 Mon. & - & $\begin{array}{l}\text { unbe- } \\
\text { kannt. }\end{array}$ & - \\
\hline 99 & $\begin{array}{l}\text { Friedr. } \\
\text { spiegelberg. }\end{array}$ & 13 & Links: Empyem. & 2 Mon. & 2 Mon. & Geheilt. & - \\
\hline 100 & $\begin{array}{l}\text { Max } \\
\text { Sulimma. }\end{array}$ & 4 & Links: Empyem. & 2 Mon. & 3 Mon. & Geheilt. & - \\
\hline 101 & Fritz Nagel. & $3^{1} / 2$ & Links: Mastoiditis. & 36 Tage. & 36 Tage. & Gestorben. & $\begin{array}{l}\text { Sobarlachoti- } \\
\text { tis. Pyämie. }\end{array}$ \\
\hline 102 & Derselbe. & $3^{1 / 2}$ & Rechts: Mastoiditis. & & & & - \\
\hline 103 & $\begin{array}{c}\text { Emma } \\
\text { Przibilla. } \mathrm{T} .\end{array}$ & 11 & Chron. Caries. & 2 Mon. & 2 Mon. & Geheilt. & - \\
\hline 104 & $\begin{array}{l}\text { Max } \\
\text { Müller. } T .\end{array}$ & 21 & Rechts: Chron. Caries. & 4 Mon. & 4 Mon. & Geheilt. & - \\
\hline 105 & $\begin{array}{c}\text { Gertrud } \\
\text { Stockmann. }\end{array}$ & 1 & Links: Acute Eiterung. & 3 Tage. & 3 Tage. & Gestorben. & $\begin{array}{l}\text { Probat. Ein- } \\
\text { griff; Suche } \\
\text { nach Weglei- } \\
\text { tung. Tuber- } \\
\text { cul. Mening. }\end{array}$ \\
\hline 106 & $\begin{array}{l}\text { Emilie } \\
\text { Felkel. }\end{array}$ & 7 & Rechts : Mastoiditis. & 2 Mon. & 2 Mon. & Geheilt. & - \\
\hline 107 & $\begin{array}{c}\text { Christiane } \\
\text { Jung. }\end{array}$ & 63 & $\begin{array}{l}\text { Links: Acutes Em- } \\
\text { pyem. }\end{array}$ & 21/2 Mon. & $2^{1 / 2}$ Mon. & $\begin{array}{l}\text { unbe- } \\
\text { kannt. }\end{array}$ & $\begin{array}{l}\text { Extradural- } \\
\text { abscess. }\end{array}$ \\
\hline 108 & Lina Krilger. & 19 & $\begin{array}{l}\text { Ausmeisselung wegen } \\
\text { Neuralgie. }\end{array}$ & - & - & $\begin{array}{l}\text { unbe- } \\
\text { kannt. }\end{array}$ & - \\
\hline 109 & $\begin{array}{l}\text { Anna Lich- } \\
\text { tenfeld. T. }\end{array}$ & 17 & $\begin{array}{l}\text { Links: Chronische Ei- } \\
\text { terung. }\end{array}$ & $11 / 2$ Mon. & - & Geheilt. & - \\
\hline 110 & $\underset{\text { Dietrich. }}{\text { Anna }}$ & 25 & Links: Acute Eiterung. & 2 Mon. & 2 Mon. & Geheilt. & - \\
\hline 111 & $\begin{array}{l}\text { Willi } \\
\text { Köhler. T. }\end{array}$ & 18 & Links: Caries. & 3 Mon. & - & $\begin{array}{l}\text { unbe- } \\
\text { kannt. }\end{array}$ & 一 \\
\hline 112 & Walensky. & 23 & $\begin{array}{l}\text { Links: Acute Mastoi- } \\
\text { ditis. }\end{array}$ & - & - & Geheilt. & $\begin{array}{l}\text { Eiterg. nach } \\
\text { Typhus. Ind. } \\
\text { med. Klinik } \\
\text { weit. behand. }\end{array}$ \\
\hline 113 & $\begin{array}{l}\text { Franz } \\
\text { Hensel. } \mathrm{T} .\end{array}$ & 22 & $\begin{array}{l}\text { Rechts: Caries m. Cho- } \\
\text { lesteatom. }\end{array}$ & - & - & Geheilt. & Dépendanee. \\
\hline 114 & $\begin{array}{l}\text { Anna } \\
\text { Mtiller. T. }\end{array}$ & 14 & Links: Cholesteatom. & - & $2^{3} / 4$ Mon. & Geheilt. & Dépendance. \\
\hline 115 & $\begin{array}{c}\text { Franz } \\
\text { Hartmann. }\end{array}$ & $1^{1 / 2}$ & $\begin{array}{l}\text { Links : Acute Eiterung. } \\
\text { Empyem. }\end{array}$ & -- & - & Geheilt. & - \\
\hline 116 & $\begin{array}{c}\text { Paul } \\
\text { Reppin. T. }\end{array}$ & 16 & Links: Obron. Caries. & 4 Mon. & 4 Mon. & $\begin{array}{l}\text { unbe- } \\
\text { kannt. }\end{array}$ & Dépendance. \\
\hline
\end{tabular}




\begin{tabular}{|c|c|c|c|c|c|c|c|}
\hline$\stackrel{g}{g}$ & Nama & $\Xi$ 悬 & Diagnose, & $\begin{array}{r}\mathrm{Da} \\
\text { der } \mathrm{Bel}\end{array}$ & $\begin{array}{l}\text { uer } \\
\text { landlung }\end{array}$ & Bosultat & Pemortronom \\
\hline$\underset{Z}{E}$ & 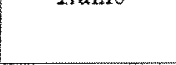 & 急 & resp. Befund & $\begin{array}{l}\text { in der } \\
\text { Elinik }\end{array}$ & aberhaupt & 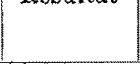 & \\
\hline 117 & $\begin{array}{l}\text { Karl } \\
\text { Falke. T. }\end{array}$ & 13 & $\begin{array}{l}\text { Rechts: Caries u. Cho" } \\
\text { lesteatom. }\end{array}$ & 3 Mon. & 3 Mon. & $\begin{array}{l}\text { unbe- } \\
\text { kannt. }\end{array}$ & - \\
\hline 118 & $\begin{array}{l}\text { Max. } \\
\text { Müller. T. }\end{array}$ & 21 & Links: Chron. Caries & 4 Mon. & 4 Mon. & Geheilt. & 一 \\
\hline 119 & $\begin{array}{l}\text { Karl Nau- } \\
\text { mann. } \mathrm{T} .\end{array}$ & 24 & Links: Cholesteatom. & 3 Mon. & 3 Mon. & Geheilt. & - \\
\hline 120 & $\begin{array}{c}\text { Bertha } \\
\text { Nethge. } \mathrm{T} \text {. }\end{array}$ & 38 & $\begin{array}{l}\text { Links: Zerfall. Chole. } \\
\text { steatom. }\end{array}$ & 5 Tage. & 5 Tage. & Gestorben. & $\begin{array}{l}\text { Scbläfenlap- } \\
\text { penabscess- } \\
\text { operation. }\end{array}$ \\
\hline 121 & $\begin{array}{l}\text { Erast } \\
\text { Käbel. T. }\end{array}$ & 15 & $\begin{array}{l}\text { Reehts: Caries a. Cho- } \\
\text { lesteatom. }\end{array}$ & $2^{1 / 2}$ Mon. & $\begin{array}{l}\text { oirea } \\
4 \text { Mon. }\end{array}$ & Gebeilt. & - \\
\hline 122 & $\begin{array}{c}\text { Frau } \\
\text { Wanke. } \mathrm{T} .\end{array}$ & 33 & Rechts: Cholesteatom. & 22 Tage. & 6 Mon. & Geheilt. & - \\
\hline 123 & $\begin{array}{c}\text { Auguste } \\
\text { Karlisch. } T \text {. }\end{array}$ & 21 & $\begin{array}{l}\text { Links: Caries m. Cho- } \\
\text { lesteatom. }\end{array}$ & 3 Mon. & - & $\begin{array}{l}\text { Nicht } \\
\text { geheilt. }\end{array}$ & - \\
\hline 124 & $\underset{\text { Mieth. } \mathrm{T} .}{\text { Karl }}$ & 20 & Reehts: Cholesteatom. & - & - & $\begin{array}{l}\text { unbe- } \\
\text { kannt. }\end{array}$ & $\begin{array}{l}\text { Ambulato- } \\
\text { risch. }\end{array}$ \\
\hline $12 \dot{\jmath}$ & $\begin{array}{c}\text { Martha } \\
\text { Drescher. T. }\end{array}$ & 19 & Caries. & - & - & $\begin{array}{l}\text { unbe- } \\
\text { kannt. }\end{array}$ & Dépendance. \\
\hline 126 & Andres. & 8 & $\begin{array}{l}\text { Rechts: Acute Mastoi- } \\
\text { ditis. }\end{array}$ & 2 Mon. & 2 Mon. & Geheilt. & Dépendance. \\
\hline 127 & $\begin{array}{l}\text { Anna } \\
\text { Tinscher. T. }\end{array}$ & 18 & Rechts: Chron. Caries. & - & $21 / 2$ Mon. & Geheilt. & Dépendance. \\
\hline 128 & Felix Hesse. & 10 & Links: Empyem. & - & - & Geheilt. & Dépendance. \\
\hline 129 & $\begin{array}{l}\text { Marie } \\
\text { Grosse. T. }\end{array}$ & 6 & Rechts: Chron. Caries. & $\ldots$ & - & $\begin{array}{l}\text { unbe- } \\
\text { kannt. }\end{array}$ & Dépendance. \\
\hline 130 & $\begin{array}{l}\text { Walter } \\
\text { Töpfer. T. }\end{array}$ & 12 & Rechts: Chron. Caries. & 1 Mon. & 1 Mon. & $\begin{array}{l}\text { Noch in } \\
\text { Behandlg. }\end{array}$ & - \\
\hline 131 & $\begin{array}{l}\text { Emanuel } \\
\text { Kunze. T. }\end{array}$ & 24 & Rechts: Chron. Caries. & - & 4 Mon. & Geheilt. & - \\
\hline 132 & $\begin{array}{l}\text { Elise } \\
\text { Böhlmann. }\end{array}$ & 4 & Rechts: Acut. Empyem. & 10 Tage. & 6. Mon. & Geheilt. & - \\
\hline 133 & $\begin{array}{l}\text { Anna } \\
\text { Föliner. }\end{array}$ & 19 & Reohts: Aout. Empyem. & 1 Mon. & 21/2 Mon. & Geheilt. & $\begin{array}{c}\text { Extrasinuös. } \\
\text { Abscess. }\end{array}$ \\
\hline 134 & $\begin{array}{l}\text { Osoar Jung- } \\
\text { nickel. } \mathrm{T}\end{array}$ & 17 & Caries d. Ossicula. & 6 Woch. & 6 Woch. & Geheilt. & - \\
\hline 135 & $\begin{array}{l}\text { Frau Nau- } \\
\text { mann. T. }\end{array}$ & 25 & Chron. Eiterg. Caries. & $11 / 2$ Mon. & - & $\begin{array}{l}\text { unbe- } \\
\text { kannt. }\end{array}$ & - \\
\hline
\end{tabular}

